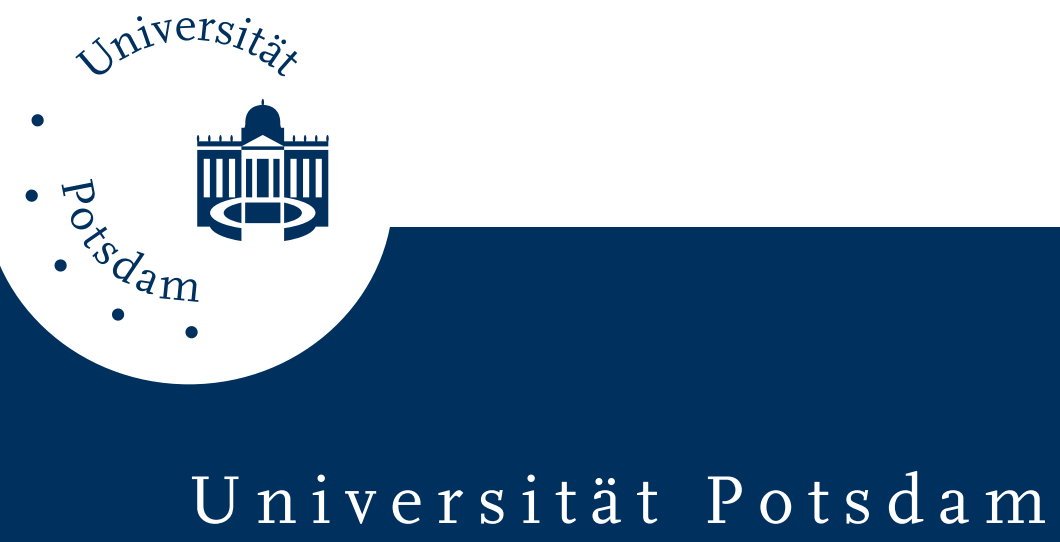

André Laschewsky

\title{
Molecular concepts, self-organisation and properties of polysoaps
}

first published in:

Advances in Polymer Science. - 124 (1995) S. 1-86, ISSN (print) 0065-3195

DOI 10.1007/BFb0025228

Postprint published at the Institutional Repository of Potsdam University:

In: Postprints der Universität Potsdam

Mathematisch-Naturwissenschaftliche Reihe ; 87

http://opus.kobv.de/ubp/volltexte/2008/2689/

http://nbn-resolving.de/urn:nbn:de:kobv:517-opus-26895

Postprints der Universität Potsdam

Mathematisch-Naturwissenschaftliche Reihe ; 87 


\title{
Molecular Concepts, Self-Organisation and Properties of Polysoaps
}

\author{
A. Laschewsky \\ Université Catholique de Louvain, Dépt. de Chimie, Place L. Pasteur 1, \\ B-1348 Louvain-la-Neuve
}

\begin{abstract}
The article reviews water-soluble polymers characterized by surfactant side chains, and related amphiphilic polymers. Various synthetic approaches are presented, and rules for useful molecular architectures are given. Models for the self-organization of such polymers in water are presented comparing them with the micellization of low molecular weight surfactants. Highlighting key properties of aqueous polysoap solutions such as viscosity, surface tension and solubilization power, some structure-property relationships are established. Further, the formation of mesophases and of superstructures in bulk is addressed. Finally, the functionalization of polysoaps, and potential applications are discussed.
\end{abstract}

1 Introduction.......................... 3

2 The Structure of Polysoaps $\ldots \ldots \ldots \ldots \ldots \ldots \ldots \ldots \ldots$

2.1 Micellar Polymers...................... 3

2.2 Synthetic Strategies to Polysoaps ............... 6

2.3 Molecular Architecture of Polysoaps . . . . . . . . . . . 9

2.3.1 General. ....................... 9

2.3.2 Surfactant Side Chains . . . . . . . . . . . . 10

2.3.3 Steric Requirements of the Polymer Architecture. . . . . . 12

2.3.4 The Spacer Concept . . . . . . . . . . . . . . . 15

2.3.5 Flexibility of the Polymer Backbone ............ 19

2.4 Functional Polysoaps . . . . . . . . . . . . . . . . . . 20

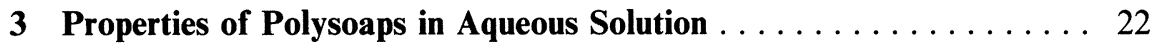

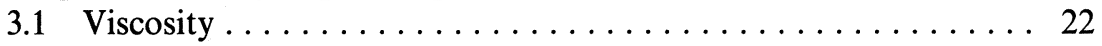

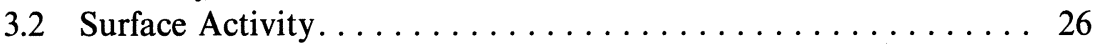

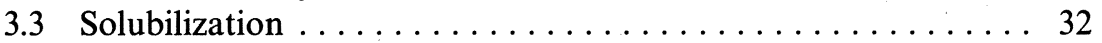

3.3.1 Solubilization of Probe Molecules . . . . . . . . . . . . 34

3.3.2 Solubilization Capacity. . . . . . . . . . . . . . . . 37

3.4 Emulsifying and Dispersing Properties ............. 39

3.5 Dynamic Properties ................... 40

4 Aggregation in Aqueous Solution . . . . . . . . . . . . . . . 42

4.1 Micelles. . . . . . . . . . . . . . . . . . . . 42

4.2 Polymeric Micelles . . . . . . . . . . . . . . . 43

4.2 .1 Models . . . . . . . . . . . . . . . . 43

4.2.2 Experimental Data and Aggregation Numbers. . . . . . 46

4.3 Lyotropic Liquid Crystals. . . . . . . . . . . . . . . . . . . . . . 49 
5 Aggregation in the Solid State $\ldots \ldots \ldots \ldots \ldots \ldots \ldots \ldots \ldots \ldots \ldots \ldots \ldots \ldots$

6 Molecular Weight Effects and the Behaviour of Oligomers ....... 53

6.1 Defined Oligomeric Surfactants . . . . . . . . . . . . . . 53

6.2 Oligomeric Mixtures................... 58

7 Applications of Polysoaps ........................ 59

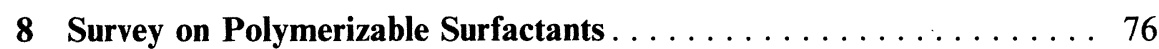

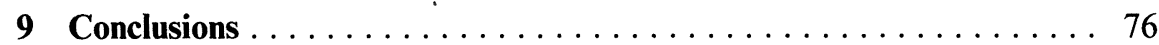

10 References............................. 76 


\section{Introduction}

Amphiphilic polymers, i.e. polymers bearing hydrophilic and hydrophobic fragments, have been known for a long time. They have attracted much attention in recent years because of their resemblance to biological systems as well as their strong tendency for self-organization in aqueous environments due to the hydrophobic effect [1-3], creating plentiful superstructures $[4,5]$ on the intermediate level between molecular and macroscopic structures ("mesoscopic scale" [6]). In particular, the subgroups of polymeric lipids and lipid analogs have been investigated in detail with respect to their self-organization in insoluble monolayers, in (Langmuir-Blodgett) multilayers, in vesicles and in myelin structures, thus providing general concepts for their understanding [7-17].

Whereas the above systems which give rise mainly to phase separated superstructures in aqueous systems are now fairly well understood, the situation for more hydrophilic and thus watersoluble amphiphilic polymers is less clear. Such polymers are often referred to as "micellar polymers" because they have properties similar to surfactant micelles [18-23], and thus similar superstructures are implicitely assumed.

There is a considerable practical interest in the micellar polymers based on their many attractive properties and thus their potential uses, e.g. as protective colloids, emulsifiers, surfactants, wetting agents, lubricants, viscosity modifiers, (anti) foaming agents, pharmaceutic and cosmetic formulation ingredients, catalysts etc. (see also Sect. 7). This is reflected by the plethora of compounds in the scientific and patent literature which can be addressed as micellar polymers. However, the number of systematic studies of the molecular structures is surprisingly small, as is the number of investigations of the detailed nature of the hydrophobic aggregation. Therefore our understanding of polysoaps is still limited, despite many advances in recent years, compared to the state of knowledge in the mid-1970s documented in the review of Bekturov and Bakauova [24].

\section{The Structure of Polysoaps}

\subsection{Micellar Polymers}

Compared to low molecular weight amphiphiles, the size of polymeric amphiphiles allows for much more diverse arrangements of the hydrophilic and hydrophobic segments, as exemplified in Fig. 1. Accordingly, micellar polymers are characterized by versatile molecular architectures, giving rise to distinct subgroups. Diblock-copolymers with a clear separation of the hydrophilic 
a
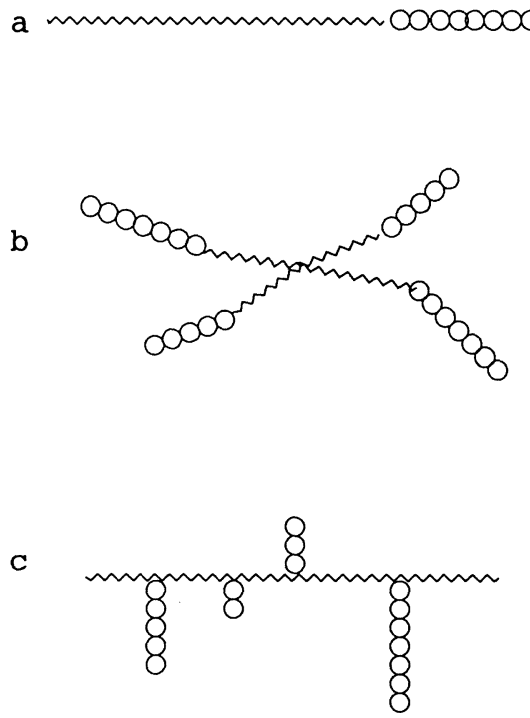

d

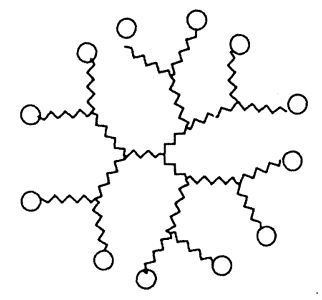

e
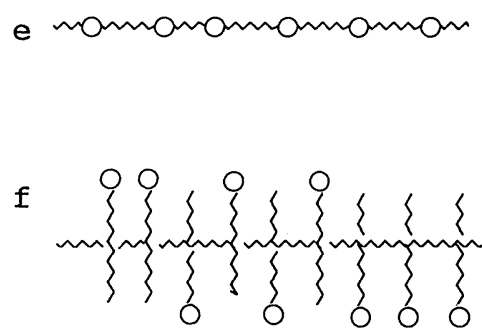

Fig. 1a-f. Types of micellar polymers: a block copolymers (macrosurfactants); b stars; c graft copolymers; d dendrimers; e segmented block copolymers; f polysoaps

("head") and the hydrophobic ("tail") parts come closest to the architecture of standard surfactants; they are often referred to as "macrosurfactants" (Fig. 1a). Representing the best studied micellar polymers at present, they behave in many respects like "oversize" standard surfactants although a unified picture is still missing [25-32]. Hydrophobic aggregation generally takes place by intermolecular association. In contrast, amphiphilic star block-copolymers [32-35] and graft polymers [36-40] should undergo preferentially intramolecular aggregation (Fig. 1b,c). Amphiphilic dendrimers [6, 41-45] represent the extreme case (Fig. 1d). They can form intramolecular hydrophobic aggregates comprising the whole macromolecule. All of these types of micellar polymers are characterized by large, well separated blocks of hydrophilic and hydrophobic groups, and the amphiphilic character is based on the overall macromolecular architecture.

Alternatively, the hydrophilic and hydrophobic groups may be scattered all over the macromolecule. Here, the amphiphilic character of micellar polymers results from the presence of many independent, surfactant-like structural units which are covalently linked. This is realized in polymers which bear a limited number of ionic groups in their otherwise hydrophobic backbones - corresponding to a longitudinal linkage (Fig. 1e) - or in polymers with functional sidechains - corresponding to a lateral linkage of surfactant units (Fig. 1f).

The structural similarities of the individual polymer fragments with low molecular weight surfactants are paralleled by the similarities of two important 
properties of such polymers and of surfactants: i) high solubilization capacity for hydrophobic molecules implying a "molten character" of the aggregated hydrophobic parts, and ii) low viscosities of aqueous solution due to the hydrophobic aggregation which reduces the hydrodynamic radii dramatically. Thus the term "polysoap" was coined [24, 46-55]. Originally confined to functional side-chain polymers (Fig. 1f), the term is increasingly used as well for segmented blockcopolymers [56-60] (Fig. 1e).

a

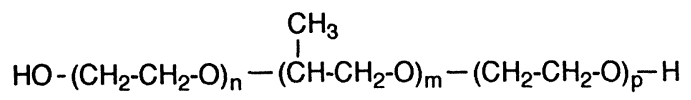

1

b

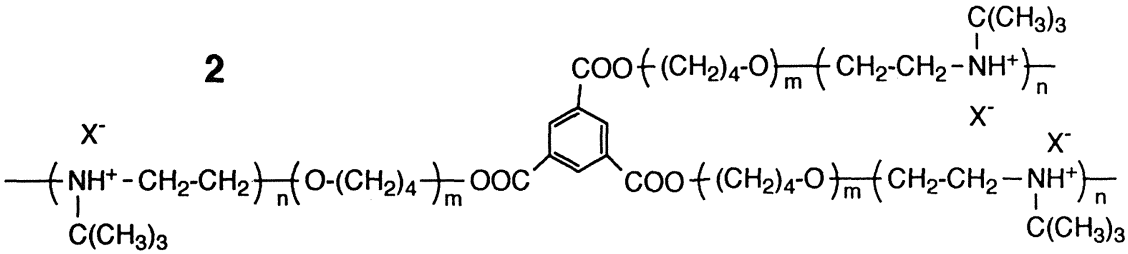

C<smiles>[X]C(C)(C)CCNC(C)(CC=CCCC)CCCCCC</smiles>

d

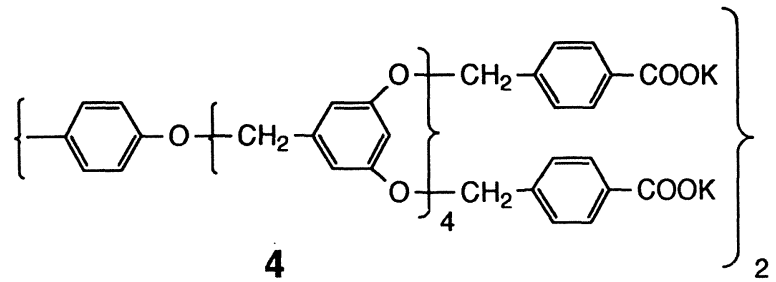<smiles>CN(Br)[N+](C)(C)CCCC(C)(C)C</smiles>

f<smiles>CC(C)CCCCCCCC(=O)O[Na]</smiles>

Fig. 2a-f. Examples of micellar polymers: a block copolymer ("macrosurfactant" [25]; b star [35]; c graft copolymer [36]; d dendrimer [44]; e segmented block copolymer [56, 57]; f polysoap [61-74] 
Despite these similarities, other properties of polysoaps can differ considerably from the ones of standard surfactants, as exemplified by their intramolecular aggregation and the usually missing critical micelle concentration "CMC" [24, 46, 51, 52, 65, 75-78].

\subsection{Synthetic Strategies to Polysoaps}

Although several natural polysoaps have been discovered [79, 80], the vast majority of polysoaps are synthetic polymers. As a basic requirement the polymers must have an appropriate hydrophilic-hydrophobic balance "HLB" to allow for water solubility on one hand (not just dispersion!), but sufficient hydrophobic parts to enable aggregation on the other. Considering the successful and unsuccessful systems in the literature, it seems that the required HLB for polysoaps is slightly more hydrophilic than for low molecular weight surfactants (see also Sect. 4.2).

Many strategies for synthesis have been established applying the full range of preparative polymer chemistry to meet the practical needs (Fig. 3). The pathways chosen have to take into account as well the efficient work up of the final polysoap, as the amphiphilic character can render e.g. the purification from residual reagents and by-products extremely difficult.

Polysoaps with the best defined chemical structure are produced by the polymerization of prefabricated reactive surfactants [51, 61-74, 76, 78, 81-93] (Fig. 3a). This strategy has been widely used, in particular for model studies, as it enables the comparison of analogous monomeric surfactants and polysoaps. Additionally, if the polymerization of the surfactants is performed under micellar conditions, the rate of polymerization and the molecular weights obtained are strongly increased by the aggregation [92, 94-105]. The improved reactivity may even allow the use of poorly polymerizable moieties which would not react, or react sluggishly only by standard polymerization procedures $[61-74,76,82,84,88,106-117]$, although the degree of polymerization may still be low. Concerning the influence of micellar polymerization conditions on tacticities, the results reported even for identical systems are contradictory $[105$, 118]. In any case, the control over the chemical structure must be paid by the often demanding synthesis of the surfactant monomers, and by the difficulties in controlling or even measuring molecular weights of the polysoaps. Examples of polymerizable surfactants are given in Tables 1-5 (Sect. 8).

Alternatively, polysoaps with well defined chemical structures can be prepared by the polyaddition or polycondensation of non-amphiphilic reagents $[56,57,119,120]$ (Fig. 2b). The surfactant fragments are formed in the course of the reaction only. This technique appears particularly attractive for polysoaps of "main chain geometry" (see below and Figs. 1e, 2e and 6d). The problems concerning the molecular weights are the same as for the polymerization of reactive surfactants, and the scope of useful chemical structures seems to be limited. 
a)
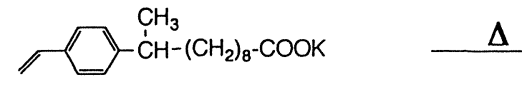

b)<smiles>CCCCCN(C)CCC</smiles>

$\mathrm{Br}-\left(\mathrm{CH}_{2}\right)_{5}-\mathrm{Br}$ $\mathrm{C}_{12} \mathrm{H}_{25} \quad \mathrm{C}_{12} \mathrm{H}_{25}$

$\mathrm{CH}_{3}$
1
$-(\mathrm{Si}-\mathrm{O})_{n}-$
1
$\mathrm{H}$

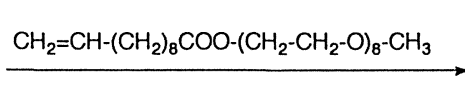

d)<smiles>CCCc1ccncc1</smiles>
$\stackrel{\text { 1) }+\mathrm{C}_{12} \mathrm{H}_{25} \mathrm{Br}}{2}$ 2) $+\mathrm{C}_{2} \mathrm{H}_{5} \mathrm{Br}$

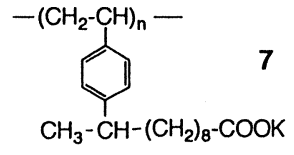

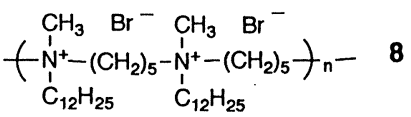<smiles>COCCOC(=O)OCC(C)(C)[Si](C)(C)C</smiles>

$\left(\mathrm{CH}_{2}\right)_{10}-\mathrm{COO}-\left(\mathrm{CH}_{2}-\mathrm{CH}_{2}-\mathrm{O}\right)_{8}-\mathrm{CH}_{3}$

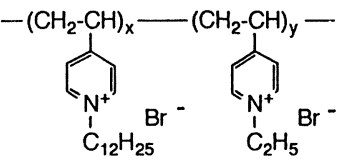

e)<smiles>CCn1c[n+]([I-])cn1</smiles><smiles>CCN1CCCC1=O</smiles>

$\Delta$<smiles>CCCCCCN1C[C-]([I-])[N+](CC)C1</smiles>
11

f)<smiles>CCOCCCCCCCO</smiles>

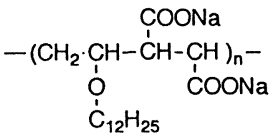

Fig. 3a-f. Synthetic strategies to polysoaps: a polymerization of reactive surfactants [51]; b polycondensation of non-amphiphilic reagents $[119,120]$; $\mathbf{c}$ grafting of surfactant fragments [121, 122]; d hydrophobization of preformed polymers $[49,52,75,130,131,138,139,141,142,146]$; e copolymerization of reactive surfactants with polar monomers [156]; $\mathbf{f}$ copolymerization of hydrophobic and hydrophilic monomers [53]

A different route to polysoaps at least with well defined surfactant fragments is the grafting of prefabricated surfactant fragments onto a reactive prefabricated polymer [50, 87, 121-129] (Fig. 3c). Appropriate choice of the latter enables the preparation of polymers with a controlled degree of polymerization. But to maintain a good control over the chemical structure, very high conver- 
sions of the grafting reaction and negligible side reactions are needed, thus severely limiting the scope of this strategy.

A more versatile strategy is the modification of (proto)-hydrophilic preformed polymers with hydrophobic reagents, or vice versa (Fig. 3d). This technique is the oldest one, and is still widely in use due to its convenience [46-49, 52, 54, 55, 130-155]. It also allows the control of the degree of polymerization by appropriate choice of the parent polymer. However, the structure of the surfactant fragments, and thus e.g. of the hydrophilic-hydrophobic balance, may be poorly defined, and purification of such polysoaps may be difficult.

Covenient and versatile as well, the preferred technique at present seems to be copolymerization. Either polymerizable surfactants are copolymerized with small, often polar or hydrophilic, comonomers, creating rather well defined surfactant fragments in the polysoaps [73, 77, 78, 156-168] (Fig. 3e). This strategy is more versatile than exclusive homopolymerization and allows the use of polymerizable surfactants whose homopolymers are not water-soluble, but it still requires considerable synthetic effort. Or, much more facile, simple hydrophobic monomers are copolymerized with small hydrophilic ones (Fig. 3f), taking full advantage of the choice of commercial or easily accessible monomers $[39,53-55,153,169-218]$.

The chemical structure of such copolymer polysoaps can be very heterogeneous, being subject to the problems of copolymerization. Also, suitable solvents for the copolymerization reaction may be difficult to find. In fact, the choice of the solvent seems to be crucial, as it strongly influences the copolymerization parameters when using monomers of greatly differing polarity $[77,156,188$, 219-222]. This effect can be exploited for the preparation of random and blocky copolymers from the same pair of monomers depending on the reaction conditions $[77,220]$, and thus enables an additional structural variation of polysoaps (Fig. 4).
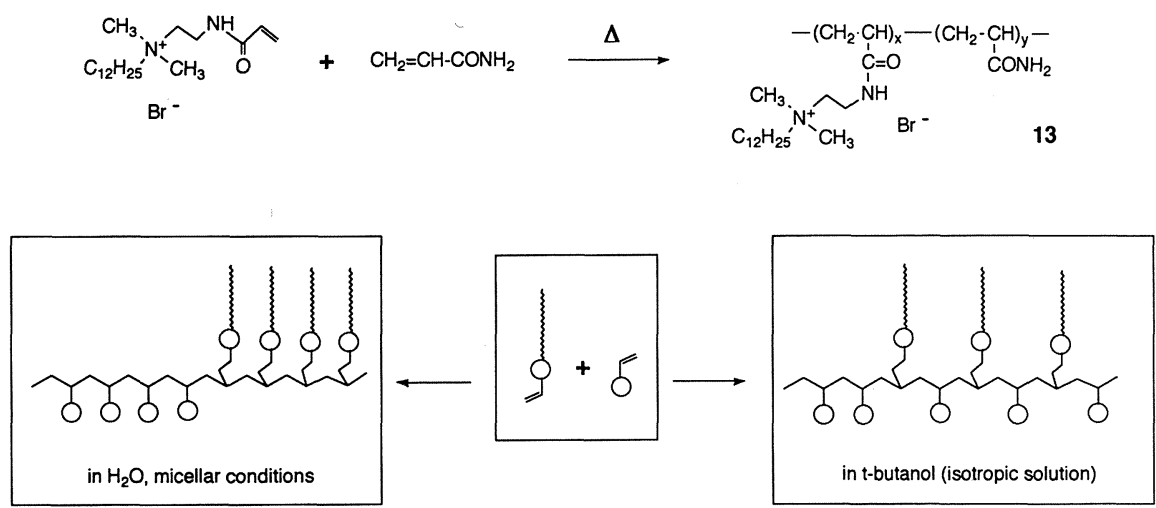

Fig. 4. Preparation of random and blocky copolymers by varying the reaction conditions [77, 220] 


\subsection{Molecular Architecture of Polysoaps}

\subsubsection{General}

As sketched in Fig. 1, the molecular architecture of polysoaps is characterized by the combination of polymer and surfactant structures. The most obvious structural parts to be varied are the surfactant fragments, with respect to the hydrophilic head and the length and branching of the hydrophobic tail. This corresponds to classical surfactant chemistry, and the majority of systematic investigations of polysoaps have been restricted to such variations. But polysoaps offer additional variations which are characteristic for polymers but do not exist for surfactants. The molecular architecture can be varied e.g. with respect to the polymer geometry $[76,78,87,88,105,126,164,167,168,223-228]$ the nature of the polymer backbone $[76,78,84,167,168,229,230]$ and the incorporation of spacer groups [100-102, 157, 223, 231, 232] controlling the distance of the surfactant fragments from the polymer backbone (Fig. 5). Such variations broaden the synthetic scope considerably, but have been explored and exploited rarely yet.

By attaching the surfactant fragments in different ways to the backbone, various polymer geometries are realized. They include "frontal" attachment at the hydrophilic head group ("head type"), "terminal" attachment at the end of the hydrophobic tail ("tail-end type"), intermediate structures ("mid-tail type") and full incorporation into the backbone ("main chain type") $[76,78,87,126]$ (Fig. 6). By varying the nature of the polymer backbone, the flexibility, the

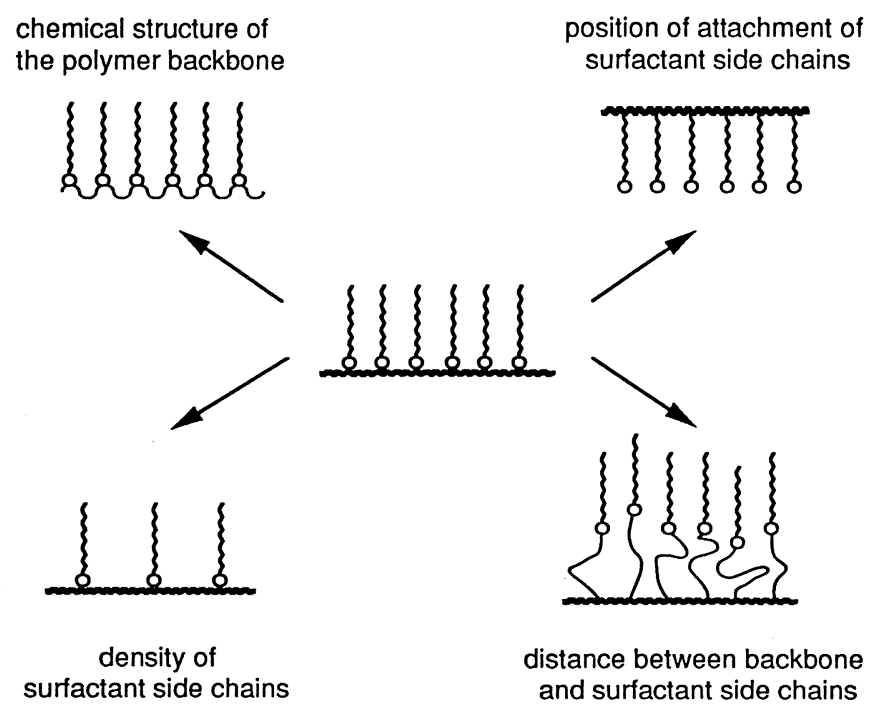

Fig. 5. Structural variables of polysoaps characteristic for polymers. (Reprinted with kind permission from [78]. Copyright 1993 Hüthig \& Wepf, Basel) 


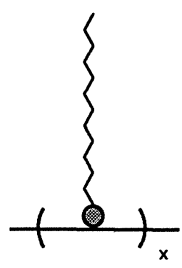

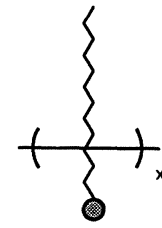

b

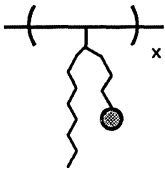

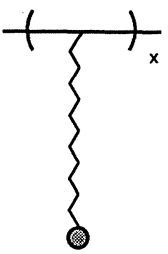

C

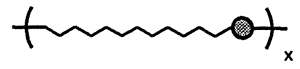

d

Fig. 6a-d. Geometries of polysoaps: a head type; b mid-tail type; $\mathbf{c}$ tail-end type; d main chain type

hydrophilicity (and thus the HLB), and the density of the surfactant side chains of the polysoap are modified. The incorporation of flexible side chain spacer groups may improve the aggregation process as shown for a number of selforganized systems such as polymeric amphiphiles $[7,8,232-235]$, or side chain liquid crystalline polymers $[8,87,236,237]$.

\subsubsection{Surfactant Side Chains}

The variations of the surfactant fragments of polysoaps found are plentiful but seldom systematical. In particular many types of head groups have been realized, covering non-ionic, cationic, anionic and zwitterionic ones (Fig. 7, Tables 1-5), although systematic variations are limited $[72,76,89,107,121,124$, $157,223,238-251]$. They are often confined to the variation of counter-ions [50, $52,53,70,130,170,173,176,177,179,182,252]$. Also, various attempts to functionalize polysoaps are reported, including the incorporation of complexing agents [253-256] chromophores [152, 177, 183, 189, 193, 204, 205, 211, 217, 257-260], mesogens [87, 122-124, 150, 248, 249, 261, 262], redox-active moieties [263-272] and electrically conductive groups [270-274] (see Sect. 2.4). But their effects on the polysoap behaviour are difficult to assess at present. Most systematic investigations of the surfactant fragments in polysoaps are restricted to the influence of the length of the alkyl tails $[54,57,68,85-89,94-97,100-104$, $108,118-120,123-125,133,135,143,144,152,153,155,161,162,169-171,176$, $177,179-182,187-196,199-203,206,213,221,241-243,249,275-293]$, in analogy to homologous surfactant series. Recently, fluorocarbon hydrophobic tails [216, 218, 222, 294-297] have been used instead of hydrocarbon ones.

Considering hydrocarbon tails, it seems that the minimal length to produce polysoap properties is about $\mathrm{C}_{8}[52,191,199,200]$. Polysoap behaviour was reported even for some shorter chains, but then additional hydrophobic units in the backbone must be present (see below). Also, hydrophobic counterions such as tetrabutylammonium [252] or alkyltrimethylammonium ions [186, 204] may induce hydrophobic aggregation for short chain "polysoaps", but in such cases it 


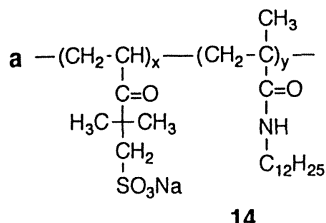

14

b

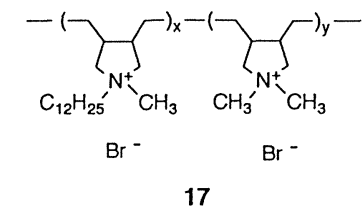

c<smiles>CCC(C)(CC(C)(C)C)OC(=O)OCC(C)(C)C</smiles>

d

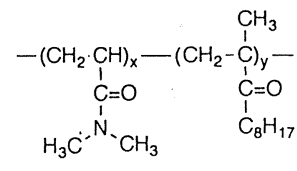

23

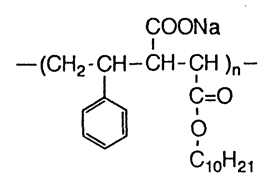

15

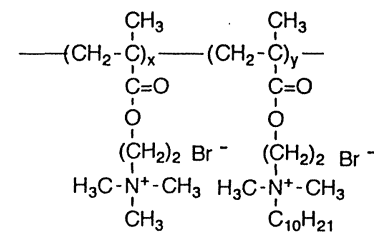

19

Fig. 7a-d. Examples of polysoaps with different types of head groups: a anionic $[155,193,195,207$, 208]; b cationic [152, 161, 167, 199, 200]; c zwitterionic [147, 158-160, 209, 210]; d non-ionic [194, $241-243,252,253]$

is disputable whether the amphiphilic ions favour the hydrophobic aggregation of the polymer, or rather the polymer favours the aggregation of the "counterions". Noteably, there are some indications for a maximal useful length of about $\mathrm{C}_{18}$ beyond which the hydrophobic chains are "crystallized" and thus the hydrophobic aggregates are no more fluid-like [239, 248, 249, 298]. Within these limits the effects of length variations generally agree well with the known effect of similar variations on low molecular weight surfactants. E.g., increasing the length of the alkyl tails or changing from hydrocarbon to fluorocarbon tails, the hydrophobic association of the polysoaps is promoted. 
Specific deviations from the behaviour of low molecular weight surfactants may arise for charged polysoaps, as they represent polyelectrolytes with all implications. For practical aspects this may be of limited importance (although gelling etc. may occur at low concentrations [50]). In the case of fundamental studies however, concentration dependent studies of charged polysoaps become difficult to interpret as the dissociation of the ionic groups and thus the HLB is concentration dependent. Attempts to suppress counterion dissociation by addition of salts often result in precipitation of the polysoaps [50, 299]. Therefore non-ionic and fully zwitterionic polysoaps have been developed to bypass such problems (see Tables 3-5). They have indeed enabled many insights, but often they suffer from some shortcomings of their own. Non-ionic systems are prone to phase separation at elevated temperatures, i.e. they exhibit lower critical solution temperatures [87, 121-124, 126, 231, 251]. Furthermore, most non-ionic head groups, such as oligoethyleneoxides or acylated oligoethylenimines, are very large in comparison to the appropriate hydrophobic moieties yielding an unfavourable ratio of hydrophobic to hydrophilic domains. Alternative non-ionic head groups in the form of sugars or related moieties face solubility problems due to strong hydrogen bonding [246, 247, 250, 300-302]. Similarly, zwitterionic polysoaps often exhibit low solubility in pure water [227]. But by minimizing these problems by proper design, a number of nonionic and zwitterionic polysoaps suited for systematic investigations have been prepared $[78,167,168]$.

Instead of using well defined surfactant fragments, micellar polymers similar to polysoaps have been prepared by combining a large number of small hydrophobic monomers with a small number of charged monomers (e.g. styrene with 2-acrylamido-2-methyl propane sulfonate AMPS [258, 303]). Alternatively, a well balanced ratio of hydrophobic to hydrophilic units is achieved by controlled, limited dissociation e.g. of carboxylic groups, as in poly(methacrylic acid) $[186,304]$ or in poly(styrene-alt-maleic acid) $[305,306]$ or by controlled, limited quarternization of amino groups, like in poly([thio-1-(diethylamino)methyl] ethylene) [307, 308]. Still, it appears that the hydrophobic domains in such polymers with very short tails are less shielded than in surfactant micelles or in polysoaps with "normal" tail lengths $[258,303]$.

\subsubsection{Steric Requirements of the Polymer Architecture}

Systematic variations of the structural variables characteristic of polymers have been addressed only recently. Most of the work was focused on the role of polymer geometry, as the surfactant fragments with their hydrophilic "front part" and their hydrophobic "back side" introduce directionality into the systems $[78,126]$. Neglecting polysoaps of the "main chain type", isomeric sets of vinylic surfactant monomers were converted into polysoaps of different geometry (Fig. 6), in which the surfactant fragments are fixed at different positions to the backbone (Fig. 8), but which have identical hydrophilic- 


\begin{tabular}{|c|c|c|c|c|c|}
\hline POLYMELLES & SPHERICAL & CYLINDRICAL & DISC LIKE & \begin{tabular}{|c|} 
INVERSE \\
CYLINDRICAL
\end{tabular} & $\begin{array}{l}\text { INVERSE } \\
\text { SPHERICAL }\end{array}$ \\
\hline 606 & की & 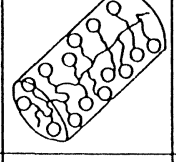 & 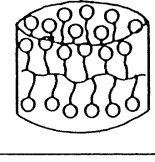 & & \\
\hline $\begin{array}{l}\text { Q-Q } \\
\text { TYPE B }\end{array}$ & & & 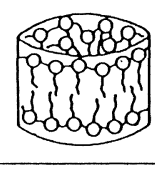 & & \\
\hline 9pq & & & 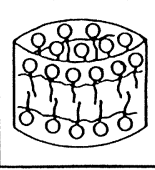 & & \\
\hline
\end{tabular}

Fig. 8. Scheme of isometric polysoaps of different geometry, and the assumed possible micellar shapes in aqueous solution. (Reprinted with kind permission from [231]. Copyright 1987 Steinkopff Verlag, Darmstadt)

hydrophobic balances. Most surprisingly to the early investigators, whereas all the monomers show comparable surfactant properties, only polymers of the "tail end" geometry (Fig. 5c) are water-soluble and behave like polysoaps. The other isomers do not dissolve in water, but instead are soluble in less polar solvents, in which the water-soluble isomers are insoluble $[76,78,85,86,126$, $156,164,167,168,225,231,279,280]$. Hence in case of vinylic polymerized surfactants, no straight forward correlation between solubility and HLB exists: apparently more hydrophilic polymers of the poorly performing "head" geometry are less soluble in water than apparently more hydrophobic ones of the well behaving "tail end" geometry. The opposite is true for organic solvents.

These observations were originally explained by a mismatch between the curvature of spherical or cylindrical micelles and the bending possibilities of the polymer backbone for the different geometries [76, 87], neglecting that many polysoaps give lamellar aggregates in which case this reasoning is not important (Fig. 8). More probably the phenomenon is more general, and independent of the shape of the "polymeric micelles" formed (see Sect. 4.2). It is based on an inherent overcrowding of surfactant fragments at the vinyl polymer backbone, keeping in mind that the $\mathrm{C}_{2}$-repeat unit of a vinyl backbone has a length of ca. $0.25 \mathrm{~nm}$, and the minimal diameter of a hydrocarbon tail is ca. $0.5 \mathrm{~nm}[78,167$, 168]: the backbone cannot offer enough space for an "amphiphilic conformation" of the surfactant fragments (Fig. 9a), independent of the shape of the hydrophobic aggregates. Instead, either the hydrophobic or the hydrophilic parts are exposed exclusively at the "shell" of the polymer to yield a "hydrophobic conformation" (Fig. 9b) or a "hydrophilic conformation" (Fig. 9c) 


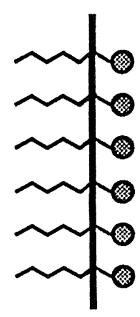

a

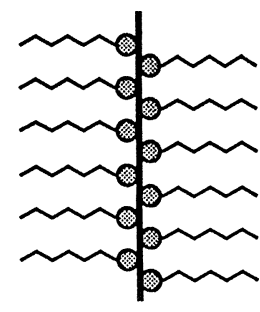

b

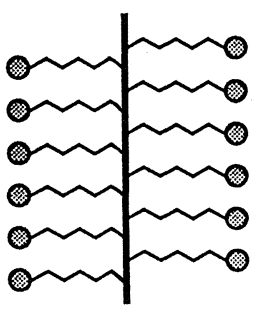

C

Fig. 9a-c. Possible arrangements of polysoaps in solution (scheme): a amphiphilic; b hydrophobic c hydrophilic. (Reprinted with kind permission from [78]. Copyright 1993 Hüthig \& Wepf, Basel)

depending on the polymer geometry. The fragments of different polarity near the backbone are hidden in the polymer "core".

These steric problems with their consequences should affect all vinylic surfactant polymers, independent of the inherent surface curvatures of the different models of "polymeric micelles" (see Sect. 4.2). Thus, vinylic surfactant homopolymers of other than "tail end" geometry should be of very limited use as polysoaps. In fact, very few exceptions to the geometry controlled model of solubility have been reported [82, 106, 128, 225, 289-291]. In these examples, the chemical integrity of the polymers prepared, the attributed structures, or the polymeric nature may be questioned considering the results obtained for very similar compounds $[115,232,309]$. But even if these exceptions are real, this rule will help to design new monomers and polymers.

It should be noticed, however, that metastable aqueous solutions of "head" geometry polymers can be obtained by micellar polymerization of some surfactant monomers with very long alkyl tails [85, 86, 103, 104, 156, 280, 288, 292] (Fig. 10). Apparently, even a poorly realized "amphiphilic arrangement" still represents a local energy minimum, which can be frozen in for long alkyl tails. Such a behaviour parallels the formation of stable insoluble monolayers at the air-water interface of some polymerized surfactants with "head" geometry [168, $245,232,310,311]$. This form of self-organization is sterically less demanding, and thus can tolerate a poor "amphiphilic arrangement" (Fig. 11).<smiles></smiles>
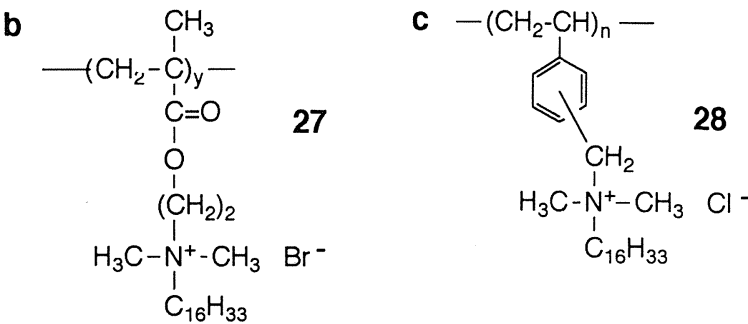

Fig. 10a-c. Polysoaps of "head" geometry reported to form metastable aqueous solutions upon polymerization under micellar conditions: a $[85,86,156]$; b $[280]$; c $[103,104,288,292]$ 


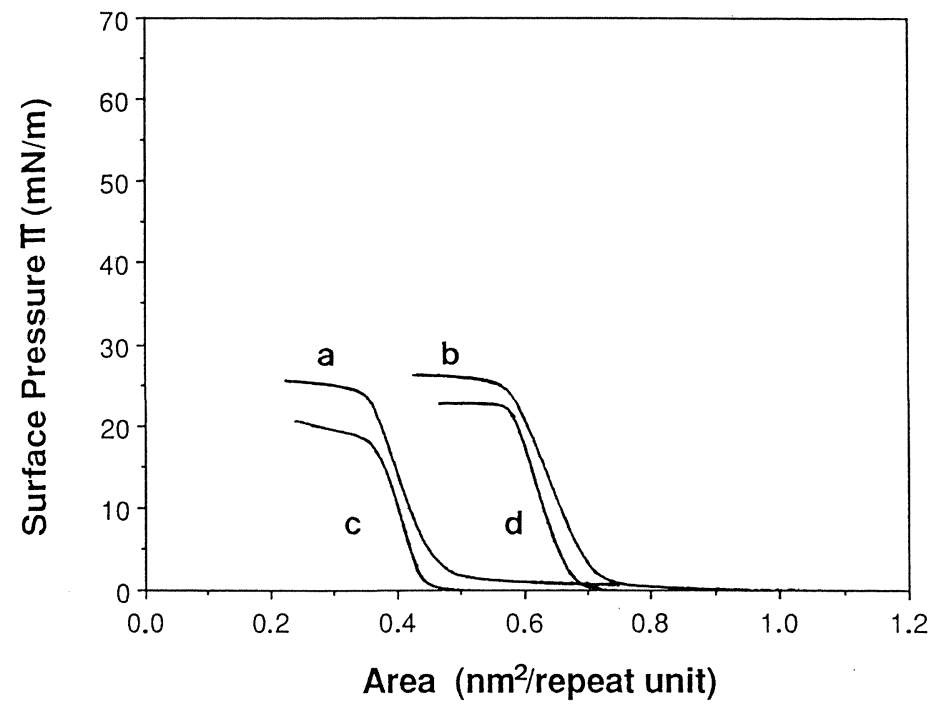

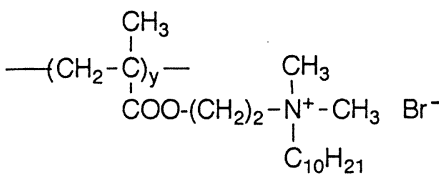

29

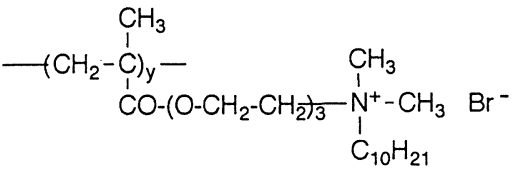

30

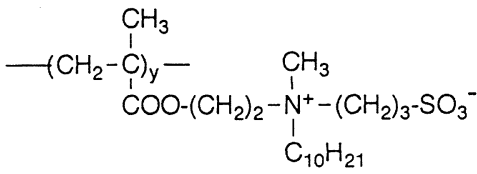

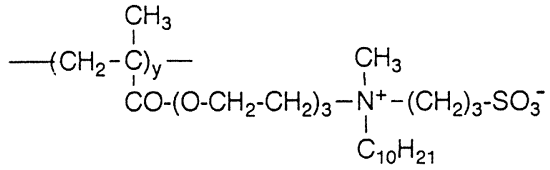

Fig. 11. Stable, insoluble monolayers from polymerized surfactants of "head" geometry. a $=\mathbf{2 9}$, $\mathrm{b}=\mathbf{3 0}, \mathrm{c}=\mathbf{3 1}, \mathrm{d}=\mathbf{3 2}$; data from $[232,245]$

\subsubsection{The Spacer Concept}

The geometrical constraints of vinyl polymers are the consequence of the excessive density of surfactant side chains. The problem is a general one encountered in functionalized polymers, and can be overcome by reducing the density by the incorporation of spacer groups. In the case of "main chain 
geometry" the effect of the spacer is straightforward. If the functional groups are in the side chain (e.g. the surfactant fragment for "tail end", "mid-tail" and "head" geometry), side-chain spacers and main chain spacers can be distinguished as illustrated in Fig. 12. Main chain spacers diminish the density of the functional groups at the backbone, whereas side-chain spacers provide additional space by separating the functional groups from the backbone. The spacer concept was particularly successful for some self-organizing polymers such as polymeric liquid crystals $[8,87,236,237]$ and polymeric lipids $[7,8,13$, $56,232-235]$. It has proven useful for polysoaps as well, making any geometry accessible $[167,168]$.

"Main chain spacers" can be realized in many ways. In fact, they have been used unconsciously from the very early days of the polysoaps in the classical approach to polysoaps, i.e. the incomplete hydrophobization of polar parent polymers (see Fig. 2c), when the non-hydrophobized units of the backbone act as spacer segments $[46-49,52,139-141]$. Another convenient approach is the copolymerization of amphiphilic monomers with small polar ones, or of hydrophobic monomers with small hydrophilic ones [73, 77, 78, 156-168] (Figs. 3e, 3f).

By incomplete hydrophobization of parent polymers and by random copolymerization, the spacer length (or the density of the hydrophobic tails) is easily controlled by the reaction conditions. In agreement with the steric constraints discussed above, the spacers have to be longest for polysoaps of the "head" geometry to guarantee water-solubility. A detailed evaluation of the spacer lengths needed is difficult to derive from the reported examples, as in particular the modified content of hydrophilic "spacer" comonomers shifts the HLB simultaneously. But spacer lengths seem to increase with both the bulkiness of the surfactant fragment and of the main chain spacer. E. g. for hydrophobized poly(sulfobetaine)s of "head" geometry, the minimal spacer length corresponds to a $\mathrm{C}_{6}-\mathrm{C}_{8}$ repeat unit, whereas for analogs of "mid tail" geometry, the minimal spacer length is roughly a $\mathrm{C}_{4}$-repeat unit [167]. According to the above discussion, the success of the polysoap copolymers poly(maleate-alt-vinylether)

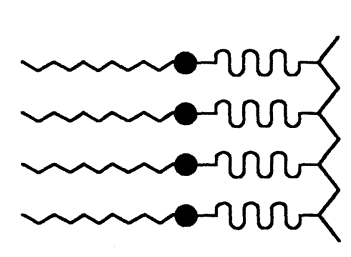

a

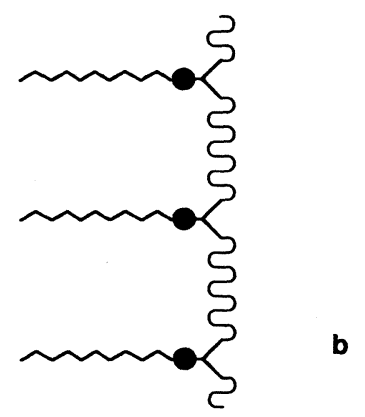

Fig. 12a,b. Scheme of spacer groups in polysoaps: a side chain spacer; $b$ main chain spacer 
and poly(maleate-alt-alkene) such as 12, 16, 33 and 34 (Figs. 3f, 7a, 13), can be attributed to their advantageous combination of favourable "mid-tail" geometry, of small head group and of small spacer unit, i.e. a repeat unit of four carbons, in combination with their ease of preparation [53-55, 169-182, 184-187, 189-192, 196, 197, 206-208, 215].

If well defined spacer segments are desired, the synthesis of polysoaps becomes more complicated. Homopolymerization of other than vinylic surfactant monomers, e.g. of epoxides [312], butadienes [168,313] or vinylcyclopropanes [168] is needed (for examples see Tables 2 and 4). Alternatively, strictly alternating copolymerization enables the preparation of defined repeat units longer than $\mathrm{C}_{2}$-fragments [54, 82, 168-170, 184-187, 189-192, 195-197, 314], usually of $\mathrm{C}_{4}$ (Fig. 13). Polyaddition or polycondensation reactions provide defined spacer segments as well, but only few such systems (e.g. hydrophobized ionenes $[119,120]$ or phenol-formaldehyde resins [241-243, $315]$ ) have been reported (see Figs. 2e, 3b). Presumably this lack is caused by the sensitivity of most of the polycondensations to humidity and protic solvents as encountered in many polysoap systems. Here the use of the thiol/ene addition polymerization [316] may offer a promising new route (Fig. 14).

In addition to considering minimal spacer lengths, the question of maximal lengths arises for which polysoap behavior is still observed. This borderline is very important, as slightly hydrophobized water-soluble polymers are known to aggregate intermolecularly thus acting e.g. as thickeners [77, 151, 162, 218, 222, 285, 294-297], whereas even lesser hydrophobized polymers do not aggregate at all. This is in contrast to the intramolecular aggregation of polysoaps producing solutions of very low viscosity (see Sects. 3.1 and 4). The maximal spacer length corresponds to a minimal density of hydrophobic groups needed for aggregation which has been called "critical alkyl group content" or "CAC" $[52,75]$ in analogy with the critical micelle concentration "CMC".

The detailed CAC values depend on the HLB of the polysoap. For a given head group, CAC values decrease with increasing alkyl lengths; typically they are in the range of $20 \mathrm{~mol} \%$ for octyl tails and of $10 \mathrm{~mol} \%$ for dodecyl tails [52, $75,133,145,152,167,276,317]$. However $3 \%$ of octadecyl tails are not sufficient [151]. Analogously, when the length and the content of the hydrophobic tails are kept constant, CAC values increase with increasing hydrophilicity of the polysoaps, and the hydrophilicity of the head group may determine whether the polymer behaves as a polysoap, or not. Thus the polysoap character of poly(maleic acid-alt-alkylvinylether)s of medium chain length depends on the extent of deprotonation, as the anionic $-\mathrm{COO}^{-}$groups are much more hydrophilic than $-\mathrm{COOH}$ groups [318] (compare Sect. 3.1). Whereas polymers with decyl tails behave like polysoaps at any degree of dissociation, polymers with hexyl tails act as polysoaps only when less than $40 \%$, polymers with pentyl tails when less than $30 \%$ and polymers with butyl tails when less than $20 \%$ of the $-\mathrm{COOH}$ groups are deprotonated $[54,176,177,181]$. As for the latter examples, much hydrophobicity derives from the polymer backbone in the partially dissociated state, and these polymers may be considered as intermediate cases 


\begin{tabular}{|c|c|c|}
\hline copolymer & (surfactant) monomer & comonomer \\
\hline 33 & $\mathrm{CH}_{3}-\left(\mathrm{CH}_{2}\right)_{9}-\mathrm{O}-\mathrm{CH}=\mathrm{CH}_{2}$ & \\
\hline 34 & $\mathrm{CH}_{3}-\left(\mathrm{CH}_{2}\right)_{9}-\mathrm{CH}=\mathrm{CH}_{2}$ & \\
\hline 35 & $\begin{array}{c}\stackrel{\mathrm{C} \mathrm{H}_{3}}{\mathrm{~L}_{3}} \\
\mathrm{CH}_{3}-\left(\mathrm{CH}_{2}\right)_{9}-\mathrm{N}^{+}-\left(\mathrm{CH}_{2}\right)_{3}-\mathrm{SO}_{3}^{-} \\
\stackrel{1}{\mathrm{C}} \mathrm{H}_{2} \\
\mathrm{CH}_{2}=\mathrm{CH}-\mathrm{O}-\mathrm{CH}_{2}\end{array}$ & \\
\hline 36 & $\mathrm{C}_{10} \mathrm{H}_{21}-\mathrm{O}-\stackrel{\mathrm{O}}{\mathrm{C}}-\mathrm{CH}=\mathrm{CH}-\mathrm{II}-\mathrm{C}-\left(\mathrm{CH}_{2}\right)_{3}-\mathrm{SO}_{3}^{-}$ & \\
\hline 37 & 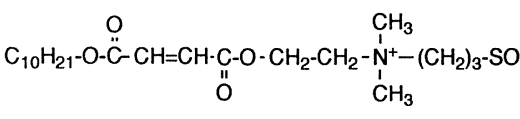 & $\underset{\mathrm{O}}{\stackrel{\mathrm{C}}{\mathrm{C}}-\mathrm{N}-\mathrm{CH}}$ \\
\hline 38 & 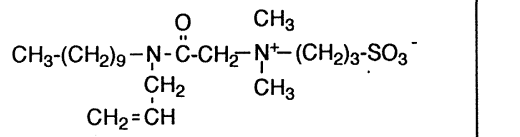 & $\mathrm{O}=\mathrm{S}=\mathrm{O}$ \\
\hline 39 & $\begin{array}{c}\mathrm{CH}=\mathrm{CH}_{2} \\
\stackrel{\dot{\mathrm{C}}}{\mathrm{H}_{2}} \\
\mathrm{CH}_{3}-\left(\mathrm{CH}_{2}\right)_{9}-\mathrm{N}_{1}^{+}-\left(\mathrm{CH}_{2}\right)_{3}-\mathrm{SO}_{3}^{-} \\
\stackrel{!}{\mathrm{C}} \mathrm{H}_{2} \\
\stackrel{\mathrm{CH}}{\mathrm{C}}=\mathrm{CH}_{2}\end{array}$ & $\mathrm{O}=\mathrm{S}=\mathrm{O}$ \\
\hline
\end{tabular}

Fig. 13. Examples of reactive surfactants yielding polysoaps with elongated repeat units by alternating copolymerization. 33: [54, 169, 170, 182, 186, 190, 196]; 34: [191, 192]; 35, 37, 38: [168]; 36: [314]

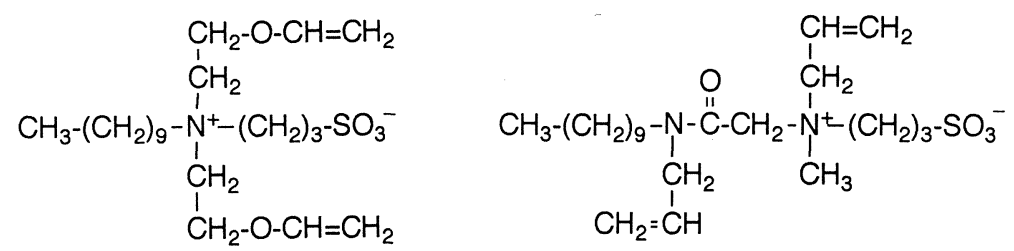

Fig. 14. Diolefinic reactive surfactants for polyaddition reactions with dithiols [316] 
between the longitudinal knotting of surfactant units and the lateral knotting found in classical polysoaps (see Figs. 1e and 1f).

The alternative to "main chain spacers" is the separation of backbone and surfactant fragments by "side chain spacers" (Fig. 12) which should allow the use of vinyl homopolymers for less advantageous geometries. However in contrast to other self-organized systems such as polymeric liquid crystals, "side chain spacers" work poorly for micellar polymers, probably because the steric requirements in polysoaps are much more stringent. The backbone must neither interfere with an efficient packing nor with the correct orientation of the side chains. Thus, extensively long spacers are needed to achieve water-solubility $[100,102,157]$, much longer than the spacer group equivalent of six to twelve carbons which are sufficient for polymeric liquid crystals or for polymeric lipids [7, 8, 87, 232-237]. The "head type" polymers having only standard tri- to octaethyleneoxide spacers (Table 5) are only able to swell, but do not dissolve in water [126, 231, 232, 251] (see also Fig. 37).

\subsubsection{Flexibility of the Polymer Backbone}

The problem of backbone flexibility has not yet been addressed for polysoaps. The vast majority of polymers reported have very flexible backbones. Clearly there must be gradual differences in the flexibility of the polysoaps prepared, depending on the main chain spacer and the reactive moieties employed. E.g., polysoaps based on polystyrene $[51,83,104,130,238,277,278,288,292$, $319-323]$ or $\operatorname{poly}(N, N$-dialkyl, $N, N$-diallyl-ammonium salt)s [161, 168, 199, $200]$ should differ from polyvinyl-esters [224, 225, 232], polybutadienes [168, $313]$ or aliphatic polysulfones $[164,168]$.

a

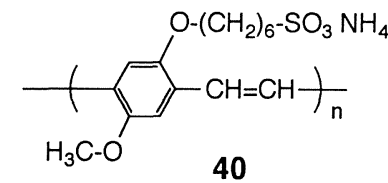

b

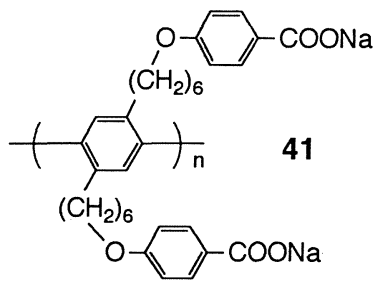

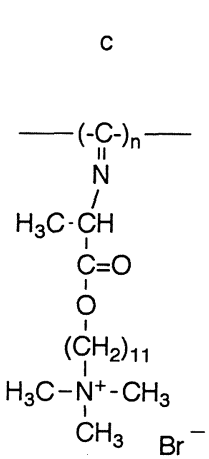

42

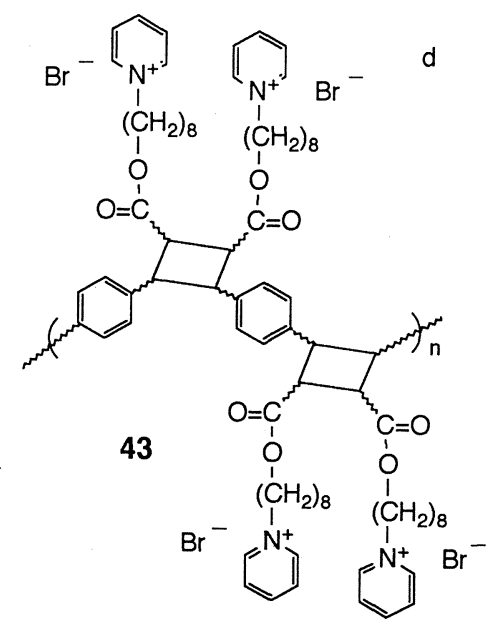

Fig. 15. Examples of amphiphilic polymers with a rigid polymer backbone (polysoap behaviour not reported). a: [273]; b: [274]; c: [329]; d: [330] 
Still the differences should be minor compared to the ones to be expected from the use of rigid-rod polymers. But very few attempts to synthesize polymers with semi-rigid or rigid backbones are described, whose chemical structure could be considered as polysoaps. In case of "main chain geometry" (Fig. 6d), this may be due to the inherent poor solubility of rigid-rod polymers. The preparation of such water-soluble rigid-rod polymers gains increasing interest [324-328] but it still at its infancy. The preparation of stiff polysoaps linking surfactant fragments laterally (Figs. 6a-c) seems more promising, as the side chains are known to improve the solubility of rigid-rod polymers. But there are but singular notes on such compounds [273, 274, 329, 330] (Fig. 15).

\subsection{Functional Polysoaps}

A number of reports deal with functionalized polysoaps, including the incorporation of chromophores, mesogens, redox-active moieties and electrically conductive groups (Fig. 16). Three basic intentions can be identified: i) the functional unit serves as probe to monitor certain properties of the parent polysoap; ii) the polysoap provides a suitable matrix for the functional unit, e.g. by compartmentalization, clustering, orientation etc.; iii) the combination of functional unit and polysoap creates new collective features in the system, e.g. improving or modifying the self-organization.

Incorporations of probe molecules and chromophores are the most widespread functionalizations with various goals aimed at. As mostly limited degrees of functionalization are wanted, such polysoaps are conveniently prepared either by copolymerization [331] or by grafting reactions onto polysoaps or polysoap precursors.

The majority of studies aim at labelling of polysoaps, to study their behaviour as discussed in Sects. 3 and 4. UV/visible-probes, fluorescence probes and ESR probes have been attached. For example azo dyes were used as labels taking advantage of their trans-cis photoisomerization [203, 217, 260]. More frequently fluorescent labels have been fixed such as dansyl [174, 175, 177, 287], naphthyl [211, 259], anthracenyl [183, 189] or pyrenyl groups [204, 259]. For ESR studies, e.g. nitroxy labelled polysoaps based on poly(ethyleneimine) are described [145].

Cases where the polysoap serves as matrix for the functional unit attached include the incorporation of catalytic sites [256, 332, 333], of naphthyl groups used as photochemical antennas [211], and of pyrenyl and naphthyl groups for energy transfer processes [193, 258, 259]. Similarly, viologen moieties were fixed to polysoaps for electron transfer processes, and to study solar energy conversion $[257,264,265]$. The use of polysoaps as matrix is reflected as well by functionalized polysoaps prepared for pharmaceutical applications [334], e.g. in form of copolymers with anticytostatica [335], or as polysoaps carrying targeting groups for drug delivery [336]. Other functional polysoaps are made for specific binding by bearing crown ethers [253-255] and saccharides. The latter 
a<smiles>CC(O)CNC(=O)C(C)(C)C(C)(C)C(C)(C)C(=O)Nc1ccc(N=Nc2ccc(N=Nc3ccccc3)cc2)cc1</smiles>

b<smiles>[Y]C(C)CC(C(=O)OCC[n+]1ccc(-c2cc[n+](C)cc2)cc1)C(C)(C)C</smiles>

46

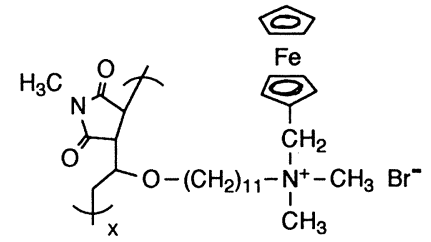

C<smiles>[Y]C([Y])(C)n1c(C)ccc1CCCC</smiles>

48

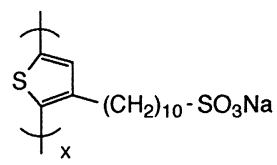

d<smiles>CCOCCOc1ccc(-c2ccc(OCCOC)cc2)cc1</smiles><smiles>[Y]C(C)(C)C1(C(=O)OCCOP(=O)([O-])OC[N+](C)(C)C)CC1</smiles>

Fig. 16a-d. Examples of functional polysoaps: a dye containing $[205,331]$; b redox-active [268, $269]$; $\mathbf{c}$ electrically conductive [271, 272]; $\mathbf{d}$ containing mesogens $[123,262]$

have been considered for molecular recognition $[246,247,250]$, immune reactions and problems linked to biocompatibility [230, 337], but the majority of polysoaps bearing sugar moieties were only prepared for their use as nonionic hydrophilic units (see Table 3 and Fig. 39) rather than as functional ones up to now. 
The combination of functional units and polysoap to create new collective properties represent the least undertaken functionalizations yet. The synthesis of such functional polysoaps often requires the preparation of particular homopolymers to obtain a high content of functional groups. By analogy with other self-organization processes, incorporation of mesogenic units takes a prominent place $[87,122-124,150,248,249,261,262]$. Mesogenic azo dyes were also linked to polysoaps with the idea of photochemical switching between different forms of aggregation [205]; the reported effects however are small. More marked changes of the aggregation are expected by the incorporation of redoxactive moieties, in particular if the systems incorporated enable the variation of the number of charged groups present, thus modifying the HLB. This was studied by synthesizing polysoaps bearing viologen, ferrocene, or nicotinamide moieties in high concentrations [266-269]. An alternative use of functional polymerizable surfactants and their polymers bearing redox-active moieties is oriented towards conductive polymers derived from polypyrrol or polythiophene [270-274]. However, most of the latter examples do not yield watersoluble polymers.

\section{Properties of Polysoaps in Aqueous Solution}

The section reviews some prominent properties of polysoaps such as viscosity in solution, surface activity, solubilization and dynamic properties. As the majority of the studies are singular, the reports do not always allow a clear opinion as to whether the amphiphilic polymers studied are indeed polysoaps or not, as an unequivocal experimental proof may be missing. In these cases, the "polysoap" character was tentatively attributed due to the strong similarity of the chemical structures of the compounds to well known polysoaps. Or the systems are discussed because the authors claim the term "polysoap" for the systems studied (even if convincing evidence is missing). On the other hand, a number of doubtful cases where the systems studied could possibly represent polysoaps have been omitted to minimize the speculative character of the discussion. Hence the selection made is somewhat arbitrary. Furthermore, many investigations are confined exclusively to one analytical technique and/or one property of the system. Therefore a full evaluation of the data and comparisons are difficult. The reader is strongly recommended to consult the original literature if interested in getting a full picture.

\subsection{Viscosity}

The viscosity of aqueous polysoap solutions is characteristically low up to high polymer contents (see Figs. 17-19). In fact this property initiated the study of 


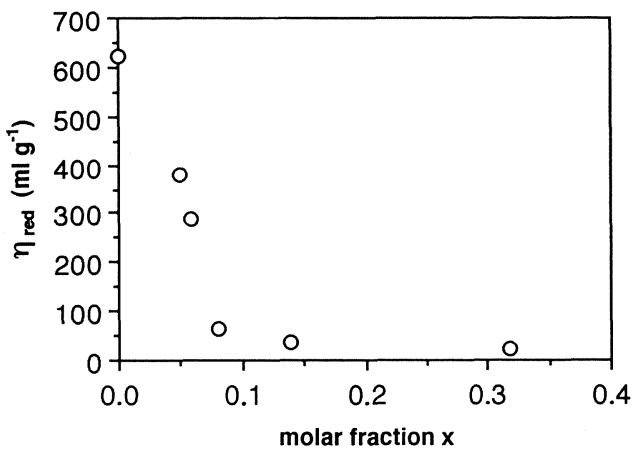

Fig. 17. Intrinsic viscosities $[\eta]$ of poly(4-vinylpyridinium bromides) quaternized with ethyl and dodecyl groups in $0.0223 \mathrm{~N}$ aqueous $\mathrm{KBr}$, as function of the molar fraction of dodecyl groups $\mathrm{x}$ (fraction of ethyl groups $y \approx 0.9-x$, fraction of not quaternized pyridines $\mathrm{z} \approx 0.1$ ). data taken from [52].

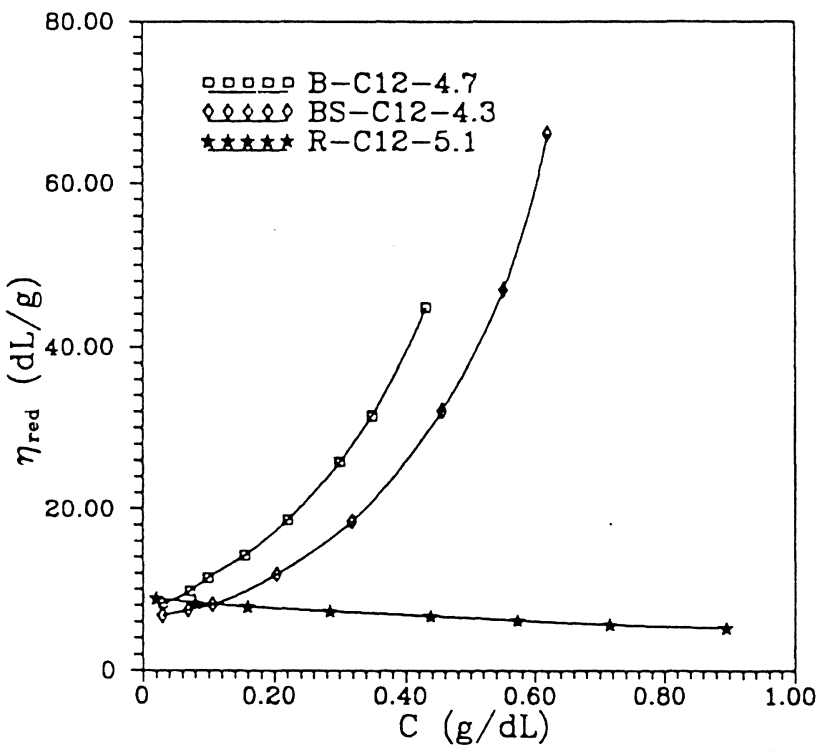

Fig. 18. Concentration dependence of the reduced viscosities of the cationic copolymer soaps 13; fraction of surfactant monomer in the copolymer ca. 0.05 . from top to bottom: $\square=$ blocky copolymer, $\diamond=$ microblocky copolymer, ${ }^{*}=$ random copolymer. (Reprinted with kind permission from [77]. Copyright 1993 American Chemical Society)

polysoaps [46]. It is considered to be a key feature distinguishing ionic polysoaps from ordinary polyelectrolytes $[50,52,75,133]$. The exceptionally low viscosities are explained by the intramolecular aggregation of the hydrophobic side chains, keeping the hydrodynamic radius small.

This behaviour contrasts with the one of slightly hydrophobized watersoluble polymers which act as thickeners [162, 220, 285, 312]. For them, the substantial increases in viscosity are attributed to intermolecular aggregation, 


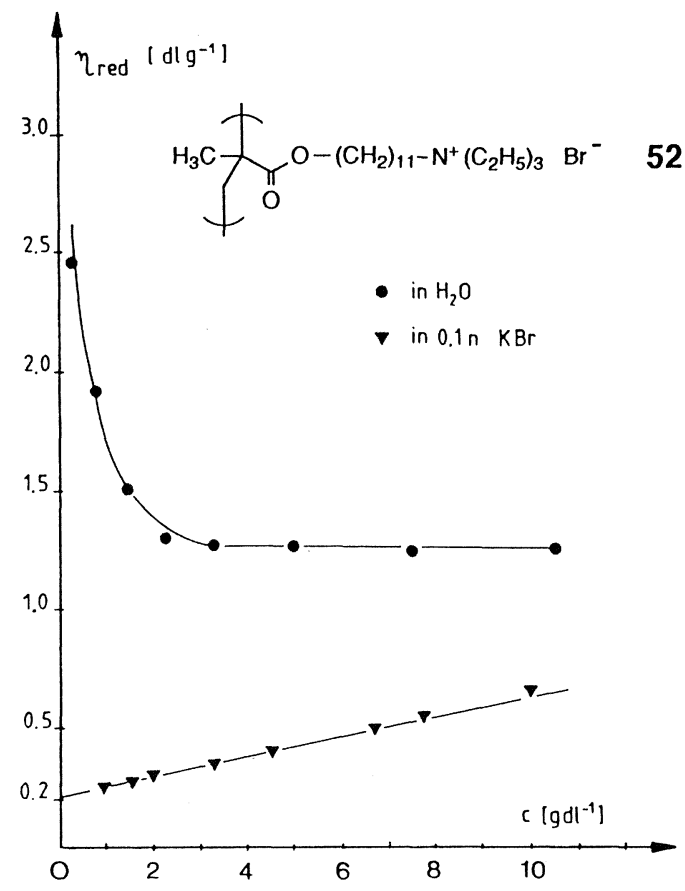

Fig. 19. Concentration dependence of the reduced viscosities of the polysoap 52 in water $(\boldsymbol{O})$ and in $0.1 \mathrm{~N} \mathrm{KBr}(\boldsymbol{\nabla})$. (Reprinted with kind permission from [126]. Copyright 1989 American Chemical Society)

presumably because the number and hydrophobicity of the scattered substituents is insufficient to create intramolecular aggregates.

Interestingly, the viscosity of polysoap solutions is frequently subject to important ageing effects $[75,99,130,163,284]$ and temperature effects $[75,130]$, dropping asymptotically towards its final value. The decrease can amount to $90 \%$ of the initial value and can endure for up to one month $[99,163]$. These effects are not well understood but are putatively attributed to conformational changes. The phenomenon has to be kept in mind when evaluating viscosity data, and should always be verified - or excluded - in viscosity studies of polysoaps.

As discussed before, the borderline between polysoaps and polyelectrolytes or thickeners is determined by the hydrophilic-hydrophobic balance HLB, as well as by the length and the density of the hydrophobic tails chosen. The longer they are, the lower is the content of hydrophobic tails - the "Critical Alkyl Group Content" CAC $[52,75]$ - needed in order to produce polysoap behaviour (cf. Sect. 2.3.2). For poly(2-vinylpyridine) and poly(4-vinylpyridine), about $20 \%$ of derivatization with octyl tails and about $10 \%$ of derivatization with dodecyl tails are needed as a minimum to obtain the characteristic low viscosities [49, 52, 75, 133, 141, 317] (Fig. 17). Comparable CAC values are obtained for derivatized poly(vinyl-imidazol)s [140] and for poly(allylamine)s [152]. Similarly in anionic copolymers of poly(sodium 2-acrylamido-2- 
methylpropanesulfonate), low viscosities characteristic of polysoaps are achieved at about $60 \mathrm{~mol} \%$ of $N$-phenylacrylamide content, $15 \mathrm{~mol} \%$ of $N$-dodecylmethacrylamide content and $10 \mathrm{~mol} \%$ of $N$-pyrenylacrylamide content [193].

Concerning the importance of the HLB, e.g. for poly(vinylether-alt-maleate)s the critical length of the hydrophobic tails yielding the typical low viscosities depends on the degree of dissociation of the carboxyl groups $[54,171]$. The tails have to be enlarged to counterbalance the increasing charge in the polymer with increasing neutralization. Only if the tail lengths exceed octyl polysoap behaviour is observed independently of the degree of neutralization [186, 190, 192, 196]. An analogous effect may be responsible for the markedly reduced viscosities seen for polysoaps with low, just sufficient hydrophobe content when a certain amount of hydrophobic solubilizate is added [47, 49, 130]: the incorporated hydrophobic compounds mimic a decrease of the HLB.

Viscosity studies on perfluoroctyl substituted hydroxyethyl cellulose suggest that the CAC values are considerably lower for fluorocarbons than for hydrocarbons [297]. The lower CAC values can be explained by the increased hydrophobicity of fluorocarbon tails.

An additional parameter defining the borderline between polyelectrolytes or thickeners on one side, and polysoaps on the other side, is the distribution of hydrophilic and hydrophobic segments in the macromolecules. Studying the viscosities obtained for copolymers of surfactant monomers with acrylamide, random copolymers (i.e. with random distribution of hydrophobic tails) behave as polysoaps: they show low viscosities pointing to intramolecular aggregation. In contrast, blocky copolymers of the same average chemical composition are prone to intermolecular aggregation thus acting as viscosifiers, although the HLB of the two types of copolymers is identical [77] (Fig. 18). Analogous effects were observed for copolymers of acrylamide and ethylphenylacrylamide [220].

Viscosity studies of ionic polysoaps in pure aqueous solution usually suffer from the polyelectrolyte behaviour experienced at low concentrations [46, 49, $52,75,78,98,99,126,130,193,219,229,338]$. Indeed, as the dissociation of the ionic groups varies with the concentration, meaningful concentration dependent studies become difficult. The problem was frequently overcome by addition of salt (Fig. 19). But ternary systems are created, making the systems even more complex, and many ionic polysoaps tend to precipitate in brine $[50,54,299]$. These problems can be avoided by zwitterionic polysoaps, facilitating the interpretation of concentration dependence [78].

Much confusion had arisen from the polyelectrolyte-like viscosity of ionic polysoaps at low concentrations. Based on the old polyelectrolyte model of coilto-rod transition [339-342], it was suggested that the strong increase of reduced viscosities at low concentrations would indicate a transition of intramolecularly aggregated coils to extended conformations of the polysoaps which are no more aggregated. This would mean that the polysoap characteristics would be suspended at low concentrations [126, 229, 292].

This interpretation clearly disagrees with the presence of hydrophobic aggregates in solutions of charged polysoaps down to high dilutions, as evid- 


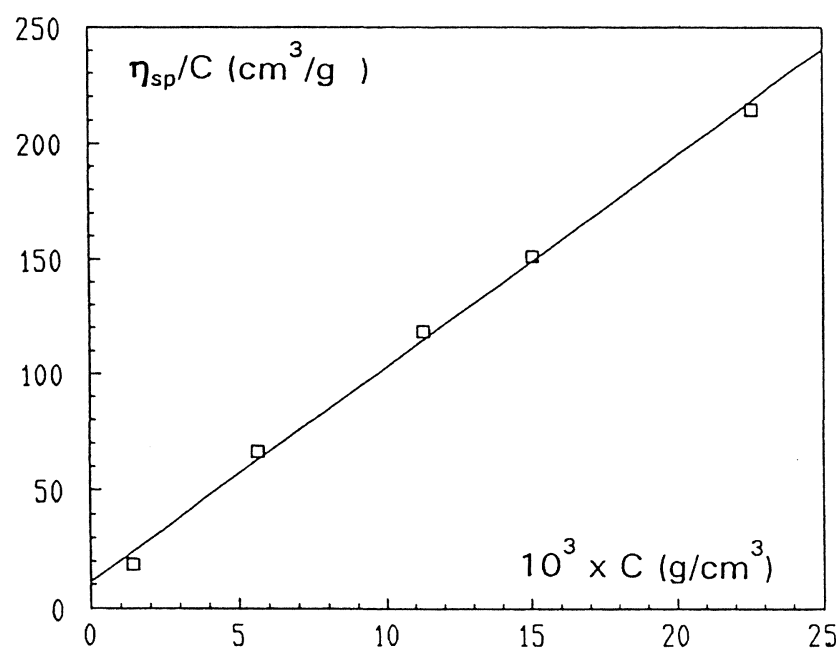

Fig. 20. Concentration dependence of the reduced viscosities of the metastable solutions of polysoap 28 in water. (Reprinted with kind permission from [292]. Copyright 1993 American Chemical Society)

enced by many other analytical techniques, in particular by qualitative and quantitative solubilization studies $[72,78,343]$ (cf. Sect. 3.3). Considering recent theories of polyelectrolytes which assume the formation of superstructures to explain the marked maximum of the reduced viscosity at low concentrations without postulating a coil-to-rod transition [344-346], the apparent contradiction is easily resolved: polyelectrolyte behaviour does not imply the absence of micellar structures.

Still, there is the most interesting phenomenon that the cationic polymer poly $(N$-hexadecyl- $N, N$-dimethy- $N$-vinylbenzyl ammonium chloride) 28 exhibits very low reduced viscosities but does not show polyelectrolyte behaviour in aqueous solution [103, 292]: the plot of reduced viscosity vs concentration is strictly linear, and is insensitive to added salt (Fig. 20). Importantly, this "head" type vinyl polymer without main chain spacer is not water-soluble and thus not a "true" polysoap, but forms only metastable aqueous solutions (see Sect 2.2.4). Similar results were reported for alkylated poly(vinylimidazoles) such as $\mathbf{2 6}$ [347]. It may be speculated that such solutions represent rigid "molecular latexes" rather than flexible "polymeric micelles", and further studies on such systems would be most interesting.

\subsection{Surface Activity}

The surface activity of polysoaps has rarely been studied. This is surprising because surface activity is one of the key features in soap performance, as 
reflected in the more general term "surfactant" used for natural and synthetic soaps and for similar compounds. The few reports do not provide a clear, coherent view at present, but nevertheless they illustrate substantial differences to low molecular weight surfactants. Unfortunately, experimental work is hampered as the measurements are very sensitive to trace impurities [348]. Therefore an accurate evaluation of the experimental data may be difficult, or may even be fooled by artefacts. Also, extensive equilibration times may be necessary $[349,350]$. The latter may be attributed to slow diffusion $[144,351]$, or to conformational changes of the polysoaps [144].

The surface activity of low molecular weight surfactants is easily characterized by following the aqueous surface tension as a function of the logarithm of concentration as derived from the transformation of Gibbs' equation [28]. In the very dilute concentration regime, molecularly dissolved surfactants are in equilibrium with a soluble monolayer at the interface. Increasing enrichment of the surfactant at the interface causes a continuous decrease of surface tension with increasing concentration. But passing the critical micelle concentration $\mathrm{CMC}$, all newly added surfactants will be incorporated into the micelles. As a consequence the surface activity of the molecular dissolved surfactants is kept constant above CMC (in a first approximation), and the equilibrium concentration at the interface, too. In consequence, the surface tension stagnates above CMC, producing the classical shape of the semilogarithmic surface tension vs concentration curves (Fig. 21).

In the existing studies on the surface activity of polysoaps, three cases can be distinguished:

i) the polysoaps decrease only marginally the surface tension, if at all $[50,72,82$, 113, 131, 228, 229, 245, 300, 317] (Fig. 21);
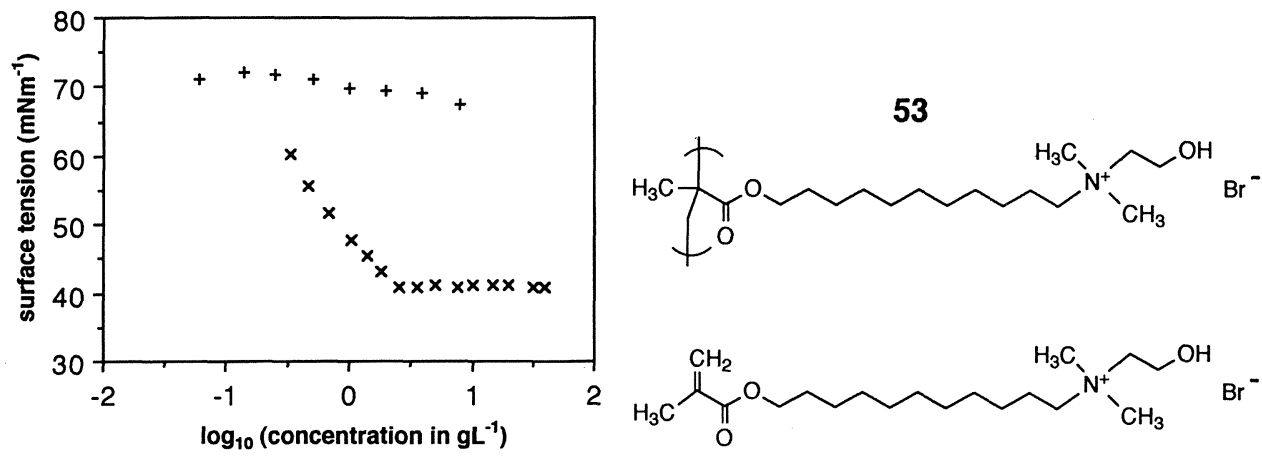

Fig. 21. Surface activity of surfactants and polysoaps in water at $25^{\circ} \mathrm{C}$, exemplified by a cationic methacrylate: $+=$ polysoap $\mathbf{5 3}, \mathrm{X}=$ corresponding surfactant monomer. (Data taken from [245]) 
ii) the polysoaps induce a continuous, notable decrease of surface tension with increasing concentration, but no CMC or a break point resembling a CMC is observed [55, 78, 131, 164, 167, 168, 193, 228, 245, 350, 352]; (Figs. 22, 23).

iii) the polysoaps induce a decrease of surface tension with increasing concentration exhibiting a break point resembling a CMC $[143,144,193,213,241,242$, $251,353]$.

There are some additional reports stating considerable surface activity of polysoaps, but without specifying the concentration dependence $[152,194,301]$.

The first two cases lacking any indication for the presence of "CMC"s are in agreement with the idea of intramolecular hydrophobic aggregation. The third case points to an intermolecular aggregation of the polysoaps, similar to low molecular weight surfactants. However it is difficult to decide by the present data whether this rare case is indeed real or artificial, and whether the break points in the semilogarithmic plots of surface tension vs concentration indeed reflect the onset of aggregation. It should be noted that many of such "CMC" values reported are virtually independent of the length of the alkyl tails [143, $144,241,242]$ which is difficult to rationalize, or the surface tension starts to decrease at much higher concentrations than those where hydrophobic aggregation can be detected by the solubilization experiments [213]. Also, reported break points from surface tension studies interpreted as "CMC" or "pre-CMC" are in contradiction to solubilization studies where no "CMC" is observed (compare $[66,67,71]$ with $[65]$ ).

The appearance of surface activity and an apparent "CMC" could well be caused by low molecular weight contaminants, originating e.g. from insufficient removal of educts or as by-products of the synthesis, or from partial decomposition $[143,144,213]$. The strong effects of hydrophobic counterions bound to polyelectrolytes on the surface tension are well known [350] and traces many suffice to provoke the effect. Alternatively, apparent "CMC"s of polysoaps have been reported when low oligomers are involved [241, 242, 251, 353]. Thus dimers or trimers etc. might be responsible for the effect, exhibiting intermolecular micellization (see Sect. 6).

The appearance of "CMC"s for polysoaps bearing particularly short hydrophobic tails [193] is rather a semantic problem as these examples do not match the original definition of polysoaps anymore. If the hydrophobe tails are too short, no intramolecular aggregation can take place as evident from viscosity measurements $[24,133,193]$, and intermolecular aggregation is needed to reduce hydrophobic interactions.

Although originally it was assumed that intramolecular aggregation would result in a complete lack of surface activity, the first two cases where no "CMC" is observed seem to represent extremes of the same general behaviour. In fact, gradual transitions from hardly to strongly surface-active polysoaps can be found if the chemical structure is gradually modified or if certain additives are gradually fed in. Molecular parameters which influence surface activity are the 
polysoap geometry, the hydrophilicity of the head group, and size and content of the hydrophobic groups. The rules do not always agree with the ones observed in low molecular weight surfactants.

Concerning the role of the polysoap geometry, the reported data suggest that the surface activity increases with increasing proximity of the backbone and the surfactant head group [78, 167, 228]. The surface activities reported for polysoaps of the "tail end" geometry are generally lower than those reported for analogues of the "head" geometry (Fig. 22). This holds true even if the "head" type polysoap has a considerably higher HLB, counting the various molecular fragments on the polymer: e.g. the "head" copolymers 19 with choline methacrylate reduce the surface tension much more strongly than the "isomeric tail end" homopolymer 53.

This behaviour is opposite to that of low molecular weight surfactants for which a higher HLB at a given concentration will cause higher surface tensions $[251,281,354]$. But it parallels the problem of the different polysoap geometries in realizing an optimal amphiphilic arrangement in solution: "tail end" geometry enables a more efficient "shielding" of the hydrophobic aggregates, thus reducing the tendency to adsorb at interfaces. This picture may also explain why "tail end" polysoaps bearing the same surfactant moiety but having different polymeric backbones exhibit virtually identical reductions of aqueous surface tension (Fig. 23), although the monomers behave quite differently. In agreement with the above discussion of shielding efficiency, random copolymers show higher activity than graft copolymers of identical composition [228]. These observations are instructive examples for how the polymer architecture can modify - or even override - the properties expected from simple cumulation of the fragment's properties.

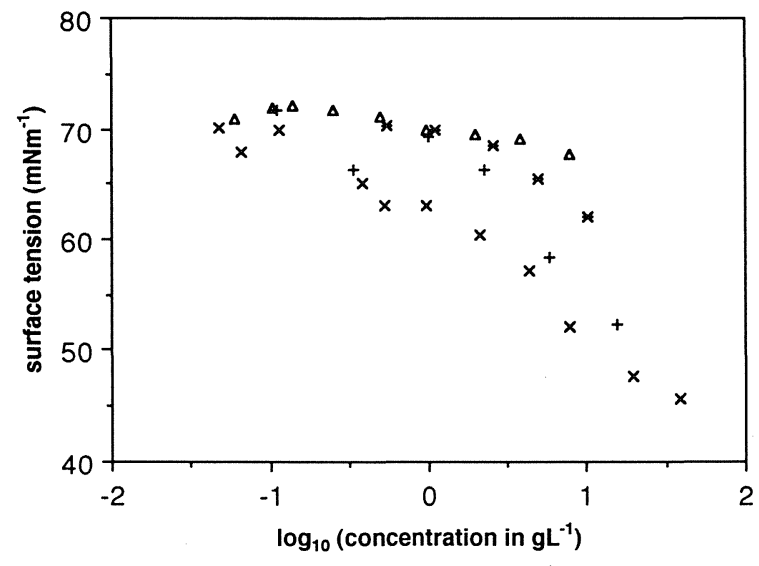

Fig. 22. Surface activity of closely related cationic polysoaps in dependence on their geometry and on their main chain spacer in water at $25^{\circ} \mathrm{C}$. (Data from [167, 245]). "Tail end" geometry: $\triangle=$ polysoap 53. "Head" geometry: $X=$ copolymer soap 19a (hydrophobe content $\mathrm{y}=0.4),+=$ copolymer soap 19b $(\mathrm{y}=0.2),{ }^{*}=$ copolymer soap $19 \mathrm{c}(\mathrm{y}=0.1)$ 

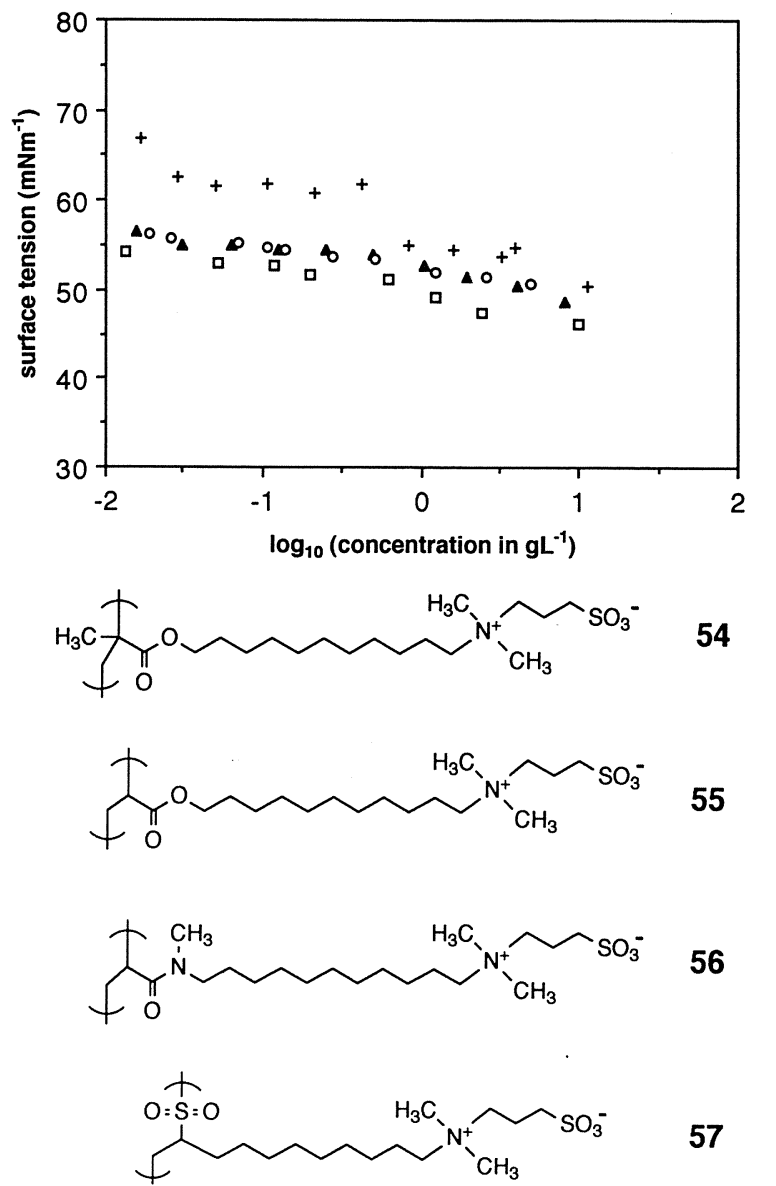

Fig. 23. Surface activity of four analogous zwitterionic polysoaps of tail-end geometry with different polymer backbones. (Data from $[164,167,245]$ ). $\boldsymbol{\Delta}=$ polymethacrylate $54, \square=$ polyacrylate $\mathbf{5 5}$, $\mathrm{O}=$ polyacrylamide $\mathbf{5 6},+=$ polysulfone 57

Looking however at polysoaps of one geometry only, the available data suggest that decreasing HLB causes increasing surface activity. E.g. for "head" type copolymers made from hydrophobic monomers (or from surfactant monomers respectively) with hydrophilic comonomers, the surface activity increases with increasing hydrophobe content [152, 167, 193, 228, 350, 355] (see copolymers 19, Fig. 22). This observation also fits into the general scheme discussed above: the shielding of the hydrophobic groups in "head" type polysoaps becomes more difficult with less strongly hydrophilic groups available. The simultaneously reduced length of the main chain spacer group however seems to be of minor importance for the effect. If the polar backbone is made from 
uncharged acrylamides instead of charged units and the hydrophobic tails are incorporated in the form of complete surfactant fragments (not only of pure hydrophobic tails), the HLB is kept approximately constant, and the increasing density of hydrophobic tails in the polysoaps results only in marginal changes of the surface activity [167].

There are very few studies on the influence of the length of the hydrophobic tails in polysoaps. The reported increase of surface activity for some ionic polysoaps with increasing length of the hydrophobic tails corresponds to the behaviour of standard surfactants $[152,155,193]$. However, decreasing surface activity with increasing length was reported for substituted acrylamides [194] Another strange result was reported from some nonionic liposaccharide polysoaps for which surface activity increases monotonously with the length of the hydrophobic tails, but the values measured for monomers and polymers are identical [301].

In analogy with the above discussion of the influence of the hydrophobe content, increasing hydrophilicity of the head groups coincides with decreasing surface activity. This trend goes along with the one of low molecular weight surfactants, but the effects are much more pronounced. E.g. zwitterionic polysoaps of "tail end" geometry exhibit moderate surface activity, whereas cationic analogues with the higher HLB are only slightly surface active [245] (Fig. 24).

The observed effects of added salts [131, 208, 299] are much stronger than for low molecular weight surfactants. They can be rationalized in the same way. Added salt enhances the surface activity of cationic polysoaps [131, 299] by depressing the dissociation of the ionic head groups and reducing their hydrophilicity. Similarly, the surface activity of some anionic polysoaps based on hydrophobized maleic acid copolymers is increased by lowering the $\mathrm{pH}$, which reduces the dissociation of the pendent carboxylates and thus the HLB [208] Similar (though much weaker) effects are found even for polymethacrylic acid [304]. In agreement with this discussion, the surface activity of zwitterionic polysoaps is decreased when salt is added [299] due to their anti-polyelectrolyte character [356], contrasting well with ionic polysoaps.

The rule concerning the influence of the hydrophilicity of the head groups may serve as a useful guideline, but some exceptions should be noted. In contrast to their ammonium analogue 53, the viologen polysoaps 58 exhibit notable surface activity which is similar to one of their sulfobetain analogue $\mathbf{5 4}$ (Fig. 24), though 58 has the highest HLB adding the various molecular fragments and in agreement with the increasing CMCs of the respective monomers. Perhaps the tendency of the polymer bound viologene moieties to aggregate, as evidenced from electrochemical studies [268] - is intervening.

For certain hydrophobic substances added to polysoap solutions, a notable reduction of the surface tension is observed [131]. As more detailed studies were missing until now, the reasons are not clear. But the action of organic compounds as cosurfactants seems not unreasonable.

The influence of the molecular weight of polysoaps on the surface activity has been touched occasionally [131, 229, 357]. It seems that for high molecular 


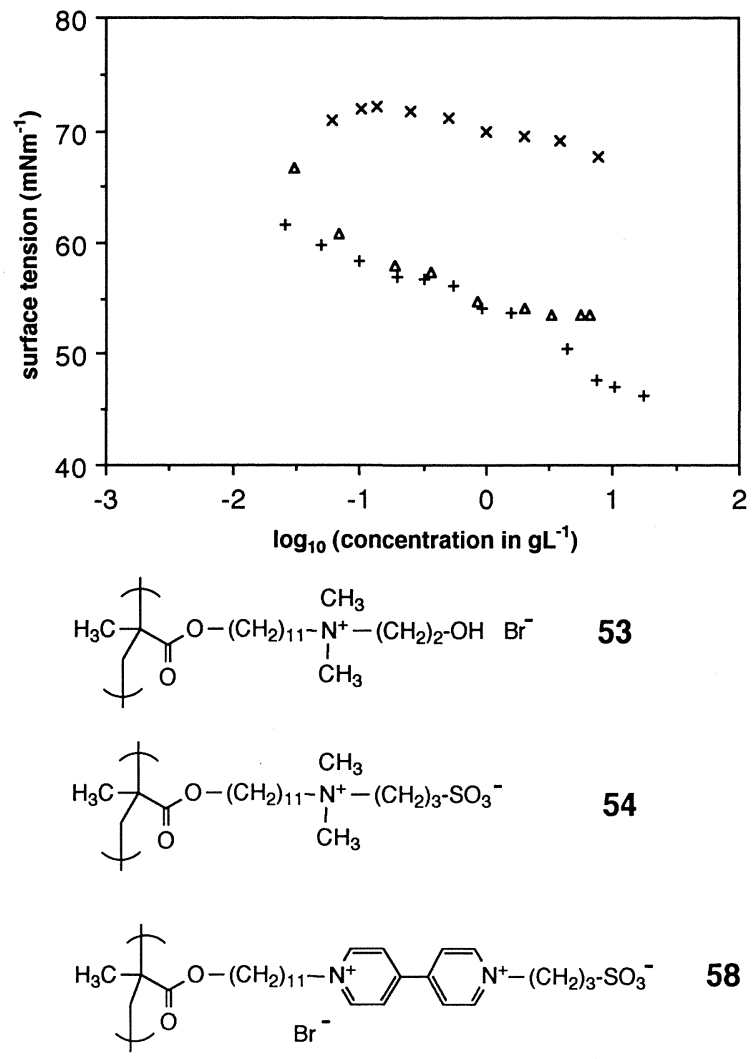

Fig. 24. Surface activity of poly(methacrylate) polysoaps of tail-end geometry with head groups of increasing hydrophilicity. (Data from $[245,267]) .+=54, X=53, \Delta=58$

weight samples the influence is minor if existing at all (Fig. 25). However for oligomers below the critical size for intramolecular aggregation, differences in the molecular weight are important, as will be discussed in Sect. 6 .

\subsection{Solubilization}

Solubilization [20, 358-360] was defined by Elworthy, Florence and Macfarlane as "the preparation of thermodynamically stable isotropic solutions of substances normally insoluble or slightly soluble in a given solvent by the introduction of an additional amphiphilic component or components" [358]. Like surface activity, the ability to solubilize water-insoluble compounds represents a key property in the performance of surfactants [21]. Therefore, solubilization by polysoaps has raised interest from the very beginning [46-51]. 


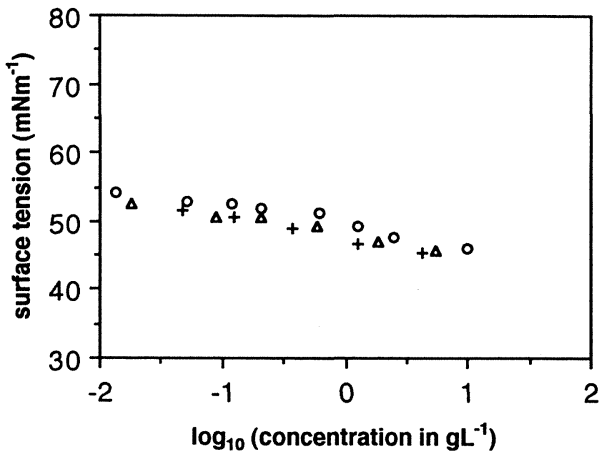

Efficient solubilization is bound to the presence of hydrophobic aggregates, in particular of micelles. This implies for surfactants subject to intermolecular aggregation - such as low molecular weight surfactants - that concentrations above the CMC must be employed [358-360]. This may cause problems if dilute solutions are needed (e.g. for reasons of stability of biological solutions, of toxicology, or of waste water treatment). In addition, as dilution of solutions of intermolecularly aggregating surfactants below the CMC will disrupt the micelles, dilution will also lead to the deposition of the solubilized material, a problem often encountered in rinsing processes. Here, polysoaps may be the perfect match to standard surfactants for special applications (see Sect. 7), as polysoaps are generally capable of solubilization at any concentration $[25,50$, 51, 53, 65, 76-78, 106, 112, 113, 186, 196, 197, 245, 361] (Fig. 26).

Basically, two types of solubilization studies can be distinguished. In the first type, solubilization is only a tool to incorporate probe molecules into the polysoaps, to learn of the nature of hydrophobic domains available, e.g. their size, form and polarity etc. ("qualitative solubilization"). The majority of such studies employs dye probes whose spectral properties are sensitive to the environment of the chromophore $[20,362-366]$. The second, less frequent type

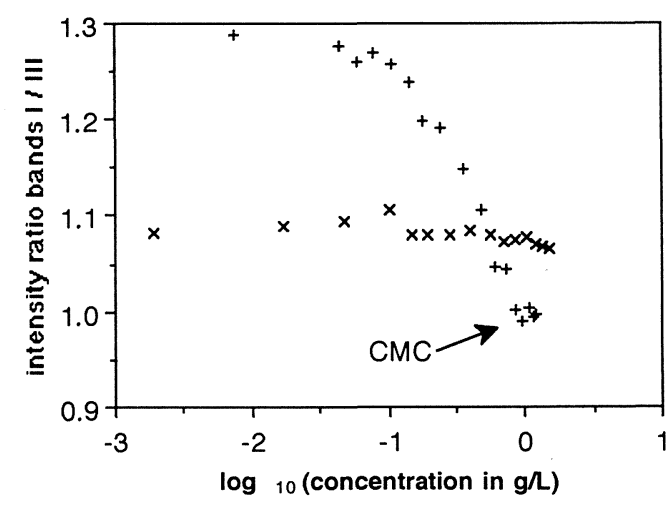

Fig. 26. Solubilization of pyrene by the zwitterionic polysoap $(x)$ and its monomer $(+)$. Concentration dependence of the intensity ratio of fluorescence bands I $(372 \mathrm{~nm})$ and III (383 $\mathrm{nm})$. Lower ratios I/III indicate a more hydrophobic environment of the dye. (Data from [245]) 
of studies is focussed on the solubilization capacity of the polysoaps ("quantitative solubilization").

\subsubsection{Solubilization of Probe Molecules}

Various spectroscopic techniques and probes have been used to investigate solubilization of probe molecules, mostly using UV/visible spectroscopy, fluorescence spectroscopy, ESR spectroscopy [64, 74, 217, 287] and NMR-spectroscopy [367-369]. Fluorescence spectroscopy is particularly versatile [370], as various static and dynamic aspects can be covered by studying excitation and emission spectra, excimer or exciplex formation, quantum yields, quenching, fluorescence life-times, fluorescence depolarization, energy transfer etc.

"Qualitative solubilization" studies are by no means trivial [362]. Like all studies based on probe molecules, they suffer from inherent uncertainties. On one hand the probe content has to be kept as small as possible to minimize the perturbation of the system (which can hardly be excluded rigorously). On the other hand it is generally not known where the actual solubilization site of the probe is, and whether the small number of probe molecules will indeed occupy representative sites in the system or - perhaps - will accumulate in exceptional locations thus monitoring non-representative - though real - properties and events. This is particularly important if very large and bulky probes such as $\mathrm{ET}_{30}$ are employed [212] which are about of the same order of size as the aggregate. Furthermore, assumptions often have to be made to enable a treatment of the acquired data which cannot be verified [196, 370]. Therefore results derived from such studies may be ambiguous and the conclusions even misleading, and several techniques should preferably be combined. But despite all these many shortcomings, there are virtually no other techniques available at present which would allow comparable studies.

Pyrene derivatives are the widest used probes for qualitative solubilization [365] by virtue of the solvatochromic shifts of the absorption bands [255], the excimer formation [145, 186], the polarity dependent quantum yields [197] and fluorescence life-times [185-187, 196, 197, 202, 215, 292], and the pyrene fluorescence fine structure $[65,74,78,103,112,167,224,363,371]$ : the intensity ratio of the fluorescence bands I at $372 \mathrm{~nm}$ and III at $383 \mathrm{~nm}$ is a convenient measure for the polarity of the environment of the pyrene label ("py"-scale; "I/III" values increase with polarity, cf. Fig. 27). As, however, the fluorescence of pyrene is very sensitive to the experimental set-up [372], absolute I/III values reported by different groups are difficult to compare.

The following will focus on studies exploring the nature of the solubilization sites. Studies concerning dynamics in polymeric "micelles", the overall shape and aggregation numbers are included in Sects. 3.5 and 4.2.

The simplest information obtained by "qualitative" solubilization is the existence (or the absence) of hydrophobic microdomains, using probes which are sensitive to the polarity of the environment. Such solubilization experiments are 

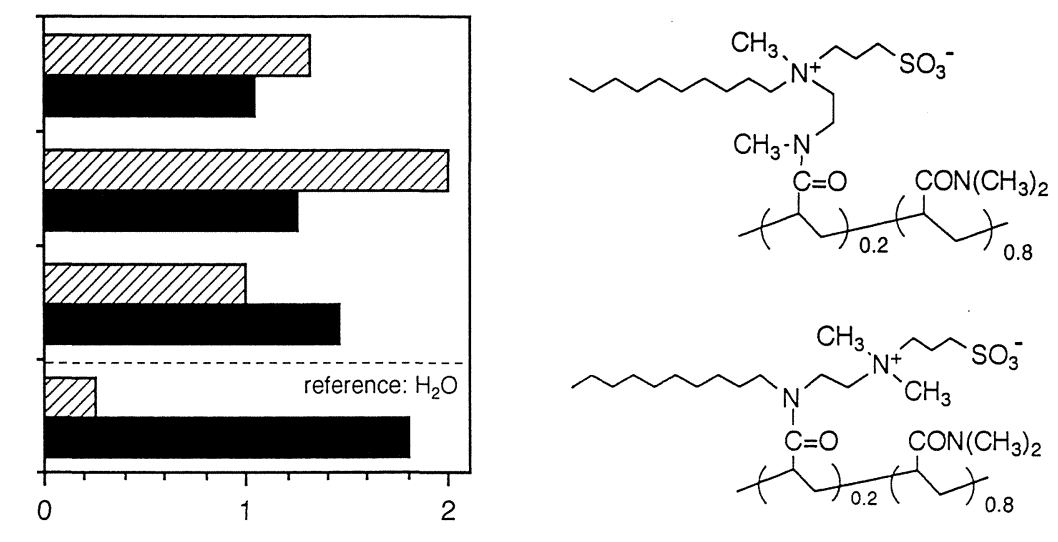

relative solubilization capacity for HNB

intensity ratio $\mathrm{I} / \mathrm{III}$ (pyrene emission)

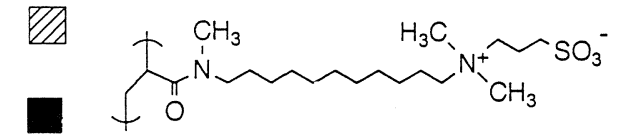

Fig. 27. Concentration dependent intensity ratio of fluorescence band I ( $372 \mathrm{~nm})$ and band III $(383 \mathrm{~nm})$ of pyrene solubilized by analogous polysoaps of different geometry, compared to their relative solubilization capacity for 4-hexyloxy-nitrobenzene. From top to bottom: 59 ("head" geometry), 60 ("mid tail" geometry), 56 ("tail end"); data from [167, 343]

easy to perform, and many techniques and probes will be useful. Solvatochromic shifts of absorbance and emission spectra are particularly simple to detect. It should be noted however that extent and magnitude of the solvatochromic shifts are often difficult to rationalize $[343,364,366]$. Furthermore, shifts due to solubilization by hydrophobic aggregates may be hard to distinguish from effects due to specific (e.g. electrostatic) binding of the probes [142, 154, 215, 238] which is not linked to the presence of micelles. Also the technique does not differentiate at this simple level between the formation of intramolecular hydrophobic aggregates and intermolecular ones.

If the probes are slightly water-soluble, an additional problem arises from partitioning of the probes between the aqueous and the "micellar phase". Thus sometimes the assumed "CMC"s, because of changing I/III values of pyrene fluorescence [213, 353], may be apparent only because of the unfavourable partition of the solubilizate between the aqueous and the "micellar phase" at low soap concentrations $[154,292]$.

In more elaborate studies with pyrene it was shown that the hydrophobicity of the solubilization sites increases with the length of the alkyl tails incorporated $[103,128,185,186,196,292]$. Similar results were obtained with various dansyl derivatives [152] and with methyl orange [200]. Such behaviour agrees well with that of low molecular weight surfactants [185]. Additionally, the polarity of the sites seems to depend on the rigidity of the hydrophobic tails. In copolymer soaps of "head geometry" based on polyacrylamide, the polarity around the 
pyrene probes increases with cyclododecyl $<$ dodecyl $<$ adamantyl tails, which sequence was attributed to the efficiency of steric shielding of the solubilizate [202]. An analogous explanation was given for the decreased polarity around dansyl based probes with increasing degree of hydrophobic substitution of poly(allylamine) [152]. The decreasing polarity of the solubilization sites with increasing degree of hydrophobic substitution is corrobated by studies of pyrene solubilized by hydrophobized poly(ethylvinylether-alt-maleic acid) [154] and methyl orange solubilized by hydrophobized poly(diallylammonium bromide) [200].

The nature of the head group seems to be of lesser importance, as the degree of dissociation in poly(vinylether-alt-maleic acid)s and poly(alkene-alt-maleic acids) does not change the I/III values [185, 186, 197]. This is somewhat surprising as, according to ${ }^{1} \mathrm{H}-\mathrm{NMR}$ studies, aromatic probes reside at the "micellar interface" [373]. Also, this result contrasts markedly with the increasing polarity in polysoaps based on poly(allylamine) with increasing protonation as sensed by dansyl probes [287]. In the case of poly (undecenoic acid), the I/III values increases strongly around a $\mathrm{pH}$ of 8 . The enhanced polarity was attributed to a transition between tightly and loosely packed micelles with increasing $\mathrm{pH}$, i.e. with increasing deprotonation of the $-\mathrm{COOH}$ groups. The difference to the constant I/III values found for the simultaneously studied poly (octadecene-alt-maleic acid) was attributed to a reduced hydrophobicity of the undecenoate residues in comparison with the $C_{16}$ tails [197]. Still, the presumably comparably hydrophobic poly(decyl-vinylether-alt-maleic acid) does not show such a transition either [196]. This makes one wonder whether geometrical effects may intervene as polysoaps of "tail-end" and of "mid-tail" type are compared.

Indeed, concerning the polymer geometry, structural variations of vinylic polysoap isomers suggest that solubilization sites in "polymeric micelles" are more polar for polysoaps of "tail end" geometry than for ones of "head" geometry [167] (Fig. 27). These observations can be rationalized by the hydrophobicity profile of the respective polysoap structures. As the polymer backbone generally bears some polar groups, it has to be considered as a fragment of intermediate hydrophobicity, partially interfering with the polarity profile of the parent surfactant side chain (cf. Fig. 29). The exact quality of the solubilization sites depends on the chemistry of the backbone chosen.

Alternatively, the geometrical effects on solubilization sites can be explained by a simple "excluded" volume effect, forcing the probe closer to the "micellar surface" in "tail end" geometry. This explanation is supported by the findings that rather high polarities were observed for a number of vinylic polysoaps of the "tail-end" type in comparison to their monomers [64, 65, 74, 164, 245]. In contrast, polysoaps of the "head type" may show similar or even less polar environments than analogous monomers [152, 167, 187]. 


\subsubsection{Solubilization Capacity}

"Quantitative" solubilization by polysoaps was studied in the very early days [46-51]. However, correlations between the molecular structure of polysoaps and their absolute solubilization capacities are problematic because - as for low molecular weight surfactants $[358,359]$ - the capacities depend in a complex way on both the surfactant and the solubilizate chosen, and may be modified by additional factors such as $\mathrm{pH}$, added salts or ionic strength. Also, the uptake of considerable amounts of solubilizate may induce changes of the aggregate structure [49], thus rendering the interpretation of the studies even more difficult. As even solubilization by standard low molecular weight surfactants is still poorly understood, it is not surprising the solubilization by polysoaps is a rather empirical topic at present.

Most notably, the solubilization capacity of polysoaps is not correlated with their surface activity $[78,343]$. Thus any combination of these two properties can be realized in polysoaps, even unusual ones such as low surface activity with high solubilization capacity. The phenomenon is not understood, but might be related to different conformations taken at the gas-water interface and in solution (cf. Sect. 6.1), or to cosurfactant effects of the solubilizates.

As mentioned above, there seems to be no lower limit for solubilization by high molecular weight polysoaps. Thus starting in the origin, the solubilization capacity increases linearly with the concentration for most polysoaps [46-48, 51-53, 78, 112, 113, 153, 196, 253] (Fig. 28). Exceptional cases show a break point with increasing capacity at intermediate concentrations $[112,113,281]$ which were attributed to the transition from purely intramolecular aggregation to additionally superposed intermolecular aggregation [281].

In contrast, oligomeric polysoaps behave similarly to low molecular weight surfactants, i.e. they require a minimal soap concentration for solubilization [67, 71, 73] (cf. Sect. 6). Analogously, in poly (alkylvinylether-alt-maleic acid) of short tail length in which aggregation is favoured with decreasing dissociation of the carboxyl groups, solubilization capacities improve with decreasing $\mathrm{pH}$ values $[54,215]$.

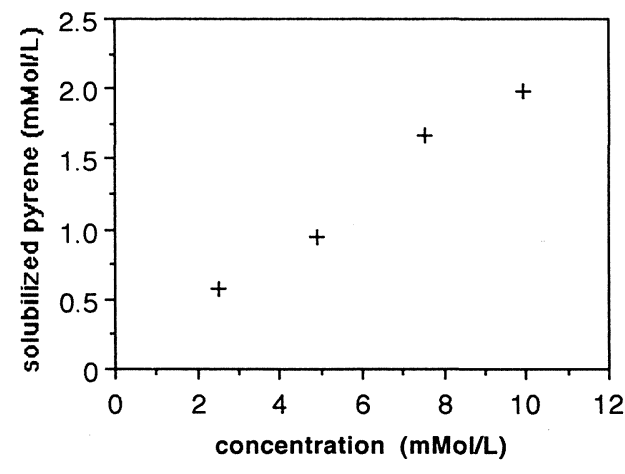

Fig. 28. Concentration dependence of the solubilization of pyrene by polysoap poly(sodium maleate-alt-decylvinylether) 33 at $25^{\circ}$, degree of neutralization $\alpha=0$; data from [196] 
The performance of polysoaps in comparison to low molecular weight analogs depends on the system polysoap/solubilizate chosen. Notably, longer equilibration times than for low molecular weight surfactants may be needed to reach maximal solubilization. Molar ratios of solubilizate per hydrophobic chain of $0.01-0.05$ are frequently reported $[53,54,72,215,361]$, but the ratio can amount to 0.15 or higher [343]. Keeping in mind that the hitherto used solubilizates were mainly chosen due the ease of quantitive analysis, these values do not represent upper limits. In comparison to their monomers or to low molecular weight analogs, all possible cases - i.e. comparable $[51,72,78,343$, 361], improved [50, 53, 78, 186, 343, 374] or inferior [78, 343] solubilization capacities - have been reported. The molar mass seems to be of little importance for high polymers $[50,213]$. Major deficiencies of polysoap performance can be avoided by optimizing certain molecular parameters, but otherwise few predictions can be made at present.

Concerning the structure of the surfactant side chains, the solubilization capacity increases with increasing length of the alkyl tails in the few systems studied $[54,135,281]$, a relationship which is widespread for standard surfactants $[358,359]$. These findings parallel the decrease of polarity of the solubilization sites discussed in the previous section. However, a general correlation between polarity of the solubilization sites and solubilization capacities is not valid [78, 343] (Fig. 27). As for the head groups, their charge and their counterions seem to have little influence on the solubilization capacities in general if the hydrophilic-hydrophobic balance HLB and steric requirements are not markedly changed [53, 72, 78, 343]. However, specific interactions between the head groups and the solubilizate may play a crucial role [255, 343]. This is most evident for electrostatic effects, i.e. cationic soaps favour anionic solubilizates, but reject cationic ones, and vica versa [53, 78, 185, 343, 361]. Other supporting interactions have been noticed as well, e.g. between aromatic compounds [375].

The role of the hydrophobe content seems rather straightforward: as the content of hydrophobic chains increases, the solubilization capacity increases as well. In some systems the solubilization capacity increases faster than the hydrophobe content $[46,213]$. But often the dependence can be approximated by a linear relationship, i.e. the solubilization capacity per hydrophobic chain is approximately constant $[78,343]$. Only in cases of extreme steric crowding a maximum of the capacity as function of the hydrophobe content is found [343]. Recalling that main chain spacers are needed for polysoaps of "mid-tail" and "head" geometry (see Sect. 2.3.4), these findings imply the existence of an optimal spacer length for such polysoaps: it must be sufficiently long to provide watersolubility, but as short as possible to allow for high performance.

The effects of the polymer geometry and of the nature of the backbone are interdepending. Considering Fig. 29, only a hydrophobic backbone will provide a hydrophobic interior of polymeric "micelles" for polysoaps of the "tail end" geometry, whereas only a hydrophilic backbone will provide a favourable polarity profile for polysoaps of the "head type". Accordingly, "optimized" 


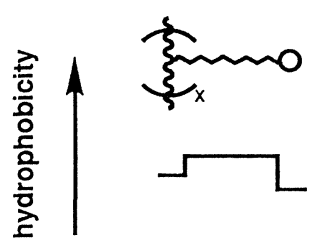

a

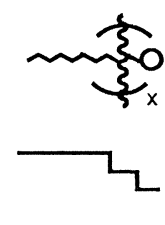

b

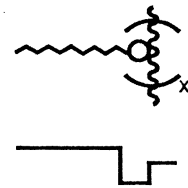

Fig. 29a-c. Schematic polarity profile in the surfactant side chains of polysoaps: a "tail end" geometry; b "mid tail" geometry; c "head" geometry. (Reprinted with kind permission from [78]. Copyright 1993 Hüthig \& Wepf, Basel)

polysoaps of different geometry should be employed for good results. Indeed, the capacity of analogous "tail end" polysoaps increases strongly in the series polysulfone $\leq$ poly (acrylamide) $<$ poly (acrylate) $<$ poly (methacrylate), i.e. with increasing hydrophobicity of the polymer backbone [78, 343].

When optimized polysoaps bearing the analogous surfactant structure were used, only gradual differences in solubilization capacity were found. More polar solubilizates which are assumed to reside close to the "micellar surface" are somewhat more efficiently solubilized by polysoaps of "tail end" geometry. In contrast, solubilisates of amphiphilic structure are somewhat more efficiently solubilized by polysoaps of "mid tail" geometry. Polysoaps of "head" geometry fall shorter in both cases [78, 343]. Similar comparative studies for pure aromatic compounds and hydrocarbons are not available. The differences observed may be due to the respective positions of the polymer backbones, occupying space which is needed to accomodate the solubilizate. Notably, the results imply that " the optimal polysoap" structure does not exist, but the systems of choise will depend on the problem adressed.

In the above discussion, polysoaps of "Head" geometry emerge as least efficient solubilizing agents. Nevertheless, the capacities observed are still fair, and therefore such polysoaps are useful solubilizing agents too. "head" type polysoaps may, for practical purposes, even prove to be the agent of choice by virtue of their straight forward synthesis (cf. Sect. 2.2).

\subsection{Emulsifying and Dispersing Properties}

The problem of emulsification and stabilization of dispersions is still to be addressed. At present, only mostly qualitative statements are available. E.g., good emulsifying properties are implied for the reported use of polysoaps in emulsion polymerization [376] and for the stabilization of latexes [50, 214]. Good emulsifying properties are reported as well for natural polysoaps $[79,80]$. Oligomeric polysoaps are efficient emulsifiers for liquid hydrocarbons [82]. High dispersing efficiency for alumina particles is claimed for some polymerized surfactants $[377,378]$. But structure-property relationships are still to be 
established. In the case of copolymers of acrylic acid and butyl and dodecylacrylate respectively, dispersing properties for carbon black improve with increasing hydrophobe content and increasing length of the hydrophobic tails. In contrast, the dispersing properties for $\mathrm{TiO}_{2}$ improve with decreasing hydrophobe content and decreasing length of the hydrophobic tails [153]. Considering the discussion in the previous chapter, emulsifying/dispersing and solubilizing abilities may thus be opposed. Such an opposing behaviour was also observed for the dispersing and solubilizing power of surfactant copolymers based on acrylamides [167]. Whereas the solubilization capacity of 4-(4'-butylphenylazo)- $N, N$-diethylaniline increases with the hydrophobe content [343], the dispersing capability of small solid dye particles decreases [357]. The parent polymers without hydrophobe content however are poor dispersants or emulsifiers.

\subsection{Dynamic Properties}

Micelles of low molecular weight surfactants are known to be very dynamic structures, although the various fragments of the molecules within a micelle are subject to some restrictions of mobility in comparison to molecular solution $[23,379-381]$. As the hydrophilic head groups are "anchored" at the micellar surface", NMR-studies show that the mobility and the order parameter decreases along the alkyl tail from its end towards the head group [379-385].

Analogously, the mobility of the various fragments of polysoaps is somewhat restricted due to hydrophobic clustering $[68,69,145,275]$. But the dynamic profile seen for standard micelles is superposed by the dynamic restrictions imposed by the polymer backbone as the backbone tends to immobilize the side chain fragments close by [276, 386, 387]. Whereas the general profile stays the same in polysoaps for "head" geometry as in standard surfactants, i.e., the head groups are the least mobile segments [388, 389], polysoaps of "tail end" geometry show a dynamic profile of the surfactant fragments opposite to the one of the monomeric analogues. Here the end of the hydrophobic tails are the least mobile segments in the system (Fig. 30) [68, 69]. The implications of this difference for the performance of polysoaps are not clear at present. They might influence e.g. the type of solubilization sites available $[64,65,74,78,164,245]$ and thus the catalytic performance of polysoaps [361], but interpretations are speculative at present.

The restricted mobilities of the hydrophobic segments and the dynamic profile are also reflected in the shape of NMR-spectra of vinylic polysoaps in aqueous solution. The signals of protons in the proximity of the polymer backbone are strongly broadened [193, 258, 303, 355] or virtually invisible [39, 227] (Fig. 31). This effect decreases with decreasing density of the hydrophobic tails $[193,303,355,357]$ and with decreasing molecular weight.

The problem of restricted mobility not only concerns the various fragments of the polysoap itself, but the mobility of solubilized material is affected as well ("microviscosity"). Studying the motion of the ESR-spin probe, polysoaps 


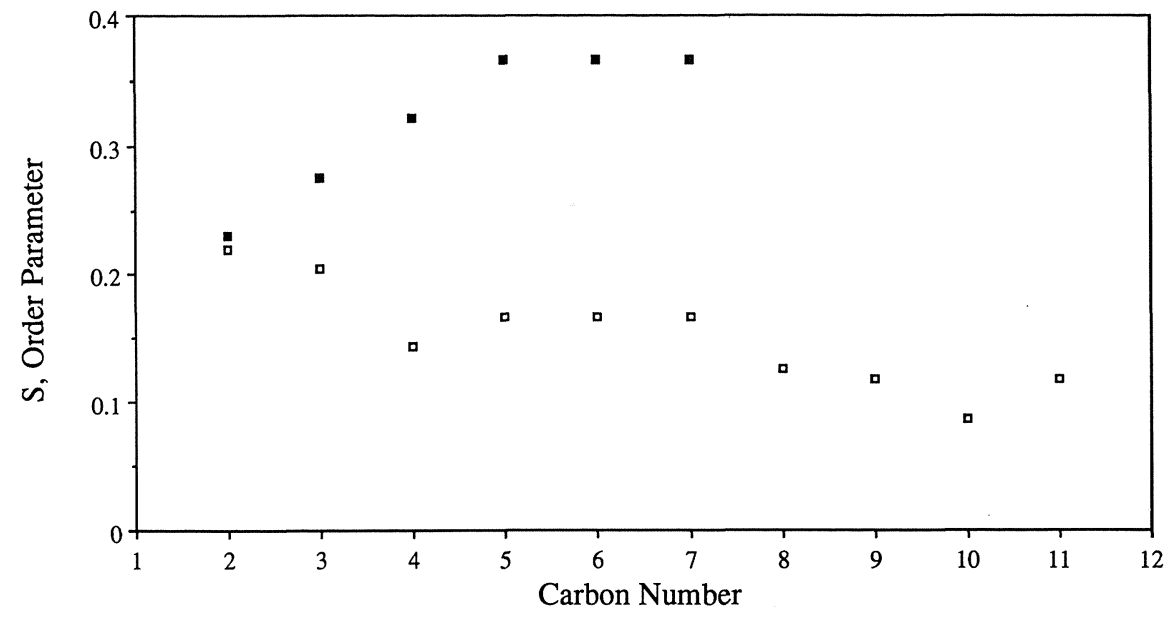

Fig. 30. Order parameter for micellar monomeric $(\square)$ and oligomeric $(\square)$ sodium undecenoate 6 as a function of the position in the hydrophobic tail $\left(C_{1}=-\right.$ COONA). (Reprinted with kind permission from [69]. Copyright 1990 Academic Press, Orlando)
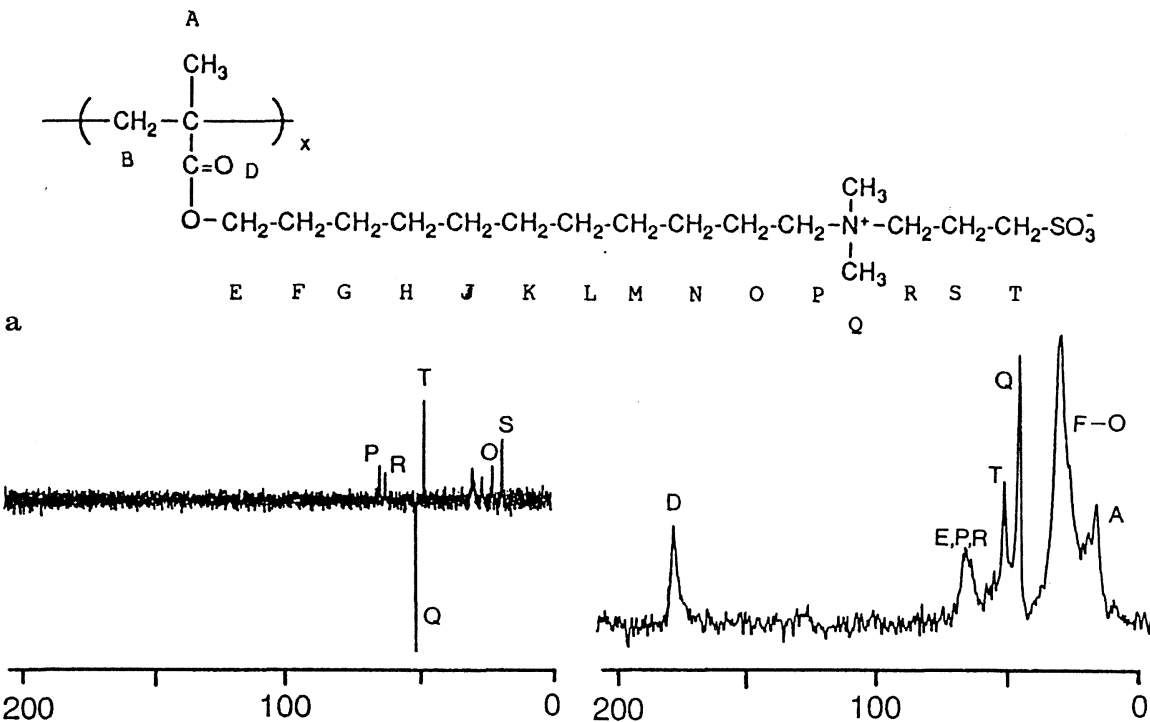

b

chemical shift (ppm)

Fig. 31a, b. ${ }^{13} \mathrm{C}-\mathrm{NMR}$ spectra of polysoap 54: a in $\mathrm{D}_{2} \mathrm{O}$ (spin-echo); b in bulk (CP-MAS) [357]

reduce the mobility of solubilized materials more strongly than micelles of low molecular weight surfactants do [64, 74, 152, 287], thus pointing to a higher microviscosity. Notably, the results vary with the probe chosen and the restriction of mobility is not limited to intramolecular aggregation but is seen for 
intermolecular aggregates as well [298]. The general behaviour is corroborated by measurements of fluorescence life-times of solubilized dyes [152, 217, 287]. Additional evidence for more restricted mobility in polysoaps in comparison to micelles of low molecular weight surfactants comes from fluorescence quenching and fluorescence depolarisation studies [185]. There seem to be steric effects of the polymer backbone, too, as the more densely packed dodecylated poly(allylamine) gives rise to stronger mobility restrictions than dodecylated poly(ethyleneamine) $[145,287]$.

Increasing the hydrophobe content and the length of the hydrophobic tails, the mobility of solubilized probes becomes more and more reduced according to both ESR- and fluorescence studies [152, 187, 189, 287]. However, for a series of anionic copolymer soaps of poly(sodium 2-acrylamido-2-methylpropane sulfonate), the mobility of the ESR-probes was found to be approximately the same for various hydrophobic tails such as $n$-dodecyl, adamantyl and naphthyl residues [217]. But within this series of compounds, the results obtained with various techniques are not consistent. In contrast to the ESR-studies, the rates of fluorescence quenching of pyrene suggest increasing rigidity in the sequence $n$ dodecyl < cyclododecyl < adamantyl (which intuitively may appear the most reasonable) [202], whereas the rate and extent of trans- to cis-isomerization of azo dyes suggest a rigidity scale adamantyl $<$ cyclo-dodecyl $<n$-dodecyl [203, 260]. These apparently contradicting results raise some doubts about the unambiguity of the information obtained by such techniques because they depend on the probe used in a way which cannot be anticipated.

In addition to the motion of the surfactant fragments within a "micelle", dynamic exchange of surfactants between micelle and isotropic solution, and dynamic formation and breakdown of micelles occur in micelles of low molecular weight surfactants $[20,23,390]$. The two processes give rise of two relaxation times. None of these topics has yet been studied thoroughly for polysoaps. Thus it is unknown whether all or only a fraction of the hydrophobic tails aggregate $[186,196]$, and, if the latter is true, whether exchange of "unimer units" and dynamic micelle formation take place or not. These questions are clearly linked to the nature of "polysoap micelles" (see Sect. 4.2). Investigations of energy transfer in polysoaps point to partial aggregation with fast exchange rates of clustered and not clustered tails [258, 259], but the scarcity or data at present precludes general statements.

\section{Aggregation in Aqueous Solution}

\subsection{Micelles}

Micelles of low molecular weight surfactants are highly dynamic aggregates which are formed spontaneously above a critical concentration, the so-called 


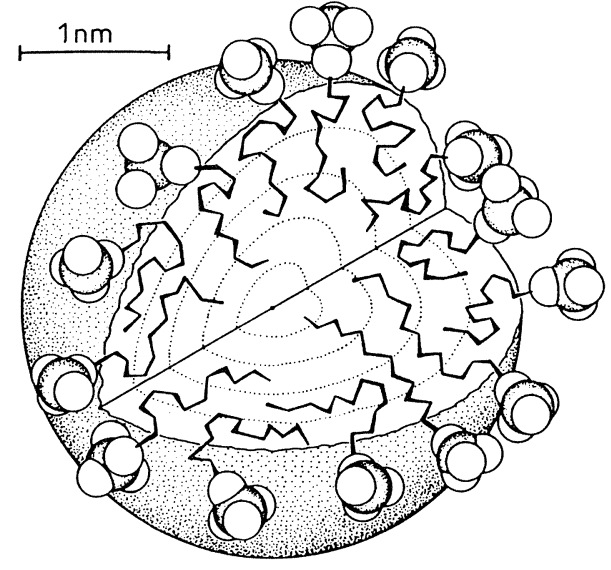

Fig. 32. Model of the standard ionic micelle (sodium dodecyl sulfate SDS). (Reprinted with kind permission from [381]. Copyright 1985 Steinkopff Verlag, Darmstadt)

critical micelle concentration CMC. They are in equilibrium with molecularly dissolved surfactants ("unimers") and a soluble surfactant monolayer at the interface. Though some problems are still to be resolved, major progress has been made in the past years to understand micelle formation, dynamics, shapes and aggregation numbers, as documented in a number of recent reviews $[20,23$, $360,381]$.

In the simplest cases, micelles can, on average, be envisaged as fluctuating aggregates of spherical shape, with aggregation numbers ranging from 10 to 200 (Fig. 32). The detailed numbers depend on the hydrophilic-hydrophobic balance HLB and the size of the surfactant; in special cases, cylindrical and discshaped micelles of extreme size can also be formed. Characteristically, the surfactant molecules in micelles have a mobility comparable to the liquid state, and undergo rapid exchange with the non-aggregated unimers in the solution. Furthermore, individual micelles have a limited, short lifetime, being continuously broken down and reformed.

\subsection{Polymeric Micelles}

\subsubsection{Models}

Basically, the aggregation of the hydrophobic tails in polysoaps is assumed to take place intramolecularly. In particular the solubilization of probe molecules has been employed to verify the intramolecular aggregation, demonstrating the lack of an equivalent of the critical micelle concentration CMC up to extreme dilutions [50, 51, 53, 65, 72, 76-78, 106, 112, 113, 126, 145, 186, 196, 197, 245, 343, 361]. Even more convincing proof was obtained by using covalently fixed probe molecules [152], because the problems of the probe's partition between the 
aqueous and the "micellar phase" (with the non-solubilized probe molecules dominating the signals at low soap concentration [292]) are avoided. A most elegant proof of intramolecular aggregation has been given by the lack of energy transfer in a mixed solution of two differently labelled polysoaps [217, 259].

A critical concentration for the onset of solubilization (pointing to intermolecular aggregation), or CMC-like breaks in the surface tension curves have been reported only for oligomeric polysoaps $[73,74,109,110,213,251,353]$ or for polymers whose hydrophobe content is below the CAC [212, 214, 298, 391].

At high concentrations, the primary intramolecular aggregation of polysoaps may be superposed by a secondary intermolecular one [128, 217, 208, 392]. The latter process seems to depend on the molecular weight [392] and on the length of the hydrophobic tails [192], but only few data are available yet. Superposed intermolecular aggregation seems to be favoured as well by high ionic strength [208].

Whereas the debate about the structure of standard micelles has now been mostly settled [23], the structure of "polymeric micelles" at the molecular level is still a matter of discussion. The few experimental studies available provide diverse results without a unified picture. This is partially due to the complexity of the phenomena involved, and partially due to the lack of straightforward analytical techniques. Still, three major models [78] have been proposed or implicitly used, which will be referred to as "local micelle", "regional micelle" and "molecular micelle" in the following (Fig. 33).

Emerging from the pioneering work of Strauss, the model of the "local micelle" (Fig. 33a) assumes the intramolecular aggregation of a limited number of neighbouring surfactant side chains in polysoaps [54, 55, 132, 180, 181, 215]. Being independent of the degree of polymerization $P_{n}$, the model allows for a gradual transition from more to less aggregated macromolecules [54, 55, 132, 133]. Also an exchange between aggregated surfactant fragments and "free unimers" is not excluded, similar to micelles of low molecular weight surfactants. The model imposes high steric demands on the polysoaps, and high flexibility of the polymer backbone would be favourable for an efficient aggregation of the surfactant fragments. But due to unavoidable steric problems, polysoaps should exhibit more hydrophobic contacts than analogous low molecular weight surfactants. Therefore, the HLB of polysoaps should be more to the hydrophilic side according to this model.

The model of the "molecular micelle" (Fig. 33c) originates in the work of Elias, and has been treated theoretically in recent years [195, 207]. It assumes the intramolecular aggregation of virtually all surfactant side chains of a given macromolecule into one aggregate $[84,87,126,185,197,322]$. Therefore there should be no dynamic process corresponding to the exchange between micellebound surfactant and free unimers. In fact the model was applied in the attempts to "fix" micelles of low molecular weight surfactants for imaging by electron microscopy (which were unsuccesful due to the fast exchange kinetics) [84, 393]. As the aggregation number would be identical to the degree of polymerization $P_{n}$, the shape and properties of the "molecular micelles" should be controlled by 


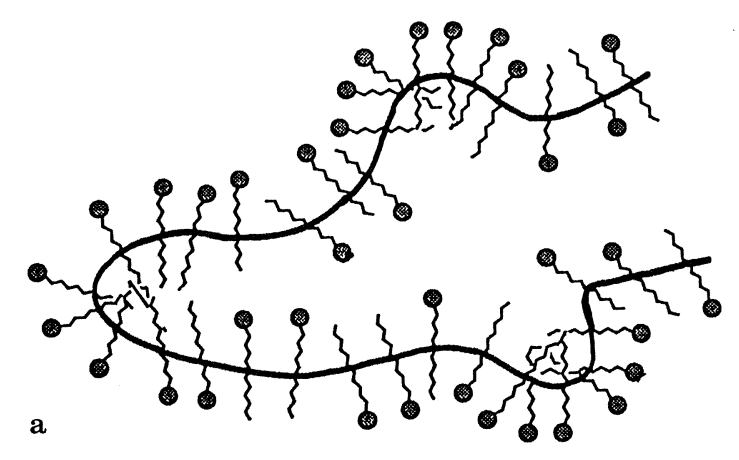

b

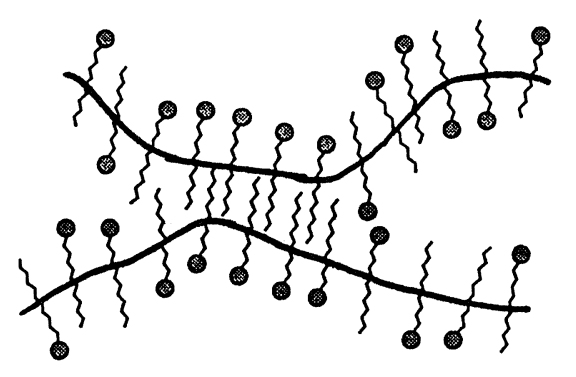

c

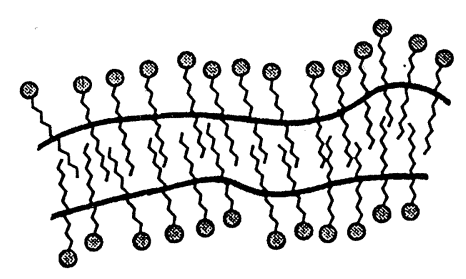

Fig. 33a-c. Models of polymeric micelles formed by polypolysoaps: a "local micelle" b "regional micelle"; c "molecular micelle". (Reprinted with kind permission from [78]. Copyright 1993 Hüthig \& Wepf, Basel)

$P_{n}$ rather than by the HLB and the size of the surfactant fragments. E.g. above a critical value of $P_{n}$, spherical aggregates could no longer be realized [126] (cf. Fig. 8). Compared to the "local micelle", the "molecular micelle" requires less flexibility of the polymer backbones, and thus the hydrophobic tails should be better shielded from contacts with water molecules. Therefore the HLB of polysoaps should be closer to that of analogous low molecular weight surfactants.

An intermediate situation between these extremes is found in the model of the "regional micelle" (Fig. 33b) [78, 203, 217]. Here the aggregation of a few neighbouring surfactant side chains is superposed by the aggregation of individual segments of the polymer. The resulting properties would be similar to the ones of the "local micelle", except that the severe geometric restrictions of the 
latter are avoided due to the more efficient regional aggregation. Similar to the model of the "molecular micelle", the HLB of polysoaps could be close to that of analogous low molecular weight surfactants. Also this model would easily account for a gradual transition from intra- to intermolecular aggregation.

\subsubsection{Experimental Data and Aggregation Numbers}

Up to now, none of the models for "polysoap micelles" can be definitively confirmed or rejected. Perhaps there exists more than a single structure depending on the molecular architecture of the polysoaps employed. More experiments will be needed to resolve this problem.

Fluorescence quenching studies are interpreted to support the model of the "local micelle", as aggregation numbers well below the degrees of polymerization studied were measured $[103,104,186,196,215,224,225,292]$. The presence of "regional micelles" would be consistent with the data, too. The combination of viscosimetric and solubilization experiments [78], potentiometric titrations [180,181] and neutron scattering studies [190-191] also support the "local micelle" or the "regional micelle" models.

From time-resolved fluorescence quenching (TRFQ) studies, small aggregation numbers of the hydrophobic side chains in "polymeric micelles" were proposed $[103,184,186,196,292]$. The numbers are virtually independent of the concentration and degree of polymerization, but surprisingly increase with temperature [196]. They also increase with the length of the hydrophobic chains, ranging from 15 to 60 [103, 196, 292]. In analogy, increasing the hydrophilicity of the head groups by deprotonation, and thus increasing the HLB, was found to reduce the aggregation numbers for some polysoaps (Fig. 34) [196], whereas in other cases no changes were observed [184]. Even for the identical systems studied the aggregation numbers determined may differ substantially $[184,215]$. In any case it should be noted that TRFQ studies suffer from several assumptions made which are difficult to verify. E.g., the ratio of aggregated and non-aggregated hydrophobic tails has to be known, but is hardly available [196]. Also notable are reports that TRFQ experiments indicate the presence of hydrophobic pockets with high aggregation numbers in some polyelectrolytes, although hydrophobic side chains are absent, and other polysoap characteristics are missing [198].

Potentiometric titrations give comparable aggregation numbers as obtained by TRFQ. The significance of the numbers obtained however may be questioned as larger aggregation numbers have been found for shorter hydrophobic tails $[180,181]$.

Small angle neutron scattering experiments yield aggregation numbers of polymeric micelles greater than the degree of polymerization [190-192]. This suggests the overlap of intra- and intermolecular aggregation as observed by light scattering investigations of polysoaps $[392,394]$ or by energy transfer studies [217]. 


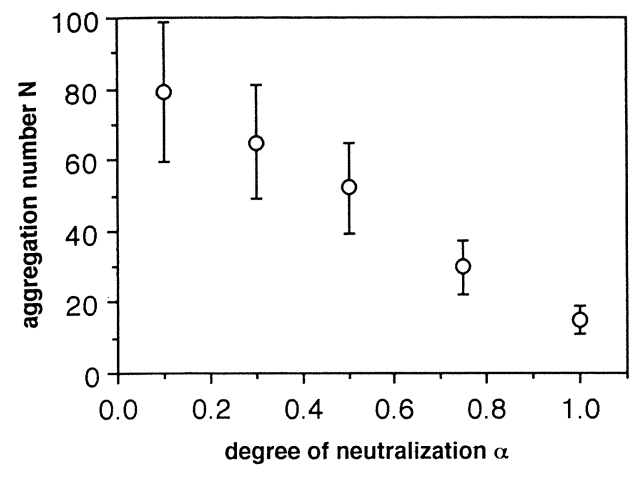

Fig. 34. Aggregation number $\mathrm{N}$ in polymeric micelles of polysoap poly(sodium maleate-alt-decylvinylether) $\mathbf{3 3}$ as function of the degree of neutralization $\alpha$ by $\mathrm{NaOH}$ at $25{ }^{\circ} \mathrm{C}$, derived from fluorescence quenching. (Data from [196])

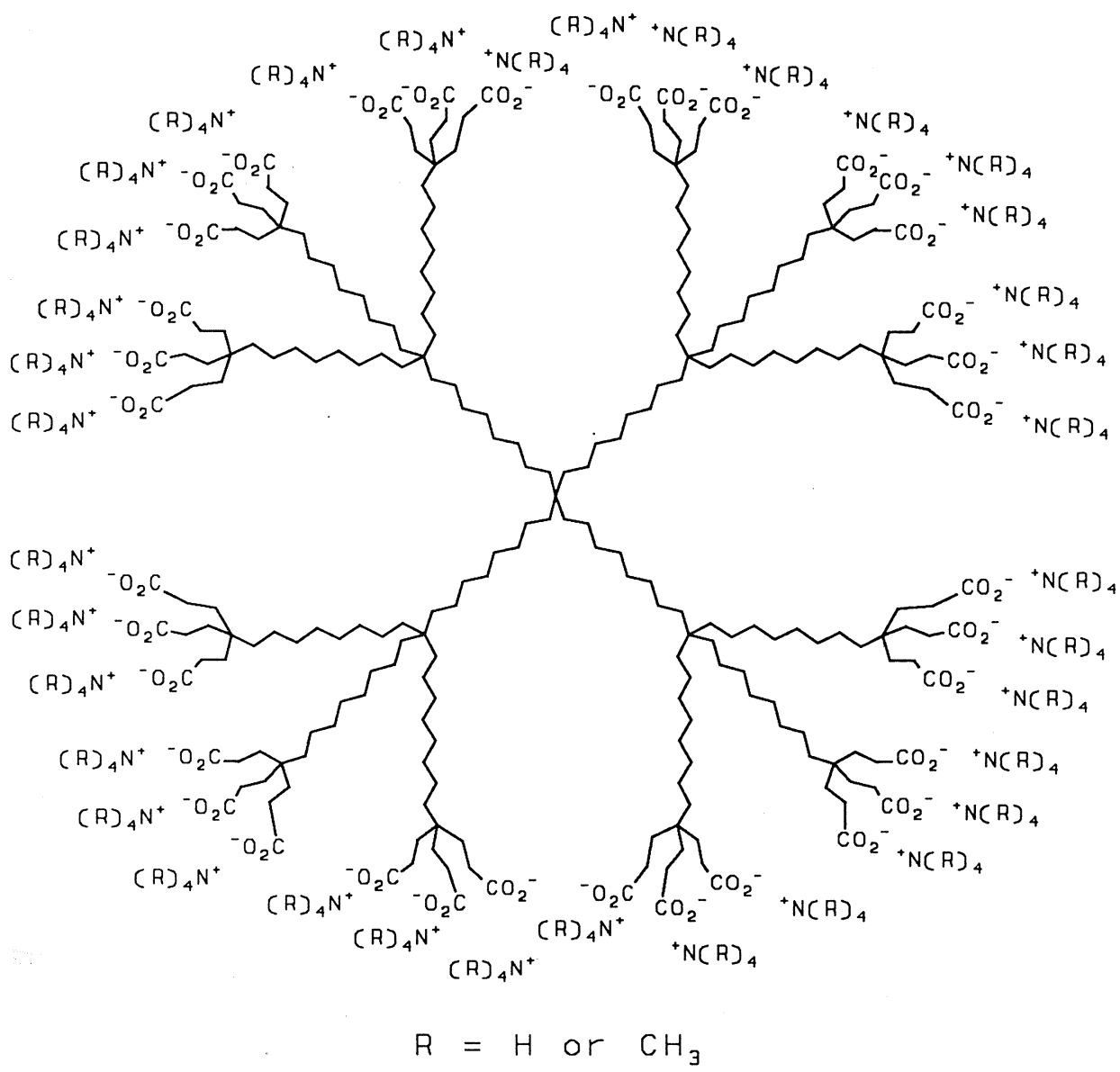

Fig. 35. Cascade polymer $\mathbf{6 1}$ forming unimolecular micelles. (Reprinted with kind permission from [43]. Copyright $1991 \mathrm{VCH}$ Verlagsgesellschaft, Weinheim) 
In contrast to the above discussion, theoretical treatments favour the model of the "molecular micelle" [195, 207]. At least an analogue to the latter has been realized recently in some dendrimers, arborols (Fig. 35) and hypercrosslinked polymers, replacing the self-organization of hydrophobic moieties by covalent bonding [41-45].

Chromatographic studies were interpreted in terms of molecular micelles [38]. Also, some TRFQ studies support the idea of "molecular micelles" as the experiments yielded aggregation numbers for the hydrophobic tails in "polymeric micelles" equal to the degrees of polymerization employed $[106,185,197]$. But at least in some cases $[106,185]$, the discrepancy with the above mentioned TRFQ studies may be apparent only because of the low degrees of polymerization used: they are of the same range as the aggregation numbers, so that "local micelles" and "molecular micelles" become indistinguishable. For very low molecular weights, even "molecular aggregation" of the hydrophobic tails is not sufficient, and intermolecular aggregates are encountered [74, 110, 117].

Recent attempts to visualize polysoaps by optical and electron microscopy do not clarify the situation. Generally the micrographs show large clusters [84, $96,161,193,361]$. Intermolecular aggregation in addition to intramolecular aggregation is presumably observed, and preparational artefacts must be taken into account. Exceptionally, cryo-transmission electron micrographs [395-397] visualize globular and threadlike structures of the polysoaps similar to giant micelles [288]. But the resolution of the micrographs does not allow an unambiguous distinction between "strings of beads" created from "local micelles" or "regional micelles" and extended cylindrical structures of real "molecular micelles".

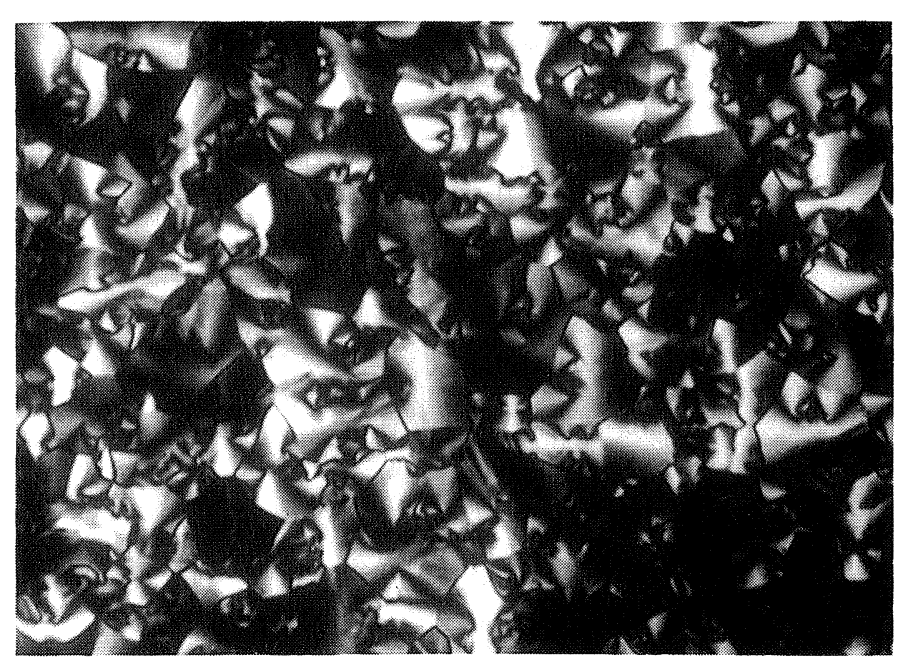

Fig. 36. Texture of the lyotropic mesophase of zwitterionic polysoap p- $X X$ between crossed polarizers [357] 


\subsection{Lyotropic Liquid Crystals}

For low molecular weight surfactants the capability to form lyotropic liquid crystals (LC) in water is an essential property [318]. Although the appropriate temperature and concentration ranges of the liquid-crystalline mesophases can be small, mesophases are always found when carefully searched for.

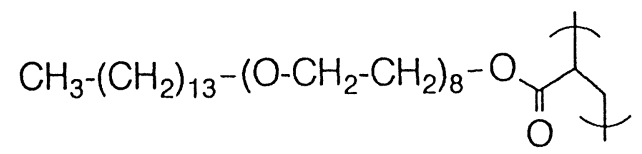

\section{2}

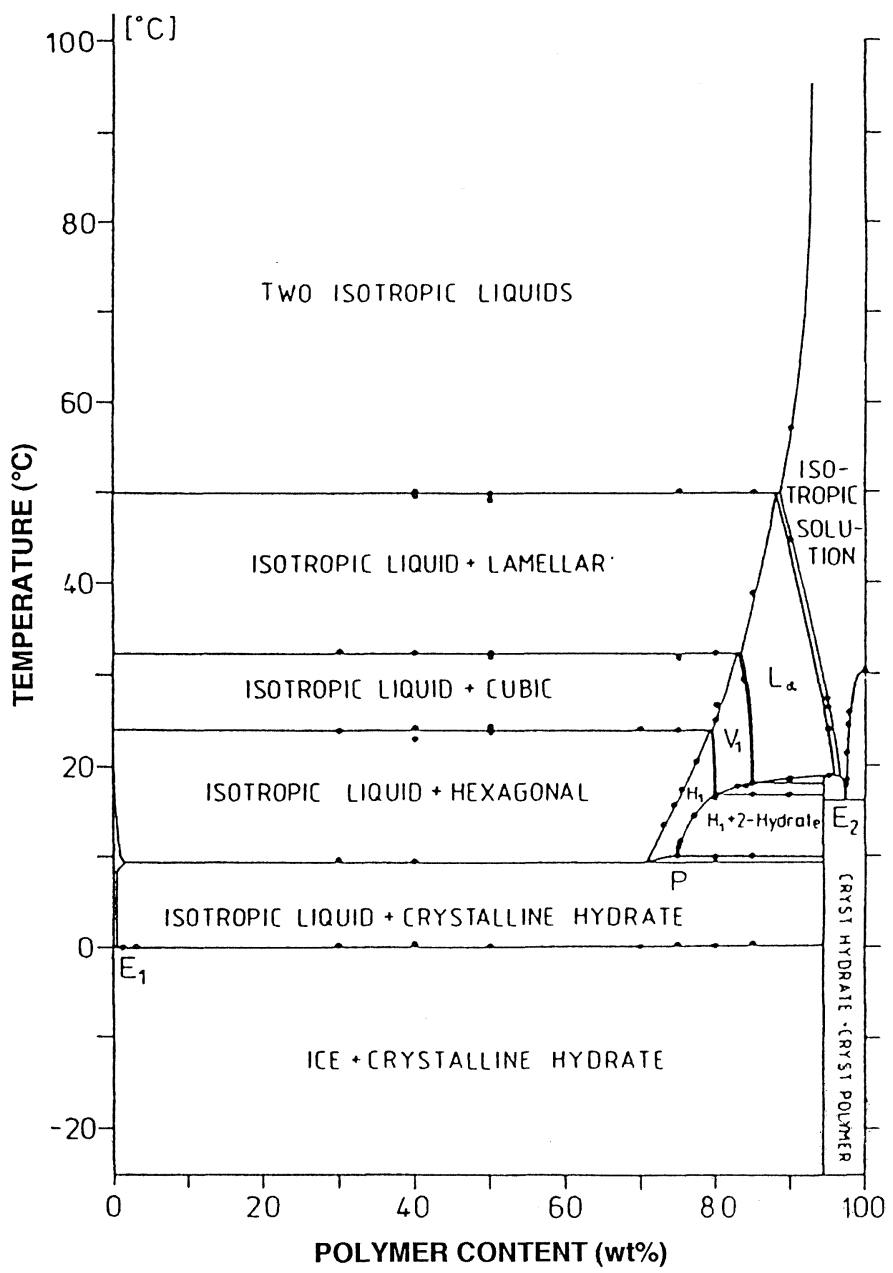

Fig. 37. Binary phase diagram of water-insoluble non-ionic polysoap 62. (Reprinted with kind permission from [231]. Copyright 1987 Steinkopff Verlag, Darmstadt) 
In this light, it is not surprising that there are many reports on polymeric lyotropic LCs formed by polysoaps at high concentrations $[62,63,70,87$, $121-124,126,172,173,178,230,231,240,244,249,261,300,331,398-404]$, particularly when polymerized surfactants are involved (Figs. 36, 37).

As for low molecular weight surfactants, the superstructures are assumed to be formed by "micellar" aggregates [126]. But it seems that the formation of lyotropic liquid crystals is supported by the additional presence of thermotropic mesogens $[87,122-124,126]$. Lamellar, hexagonal, cubic and even nematic and cholesteric mesophases were reported for binary systems, the latter being exceptional. Lyotropic mesophases were also observed in non-aqueous solvents $[240,400,401,405]$. If polymerizable surfactants are studied, not only the phase diagram but also the types of mesophases observed for the monomer and the polymer may be different.

However, for the majority of the polysoaps studied so far, lyotropic mesophases have not yet been observed. Notably, lyotropic mesophases have rarely been reported for polysoaps of other geometry than "tail end" type. It may thus be possible that the capability to self-organize into lyotropic liquid crystals is not a general feature of polysoaps, contrasting with standard surfactants.

There is a second particularity to be noted: many virtually water-insoluble polymeric amphiphiles can be swollen to yield polymeric lyotropic mesophases, even if the miscibility gap is broad (Fig. 37). Such behaviour seems to be widespread for vinylic polymerized surfactants with side-chain spacers [126, 231, 331]. I.e., neither polysoap behaviour implies the capability to form lyotropic mesophases, nor the presence of lyotropic mesophases the classification as polysoap.

\section{Aggregation in the Solid State}

In addition to the interest in lyotropic mesophases, some studies have looked into the self-organization and aggregation of polysoaps in the dry, i.e. generally in the solid state. In the case of ionic polysoaps, various lamellar superstructures are observed, the structure of which can be very complicated [331, 406-408] (Fig. 38). Although a number of surfactant monomers exhibit thermotropic mesophases $[168,331,406]$, mesophases do not normally occur for the polymers and have only been occasionally reported $[59,127,150,226,408]$. In the examples described, the incorporation of true mesogenic moieties is neither necessary nor particularly advantageous for mesophase formation. Still, due to the hygroscopy of the polymers, the distinction between dried samples with small residual water content and truly anhydrous samples is difficult. Thus, even the occasional reports on thermotropic mesophases of ionic polysoaps [203] may be erroneous, as rigorous drying of some nearly identical ionic polysoaps 

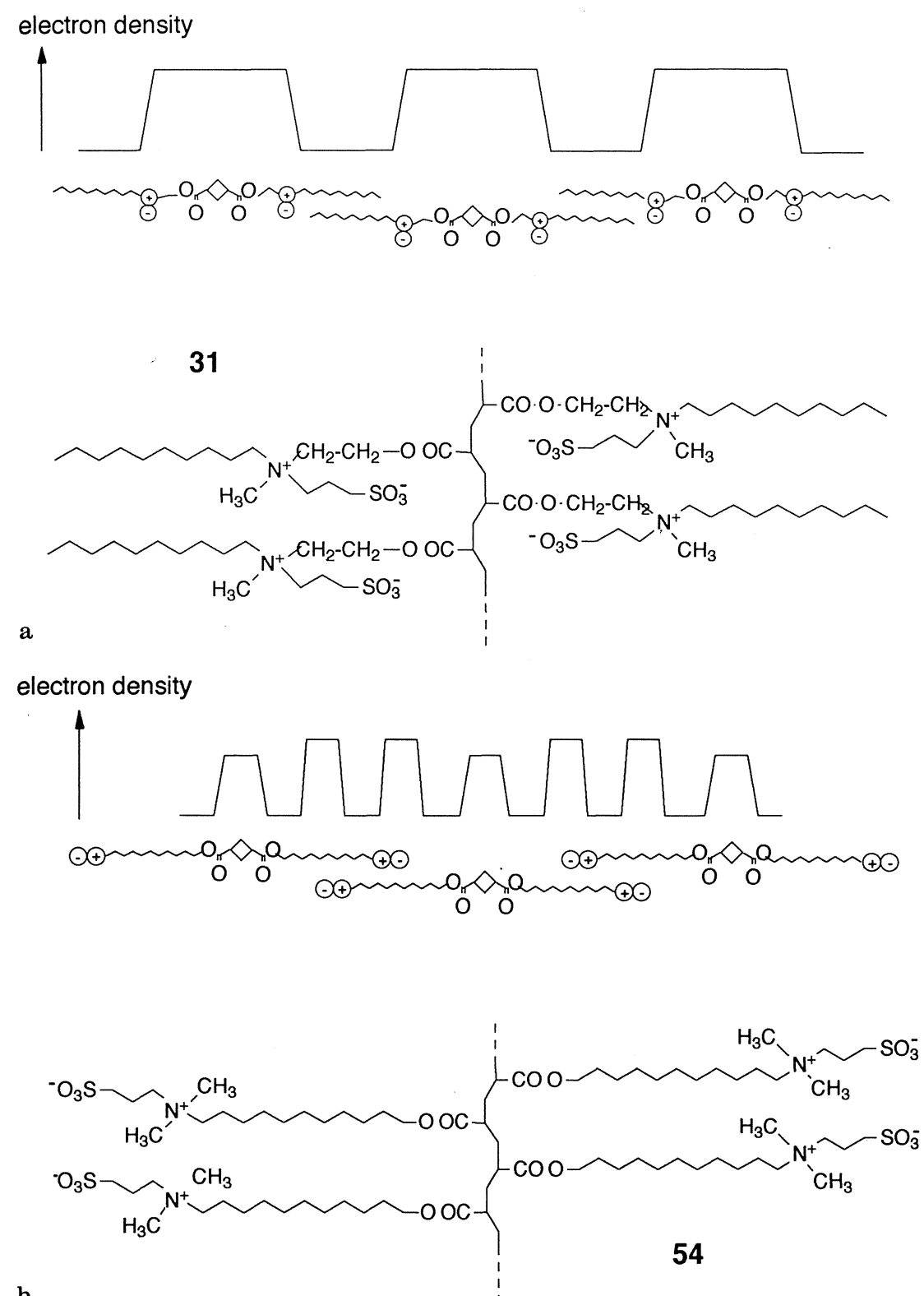

b

Fig. 38a, b. Density distribution along the normal to the layered planes $\rho(x)$ and corresponding models of the packing of two zwitterionic polysoaps in the anhydrous solid state (model adapted from [407]): a 31 ("head" type); b 54 ("tail-end" type) 
resulted in the disappearance of the mesophases seen [172, 173, 249, 331, 399] which accordingly are lyotropic ones.

For non-ionic polysoaps the situation is quite different. Whereas in the case of oligoethyleneoxide head groups thermotropic mesophases seem to be absent [87, 121-124, 126, 231, 403, 409], polysoaps with liposaccharide [230, 240, 300] surfactant fragments or with lipopeptide [244, 400-402] ones frequently show lamellar mesophases (e.g. of smectic A type) and even nematic ones (Fig. 39). It should be emphasized that the thermotropic mesophases here are not the result of mesogenic groups being present, but are the consequence of the amphiphilic character of the polysoaps and the resulting microphase separation.

Speculating on the reasons for the different behaviours of the different classes of polysoaps, ionic interactions may be too strong to allow for a mesophase without plasticizing water. On the other hand, interactions in oligoethyleneoxides may be too weak to ensure self-organization above the melting point. Only the presence of interactions of intermediate strength, such as $\mathrm{H}$-bonding or strong dipole-dipole interactions, installs the right balance of interactions needed.

a

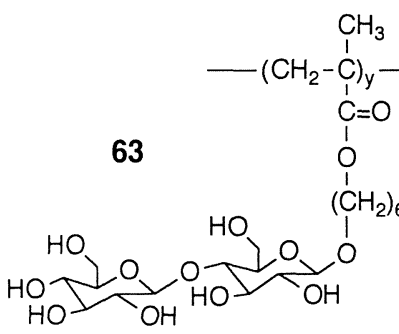

b

$$
\begin{aligned}
& \begin{array}{c}
-\left(\mathrm{CH}_{2} \cdot \underset{1}{\mathrm{CH}}\right)_{x}- \\
\mathrm{C}=\mathrm{O}
\end{array} \\
& \mathrm{NH} \quad \mathrm{O} \\
& \left(\stackrel{\mathrm{C}}{\mathrm{C}} \mathrm{H}_{2}\right)_{10} \cdot \ddot{\mathrm{C}}-\mathrm{NH}-\mathrm{CHR}-\mathrm{COOH} \\
& R:=-H \quad 64 \\
& \mathrm{R}:=-\mathrm{CH}_{3} \\
& \mathrm{R}:=-\mathrm{CH}_{2} \longrightarrow \mathrm{OH}
\end{aligned}
$$

c

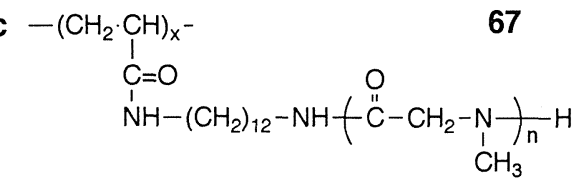

d

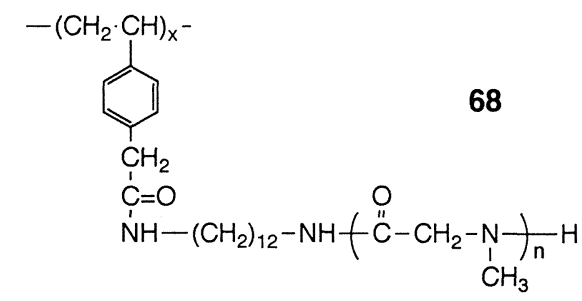

e $-\left(\mathrm{CH}_{2} \cdot \underset{!}{\mathrm{C}} \mathrm{H}\right)_{x}-$

69<smiles>CNC(=O)N(C)CC=COCCO</smiles>

Fig. 39a-e. Non-ionic polysoaps capable of forming thermotropic liquid crystals: a [230]; b [401]; c [244]; d [402]; e [240] 


\section{Molecular Weight Effects and the Behaviour of Oligomers}

In the previous sections some characteristic differences between low molecular weight surfactants and polysoaps were presented, which were attributed to covalent linkage of the surfactant fragments (instead of reversible linkage by secondary valence forces), modified dynamics, proximity effects and intramolecular aggregation. As pointed out for high molecular weight polysoaps, there are no indications of major differences between samples of different molecular weights concerning properties such as surface activity or solubilization. But of course the question arises of how the various properties of surfactants evolve with increasing degree of polymerization in the intermediate, i.e. the oligomeric regime; e.g. whether there is a gradual evolution of properties or a discrete one etc. This problem has been addressed in recent years from the aspect of speciality surfactants, without the intention to investigate polysoaps. Although the studies often appear incomplete as studies of polysoaps, and sometimes they are difficult to interpret, the results may be useful for the comprehension of the latter.

\subsection{Defined Oligomeric Surfactants}

Defined "oligomeric" surfactant structures obviously have stimulated the imagination of many colloid chemists, as a number of imaginative names were suggested for them: bola-surfactants [410-412], gemini-surfactants [413-415], tentacle molecules [416-417], octopus molecules [418], hexapus [419], multiarmed amphiphiles [420-422]. . . and so on (Figs. 40, 41). The semantic confusion is aggravated by the use of different terms for identical structures (e.g. tentacle, octopus molecules, and multi-armed) and of identical terms for different structures (e.g. gemini). Also, some of the names are misleading, e.g. if "octopus" is applied to tetrameric structures [418, 423].

As for the polysoaps, surfactant oligomers can be distinguished by their geometry. In fact two type of surfactant "dimers" can be identified in the literature, the $\alpha, \omega$-dipolar surfactants (often referred to as "bola-surfactants") representing dimers of the "head type" geometry, and twinned surfactants (often referred to as "gemini-surfactants") (Fig. 40) representing dimers of the "tail end type" geometry. Both classes of speciality surfactants have generated much interest in the past decade, and a number of systematic studies exist now, covering even some polymerizable derivatives (cf. Table 2).

Generally, both types of dimeric surfactants still show well-defined, clear CMCs, though in selected cases the CMC is less obvious to standard methods, in particular to conductometric methods [415, 424, 425]. The values of CMCs determined by different methods agree well, and the counter-ion effects are the usual ones [426, 427]. But, strikingly, CMC values of both bola-surfactants and of gemini-surfactants are lowered by one order of magnitude or more in 

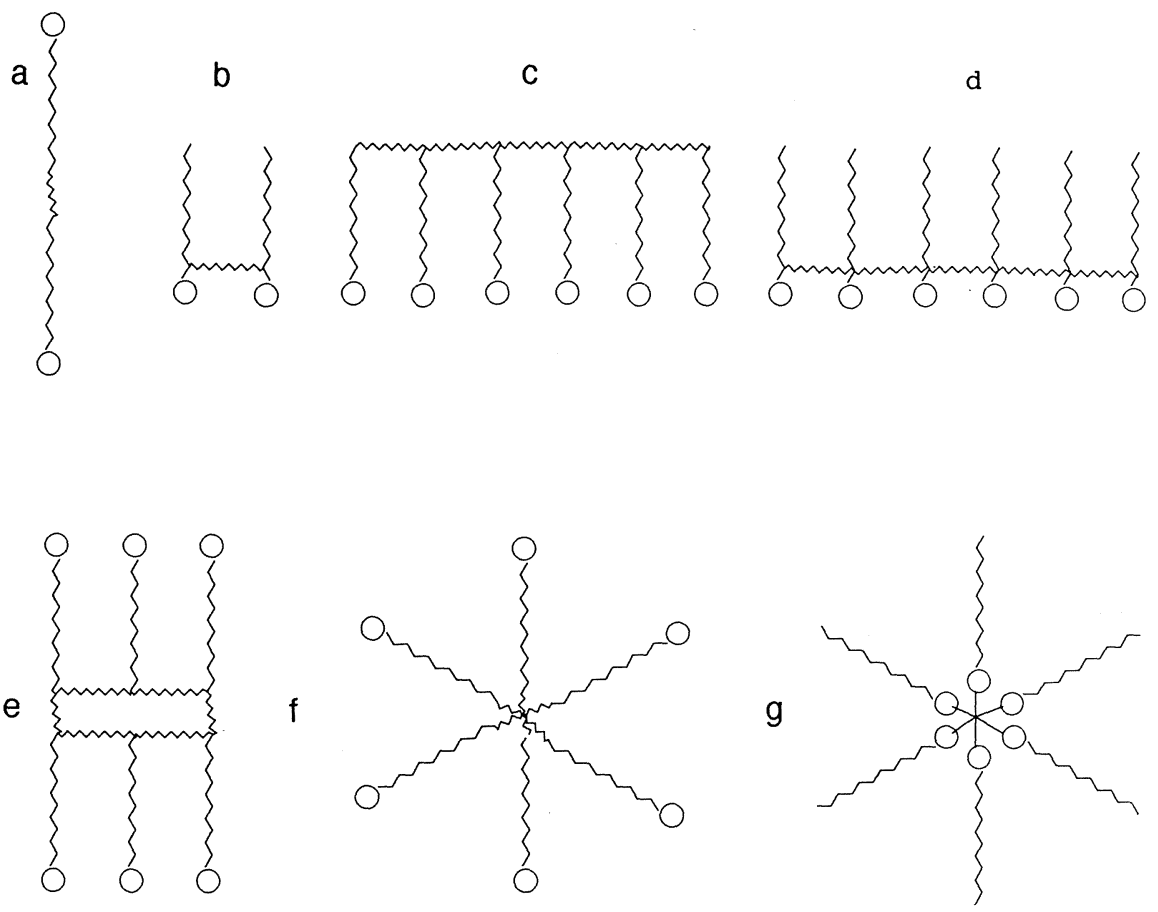

Fig. 40a-g. Various types of "oligomeric" surfactants: a "bola" dimer; b "gemini" dimer; c linear hexamer ("tail end" type) d linear hexamer ("head" type); e cyclic hexamer; f star-shaped hexamer ("tail end" type); g star-shaped hexamer ("head" type)

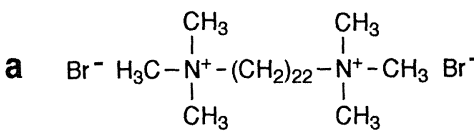

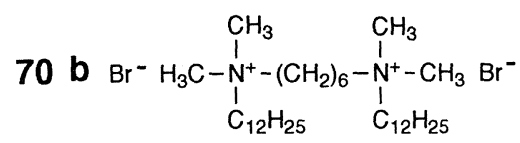

C

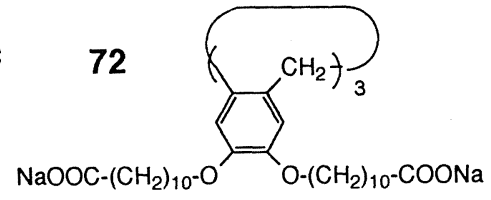<smiles>CCCCOc1cc(OCCC(=O)ON(C)O)cc(OCC(=O)O[Na])c1</smiles>

73

Fig. 41a-d. Examples of "oligomeric" surfactants: a "bola" dimer [426-428]; b "gemini" dimer [435, 445, 448]; c cyclic hexamer of "tail end" type [419]; d star-shaped trimer of "tail end" type [420] 
comparison to the corresponding "monomers" [239, 424, 428-434]. The reduction of the surface tension appears slightly lower than for the monomers, but the surface activities are still substantial [330, 405, 413, 424, 427, 429-435]. Interestingly, above the CMC a number of dimeric surfactants do not show the standard plateau of surface tension but exhibit a small but continuous decrease with increasing concentration.

From surface tension studies of bola-surfactants, it is concluded that they exhibit wicket-like conformations at the gas-water interface [239, 428, 430, 431]. In micelles and liquid crystals however, a stretched conformation is preferred $[436,437]$; this implies that surface tension data and interfacial tension data do no more describe the "micellar" interface with all the implications for solubilization (compare Sect. 3.4). In fact, some reports stress the extremely low solubilization capacity of bola-surfactants [431, 432, 437, 438], although others obtain capacities comparable to the ones of the "monomers" [430]. Also noteworthy, solubilized fluorescence probes indicate a more polar environment for the solubilizates than in micelles of the "monomers" [430-432], but micellar aggregation numbers of the bola-surfactants are comparable or only slightly lower $[429,432,438,439]$. In exceptional cases, very high aggregation numbers and the existence of an additional pre-CMC are observed [440].

NMR-studies indicate a reduced segmental mobility and higher order parameter for the central hydrocarbon fragments of bola-surfactants [437] compared to the tail ends of the corresponding monomers. The differences however are less pronounced as for oligomeric polysoaps $[68,69]$.

The majority of reports on gemini-surfactants [441-445] indicate increasing CMC values with increasing length of the hydrocarbon tails, as expected from HLB. Less evident, the surface tensions at the CMC are sometimes notably higher for higher homologues, in particular for long alkyl tails [442, 443]. Recently some surprising results were reported for gemini-surfactants with rigid spacer groups, such as increasing CMC with increasing length of the hydrophobic tails [413, 415, 446]. "Premicellar" aggregation was suggested as an explanation, based on solubilization results indicating efficient solubilization much below the CMC values which are deduced from surface tension data. But the exact positioning of some of the CMCs may also be disputable, revising the surface tension data reported. More studies are awaited to clarify the unusual findings (see also below).

The properties of gemini-surfactants are markedly influenced by the length of the linking unit, which represents the equivalent to the main chain spacer unit in "head type" polysoaps: the CMC does not decrease monotonously with increasing spacer length, as would be expected from the decreasing HLB, but shows a maximum value at intermediate spacer length $\left(\mathrm{C}_{6}-\mathrm{C}_{8}\right)[433,435,445$, $447,448]$. The surface tensions obtained at the CMC show a minimum in the same range of spacer length [435], and the solubilization capacity a maximum [448]. The coincidence with the optimal spacer length of "head type" polysoaps discussed in Sect. 2.3.4 is striking. Other effects on the CMC which cannot be 
explained by the HLB changes have also been observed with more complex spacer groups [434].

Virtually all examples reported for higher oligomeric surfactants than "dimer" belong to the "tail end type", preventing an analysis of the evolution of geometric effects. This is the more true, as the majority of the "tail end" structures represents "stars" [416, 417, 420, 422, 425, 449] rather than linear or cyclic oligomers $[418,419,423]$. Most attempts to produce "head-type" trimers suffer from the poor water solubility of the products [450], but recently some water-soluble examples have been reported [427].

The trimeric surfactants and higher oligomers investigated show pronounced peculiarities compared to "monomeric" surfactants. CMC-like transitions become less clear, in particular of studied by surface tension and conductivity measurements $[416-422,425]$. The reduction of the surface tension by such oligomers is often quite low [416-420,422, 423, 425], and the shape of the plots of surface tension vs the logarithm of the concentration can be bizarre $[417,425]$ though not necessarily for all systems studied [423]. For "hexamers" the surface activity becomes very weak [419]. Thus solubilization studies appear to be more appropriate for CMC determinations but have been seldom performed. Interestingly, the CMC values assigned from conductivity and surface tension data level approximately at the level of the "dimers" $[422,425]$ (Fig. 42), whereas the CMC value derived from solubilization data for a "hexamer" surfactant is lowered by at least a factor of 100 compared to the "monomer" [419]. The reason for such discrepancies is obscure. There are indications that solubilization and surface tension or conductimetric studies respectively do not give consistent CMC values for such uncoventional surfactants [425] which may be due to the formation of very small aggregates at low concentrations [417]. The surprising behaviour of trimeric surfactants of the "head" type was

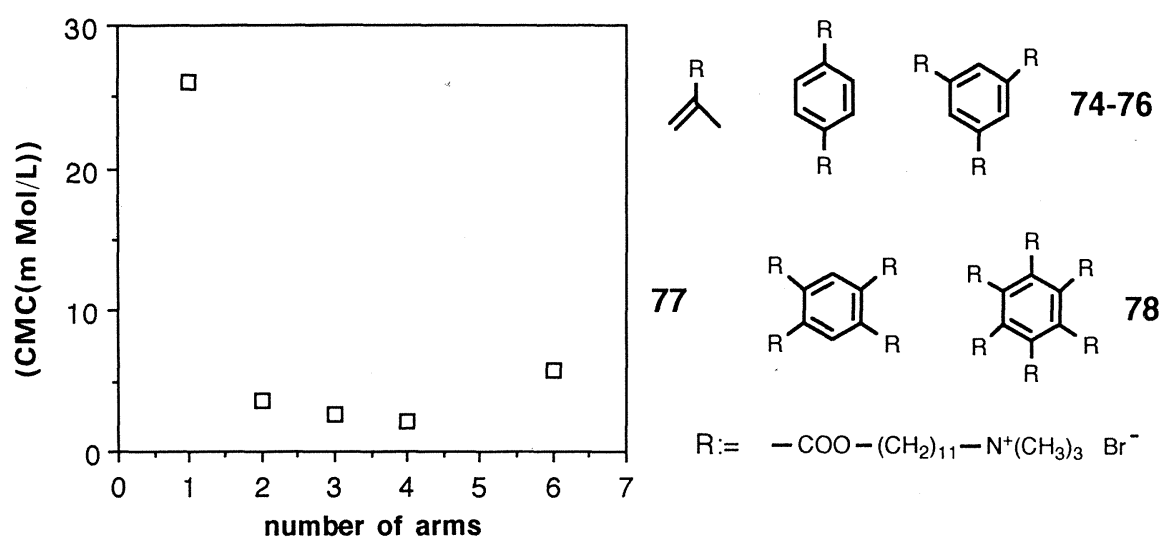

Fig. 42. Dependence of critical micelles concentration CMC of cationic oligomeric surfactants on the number of surfactant arms ("degree of oligomerization"), as determined by surface tension measurements and conductimetry. (Data from [422]) 
explained analogously [427]. They exhibit increasing CMCs with increasing length of the hydrophobic tails deduced from surface tension data, but show efficient solubilization much below the apparent CMC values, in analogy with the reports on some gemini-surfactants mentioned above $[413,415]$.

Although no full picture of the above referred studies can be obtained, some general trends are visible: oligomerization of surfactants tends to decrease surface activity and CMC, spacer effects in contrast to simple HLB considerations are evident, and the mobilities of the various molecular fragments change considerably. All these general trends parallel the differences seen between standard surfactants and polysoaps in Sects. 3 to 5 .

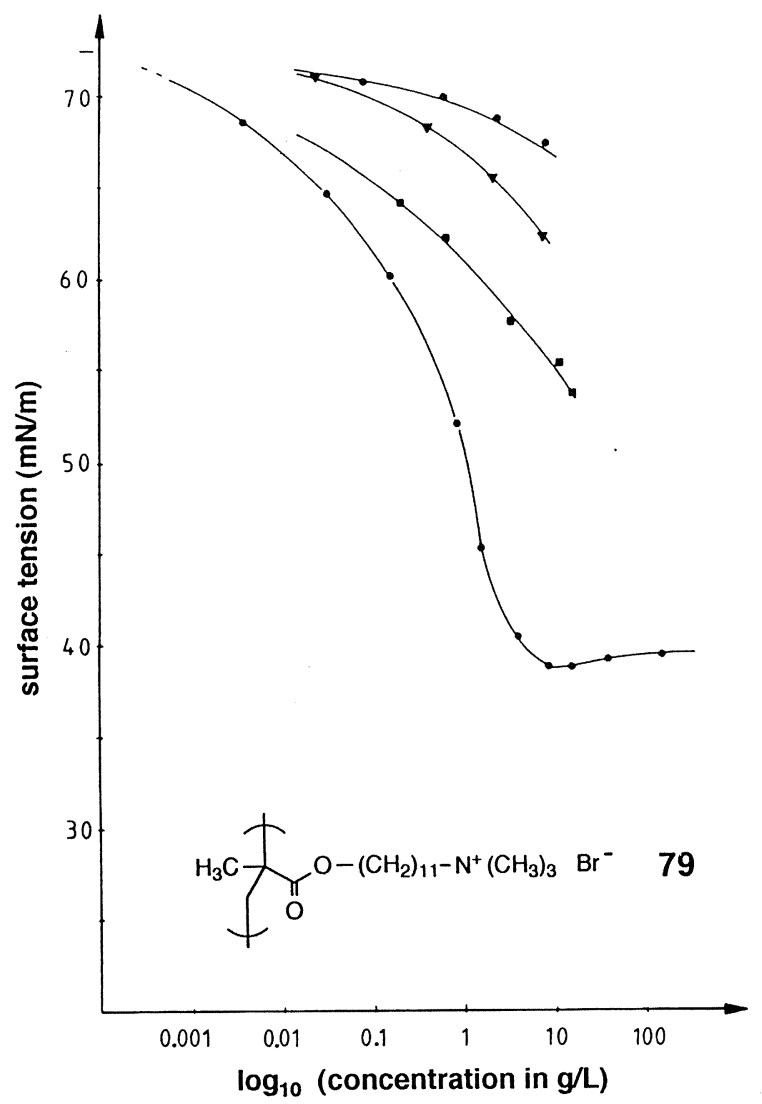

Fig. 43. Concentration dependence of the surface tension of aqueous solutions of polymerized methacrylic surfactant $\mathbf{7 9}$ as function of the amount of initiator used. (Adapted with kind permission from [229]). Top to bottom: polymer ( $0.5 \mathrm{~mol} \%$ AIBN used), polymer ( $1 \mathrm{~mol} \%$ AIBN used), polymer ( $5 \mathrm{~mol} \%$ AIBN used), monomer 


\subsection{Oligomeric Mixtures}

Oligomeric mixtures are usually obtained by oligomerization of surfactant monomers, most frequently of such bearing allylic moieties as polymerizable group (e.g. 6, Fig. 2f). In contrast to the above mentioned "multi-armed" surfactants, such mixtures are composed of linear oligomers. The average degree of polymerization is often difficult to determine exactly, but generally lies in the range of 2-10 surfactant units [61, 65, 67, 74, 82, 84, 109, 251, 315], sometimes up to 20 units $[68,69,71,110,117]$.

Molecular weight distributions have to be assumed to be broad. Better defined oligomers are obtained by polymer analogous reactions of reactive surfactants onto well-characterized polymer backbones [126, 451] (see Fig. 44).

Typically for such oligomers, CMCs are often found [74, 109, 110, 117, 213, $251,452]$, i.e. intermolecular aggregation takes place. This is not only visible by surface tension data, but also by solubilization studies $[67,71,74,110,117$, 452]. Due to distribution of molecular weights, it cannot be decided whether CMCs are still present for the higher oligomers or whether only the low oligomeric parts are responsible for the phenomenon. But as pointed out in Sect. 4.1 , it is reasonable to expect intermolecular micellization for oligomers if their degree of polymerization is lower than the aggregation numbers expected in "polymeric micelles", assuming that they are in the same range as those of standard surfactants.

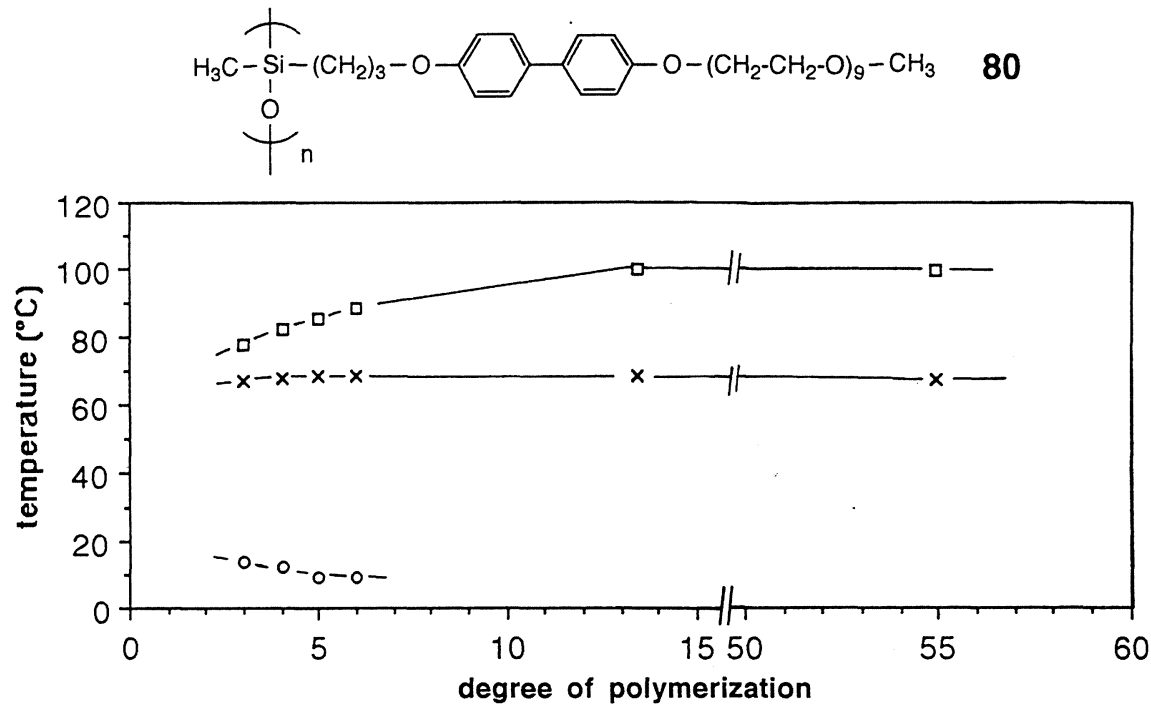

Fig. 44. Maximum clearing temperature of liquid crystalline phases of a non-ionic polysoap 80 as function of the degree of polymerization: $\bigcirc$ cubic $I_{1}$ phase, $\times$ hexagonal $H_{1}$ phase, $\square$ lamellar $L_{\alpha}$ phase. (Data from [451]; see also [126]) 
This influence of the degree of polymerization of the surface activity of oligomers has been addressed by Wagner (Fig. 43). With increasing degree of polymerization, the surface activity finally vanishes [229]. Unfortunately the data do not allow a quantitative estimation of the degrees of polymerization involved, but the trend is clear.

A quantitative evaluation of the effects of the degree of polymerization on the properties of polysoaps was undertaken for the phase diagrams of polymeric lyotropic liquid crystals. Here the property shifts level off within a degree of $10-15$ (Fig. 44) [126, 451]. This value may serve as a first approximation, but, as additional studies, e.g. on viscosity, surface tension or solubilization are missing, more studies are needed.

\section{Applications of Polysoaps}

Theoretically, polysoaps may be of interest for all the potential applications mentioned for micellar polymers in the introduction. In practice, the attempted uses of polysoaps cover a much narrower range. Besides a number of diverse suggestions, proposed uses are basically classical colloidal applications, medical or pharmaceutical applications, and catalytic systems.

Concerning colloidal applications, the uses as dispersants or emulsifiers are the most frequent ones. But although there exist several studies on the use of polymerizable surfactants [82, 91, 93, 219, 251, 314, 333, 337, 352, 452-477] - i.e. of the precursors for polysoaps - the use of polysoaps in emulsion polymerization is still the exception [376]. In both cases improved latex stabilities and improved resistance to moisture of film-formed latexes were aspired to, but at least in the former case the results were often disappointing [93, 251, 470-472]. Polysoaps are used to stabilize lattices [214, 230]. The opposite use for flocculation has also been tested, [284]. Polysoaps have also been studied as viscoelastic fluids [108].

Potential medical or pharmaceutical applications have attracted more attention. Studies cover improved efficiency and delivery [334-336, 478-480], improved stability [334], and lower toxicity [50, 315, 334, 374, 481] of polysoap bound drugs. The use of polysoaps to fix or stabilize enzymes, antibodies etc. is also discussed $[214,230]$. Cationic polysoaps were also studied for antimicrobial activities [277, 278].

The majority of the work is focused on the use of polysoaps in micellar catalysis [482-484], in particular as models for esterases [57, 71, 136-140, 332, 361]. In addition, the catalytic activities in diverse other model reactions were investigated $[141,200,211,308,317,333,361,463,464,485-487]$. Various photochemical systems for energy harvesting $[183,217,259]$, or for charge separation $[217,257-259,263]$ can be subsumed by applications of polysoaps in catalysis as well. Frequently, enhanced catalytic activity is observed compared to micelles of low molecular weight surfactants $[113,200,258,361,485,487]$. 
Table 1. Anionic polymerizable surfactants

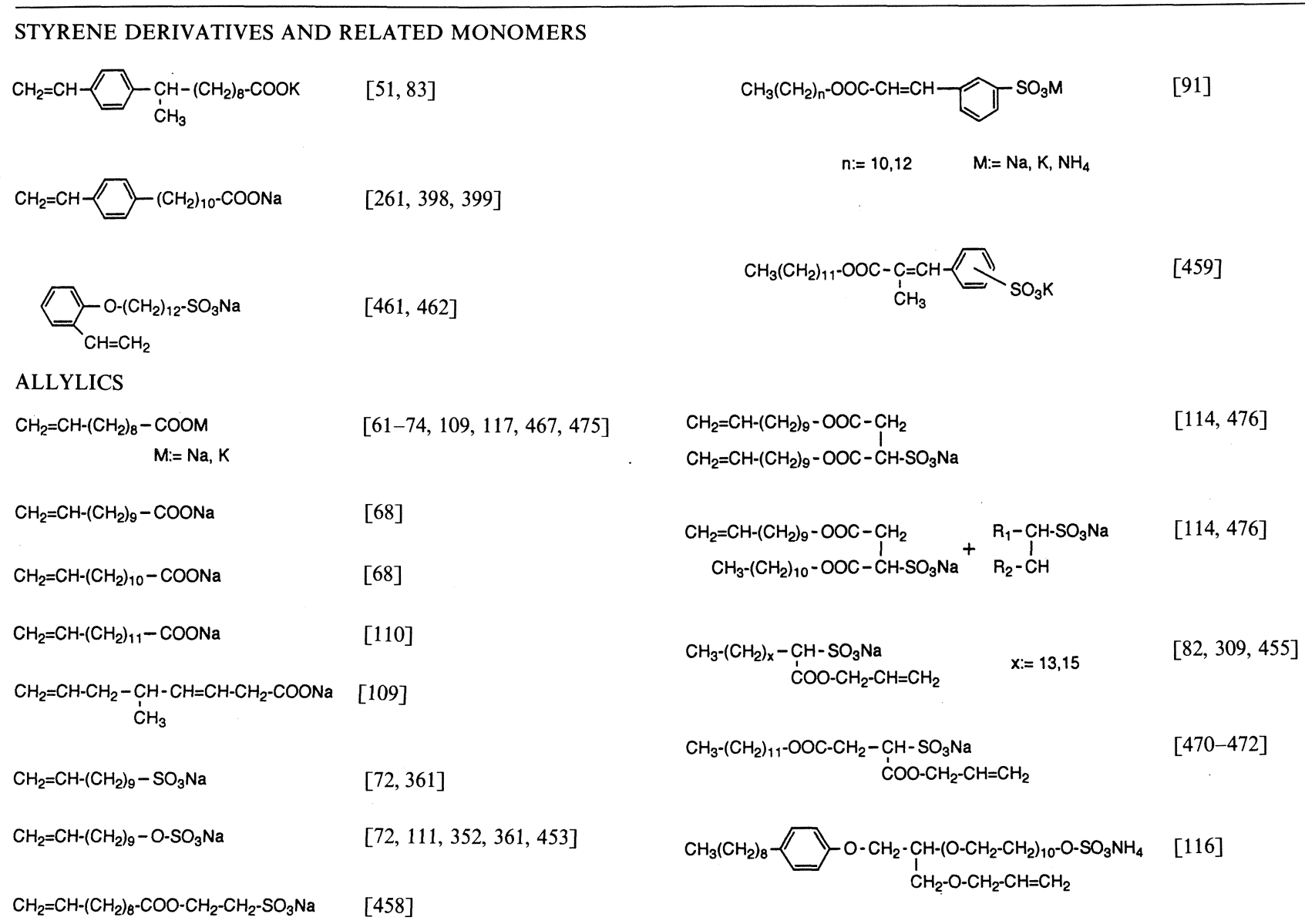


ACRYLATES

$\mathrm{CH}_{2}=\mathrm{CH}-\mathrm{COO}-\left(\mathrm{CH}_{2}\right)_{15}-\mathrm{COOK}$

[223]

$\mathrm{CH}_{3}-\left(\mathrm{CH}_{2}\right)_{5}-\mathrm{CH}-\left(\mathrm{CH}_{2}\right)_{10}-\mathrm{COOK}$

$\mathrm{CH}_{2}=\mathrm{CH}-\mathrm{COO}$

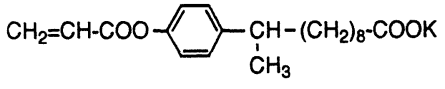

$\mathrm{CH}_{2}=\mathrm{CH}-\mathrm{COO}-\left(\mathrm{CH}_{2}\right)_{11}-\mathrm{SO}_{3} \mathrm{Na}$
$[51,83]$

[486]

METHACRYLATES
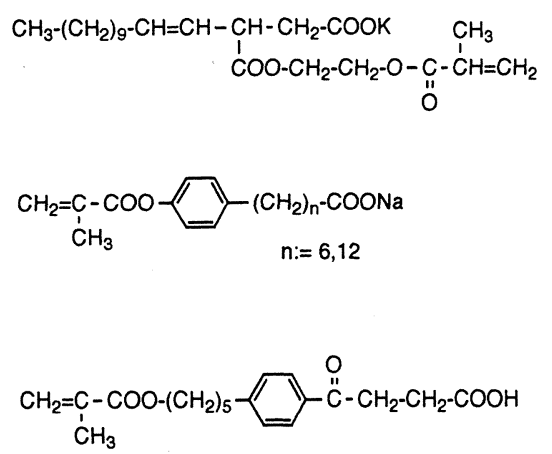

[223]

[95]

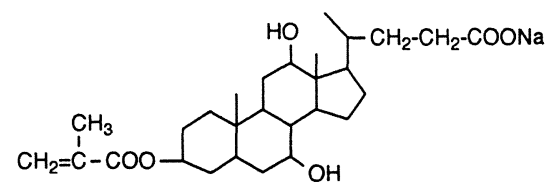

[248]

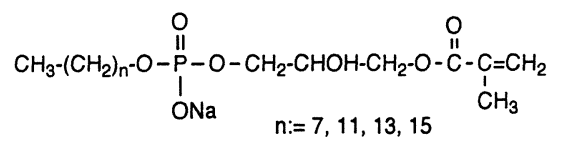

$[289,291,492]$ 


\section{ACRYLAMIDES}

$\mathrm{CH}_{2}=\mathrm{CH}-\mathrm{CONH}-\left(\mathrm{CH}_{2}\right)_{10}-\mathrm{COOM}$

$\mathrm{M}:=\mathrm{Na}, \cdots$

$\mathrm{CH}_{2}=\mathrm{CH}-\mathrm{CON}-\left(\mathrm{CH}_{2}\right)_{10}-\mathrm{COONa}$

$$
\text { R R: }=-\mathrm{CH}_{3}, \mathrm{C}_{2} \mathrm{H}_{5}
$$

$\mathrm{CH}_{2}=\mathrm{CH}-\mathrm{CON}-\mathrm{CH}-\left(\mathrm{CH}_{2}\right)_{x}-\mathrm{COONa}$

$$
\left(\mathrm{CH}_{2}\right)_{y}-\mathrm{CH}_{3}
$$

$\mathrm{CH}_{3}-\left(\mathrm{CH}_{2}\right)_{x}-\mathrm{CH}-\left(\mathrm{CH}_{2}\right)_{y}-\mathrm{COOM}$

$\mathrm{CH}_{2}=\mathrm{CH}-\mathrm{CONH} \quad \mathrm{M}:=\mathrm{Na}, \mathrm{K} \quad \mathrm{x}+\mathrm{y}:=15$

\section{METHACRYLAMIDES} $\mathrm{CH}_{2}=\mathrm{C}-\mathrm{CONH}-\left(\mathrm{CH}_{2}\right)_{10}-\mathrm{COOH}$
$\mathrm{CH}_{3}$

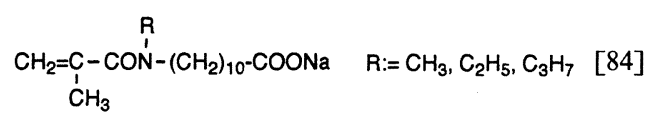

$\mathrm{CH}_{2}=\mathrm{C}-\mathrm{CONH}-\left(\mathrm{CH}_{2}\right)_{10}-\mathrm{CONH}-\mathrm{SO}_{3} \mathrm{Na}$
$\mathrm{CH}_{3}$

[455]
$[83,98,163,283,384,456,466,494]$

$$
\begin{gathered}
\mathrm{CH}_{2}=\mathrm{CH}-\mathrm{CONH}-\left(\mathrm{CH}_{2}\right)_{15}-\mathrm{CONH}-\mathrm{C} \cdot \mathrm{COONa} \\
\mathrm{R}:=-\mathrm{H}_{1}-\mathrm{CH}_{3},-\mathrm{CH}_{2} \backsim-\mathrm{OH}
\end{gathered}
$$

$[99,284,493,494]$

$[454,457,467,477,495,496]$

\section{$\mathrm{CH}_{3}\left(\mathrm{CH}_{2}\right)_{n}-\mathrm{CH}-\mathrm{CH}_{2}-\mathrm{SO}_{3} \mathrm{Na}$} $\mathrm{CH}_{2}=\mathrm{CH}-\mathrm{CONH}$

$[314,162,497]$

$$
\begin{gathered}
\mathrm{CH}_{3}-\left(\mathrm{CH}_{2}\right)_{9}-\mathrm{N}-\mathrm{CH}_{2}-\mathrm{CH}_{2}-\mathrm{SO}_{3} \mathrm{Na} \\
\mathrm{CH}_{2}=\mathrm{CH}-\mathrm{C}=\mathrm{O}
\end{gathered}
$$

$\mathrm{CH}_{2}=\mathrm{C}-\mathrm{CONH}-\left(\mathrm{CH}_{2}\right)_{10}-\mathrm{CONH}-\left(\mathrm{CH}_{2}\right)_{n}-\mathrm{SO}_{3} \mathrm{Na}$

$[309,455]$ $\mathrm{CH}_{3}$

$\mathrm{CH}_{3}-\left(\mathrm{CH}_{2}\right)_{9}-\mathrm{N}-\mathrm{CH}_{2}-\mathrm{CH}_{2}-\mathrm{SO}_{3} \mathrm{Na}$ $\mathrm{CH}_{2}=\mathrm{C}-\mathrm{I}=\mathrm{O}$ $n:=9,13$

$\mathrm{n}:=2,4$

[402]

$$
{\stackrel{1}{C} \mathrm{H}_{3}}
$$




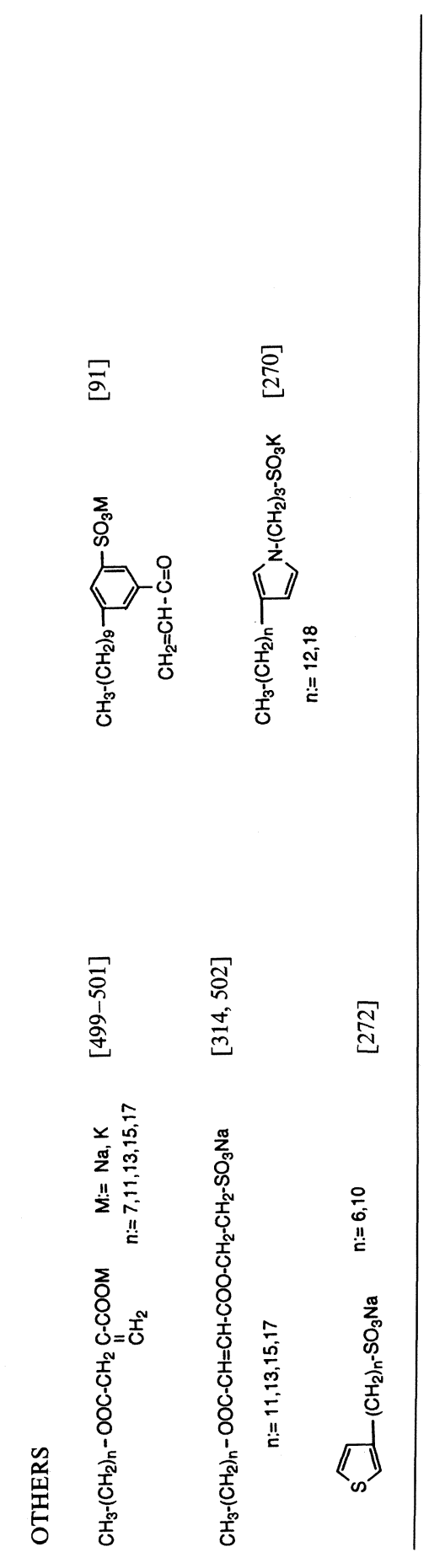


Table 2. Cationic polymerizable surfactants

STYRENE DERIVATIVES

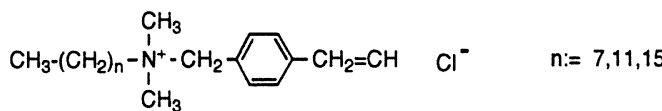

$[103,104,277,278,292,320,323,333,375,463,480]$

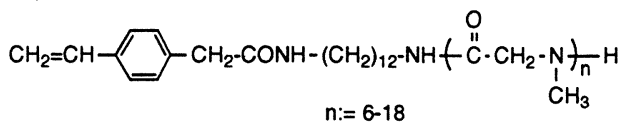

[244]

VINYLPYRIDINES AND VINYLIMIDAZOLS

$\mathrm{CH}_{3}-\left(\mathrm{CH}_{2}\right)_{\mathrm{n}}-\mathrm{N}_{\mathrm{n}:=7,11}^{+}-\mathrm{CH}_{3}=\mathrm{CH}_{2}$

$[221,503,504]$

$\mathrm{CH}_{3}-\left(\mathrm{CH}_{2}\right)_{n}-\mathrm{N}^{+} \mathrm{N}-\mathrm{CH}_{2}=\mathrm{CH}_{2} \quad x_{\mathrm{x}}^{-} \begin{aligned} & \mathrm{n}:=6,11,15 \\ & \mathrm{x}=\mathrm{I}^{-}, \mathrm{Br}\end{aligned}$

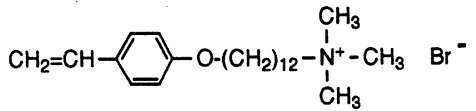

$[333,463]$
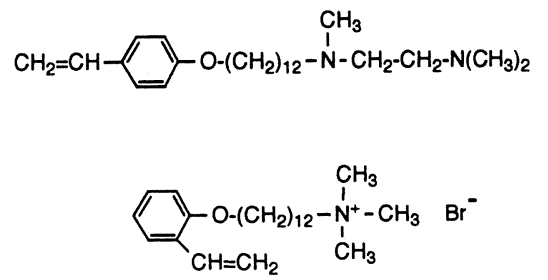

$[333,464]$ 


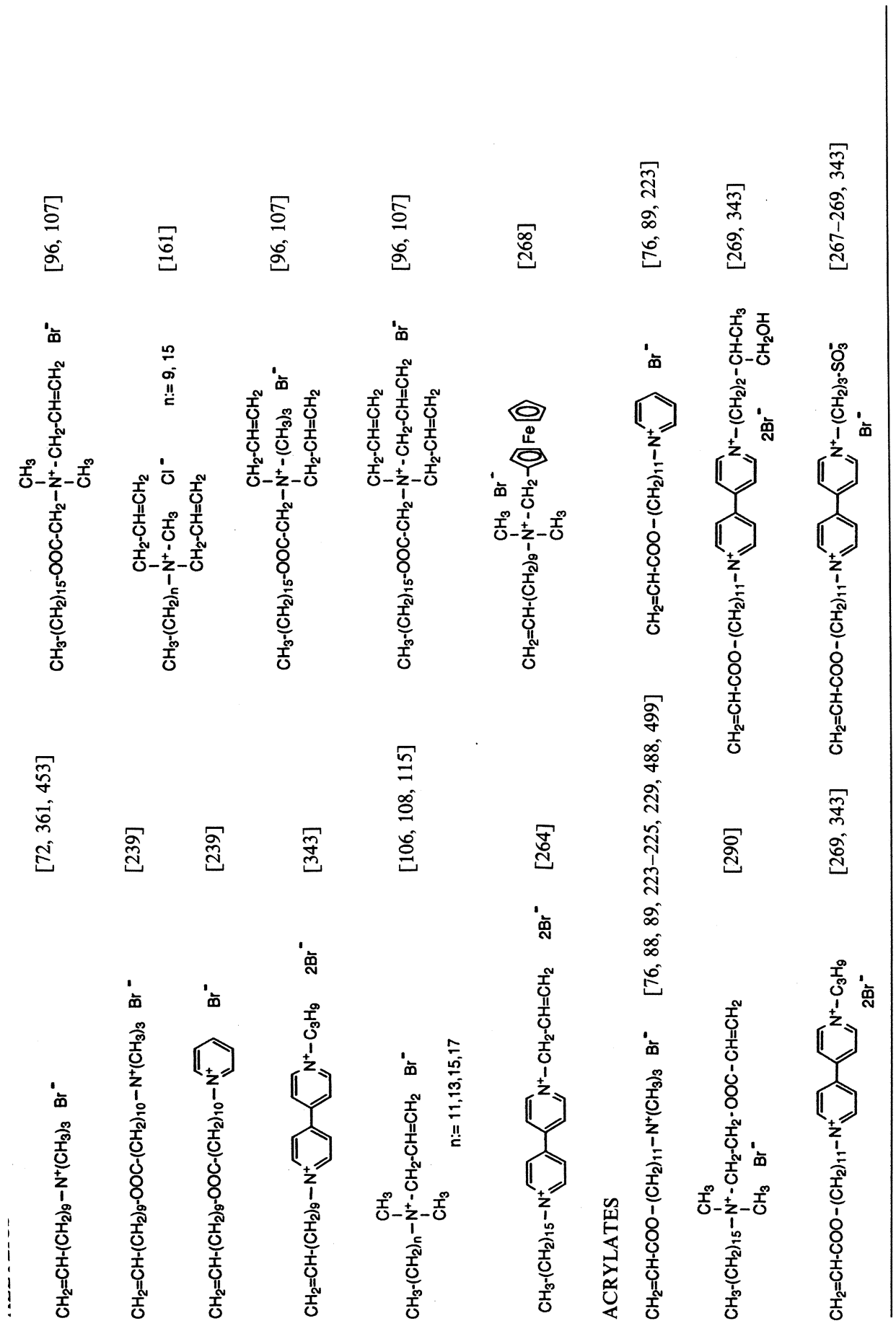


Continued

METHACRYLATES

$\mathrm{CH}_{2}=\mathrm{C}-\mathrm{COO}-\left(\mathrm{CH}_{2}\right)_{11}-\mathrm{N}^{+} \mathrm{R}_{3} \quad \mathrm{Br}-\quad \mathrm{R}:=\mathrm{CH}_{3}, \mathrm{C}_{2} \mathrm{H}_{5}$

$\stackrel{\mathrm{C}}{\mathrm{C}} \mathrm{H}_{3}$

$[76,88,89,105,126,223,226,229,491,499]$

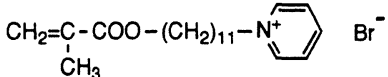

$[76,89,223]$

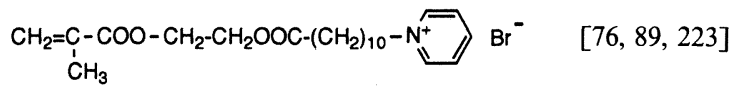

METHACRYLATES

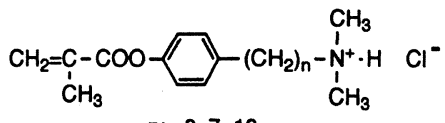

[95]

$n:=3,7,13$

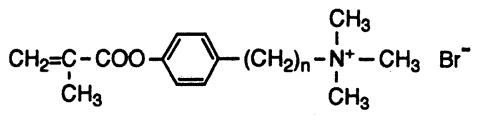

[95]

$n:=3,7,13$

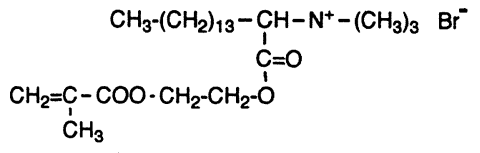

$\mathrm{CH}_{2}=\mathrm{C}-\mathrm{COO}-\mathrm{CH}_{2}-\mathrm{CH}_{2} \mathrm{OOC}-\left(\mathrm{CH}_{2}\right)_{10}-\mathrm{N}^{+}-\left(\mathrm{CH}_{3}\right)_{3} \quad \mathrm{Br}-\quad[76,89,223]$
$\underset{\mathrm{CH}}{\mathrm{CH}}$

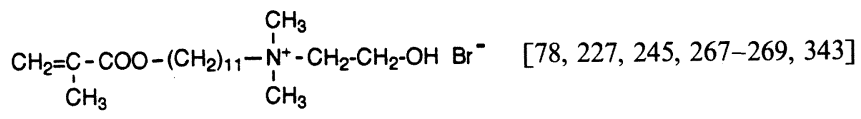

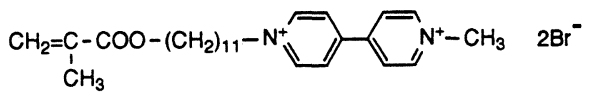

[264]

$\underset{\mathrm{CH}_{3}}{\mathrm{CH}_{2}=\mathrm{C}-\mathrm{COO}-\left(\mathrm{CH}_{2}\right)_{11}-\mathrm{N}^{+}-\mathrm{Br}^{-}}$

[267-269]

$\begin{array}{cccc}\mathrm{CH}_{3} & \mathrm{O} & & \\ \mathrm{CH}_{3}-\left(\mathrm{CH}_{2}\right)_{n}-\mathrm{N}^{+}-\mathrm{CH}_{2}-\mathrm{CH}_{2}-\mathrm{O}-\mathrm{II}-\mathrm{C}-\mathrm{C}=\mathrm{CH}_{2} & \mathrm{Br}^{-} \quad \mathrm{n}:=7,8,9,11,13,15,17 \\ \mathrm{CH}_{3} & \mathrm{CH}_{3} & & \end{array}$

$[76,88,105,118,167,219,226,227,232,245,279,280$,

$290,333,343,406,463,469]$

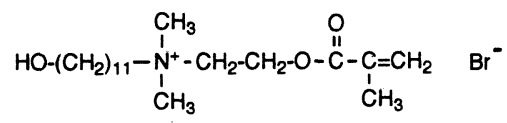

$[76,89]$

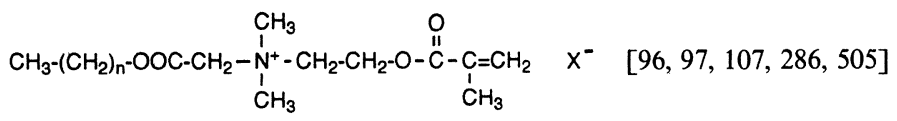

$\mathrm{n}:=7,9,11,15 \quad \mathrm{X}:=\mathrm{Cl}, \mathrm{Br}$ 


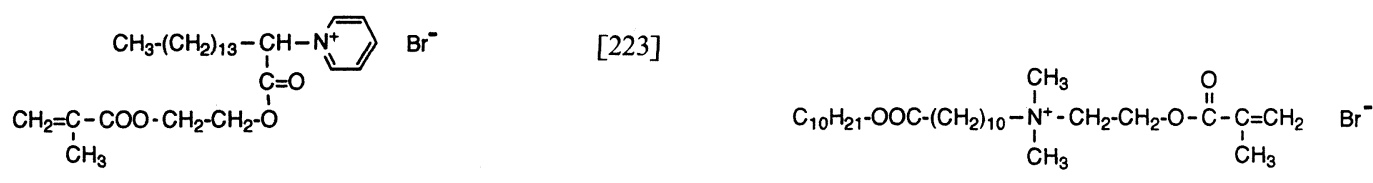

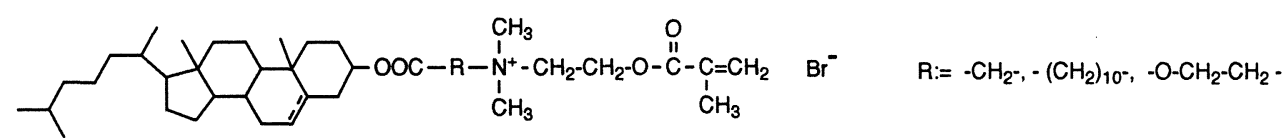
ACRYLAMIDES AND METHACRYLAMIDES

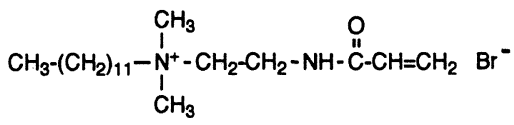

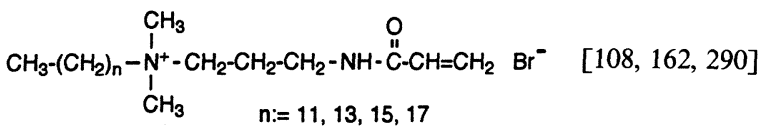

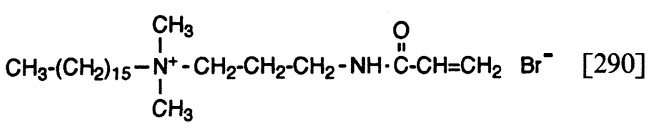

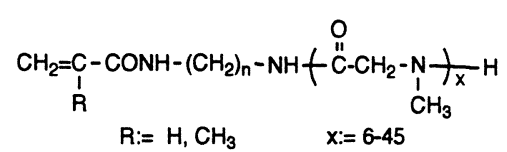

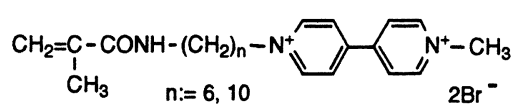

[266]

\section{OTHERS}

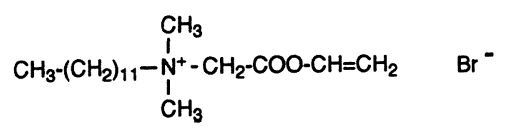




\section{OTHERS}

$\mathrm{C} \equiv \mathrm{N}-\mathrm{CH}-\mathrm{COO}-\left(\mathrm{CH}_{2}\right)_{11}-\mathrm{N}^{+}-\left(\mathrm{CH}_{3}\right)_{3} \quad \mathrm{Br}^{-}$ $\mathrm{CH}_{3}$

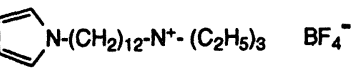

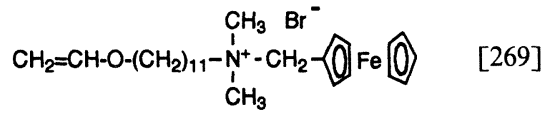

MULTIPOLAR SURFACTANTS (“BOLA"-FORM)

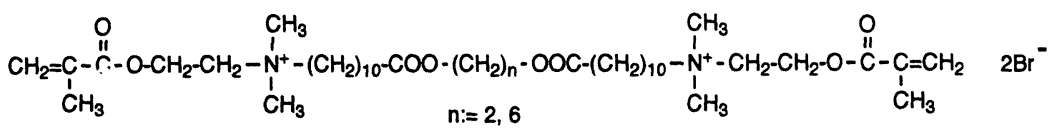

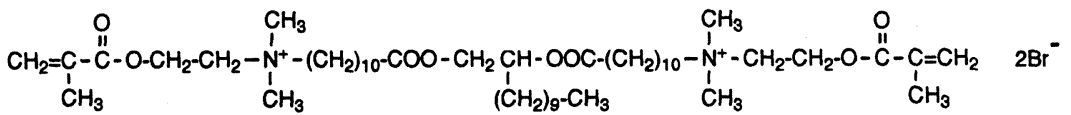

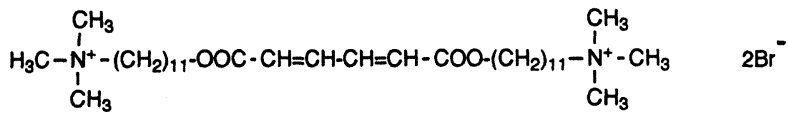

$\mathrm{N}^{+-}\left(\mathrm{CH}_{2}\right)_{11}-\mathrm{OOC}-\mathrm{CH}=\mathrm{CH}-\mathrm{COO} \longrightarrow \mathrm{OOC}-\mathrm{CH}=\mathrm{CH}-\mathrm{COO}-\left(\mathrm{CH}_{2}\right)_{n}-\mathrm{N}^{+}$ 
Table 3. Nonionic polymerizable surfactants

STYRENE DERIVATIVES

$$
\begin{aligned}
& \mathrm{CH}_{2}=\mathrm{CH}-\left(\mathrm{CH}_{2}\right)_{n}-\mathrm{O}-\left(\mathrm{CH}_{2}\right)_{10}-\mathrm{O}-\left(\mathrm{CH}_{2}-\mathrm{CH}_{2}-\mathrm{O}\right)_{120}-\mathrm{OCH}_{3} \\
& n:=1,2,7
\end{aligned}
$$

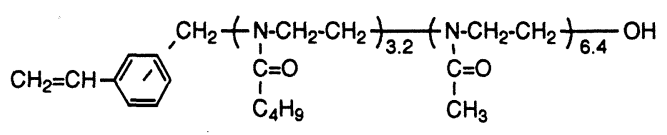

[474]<smiles>C=Cc1ccc(CCCCOC2COC3(CO)CC(O)(C2O)C3O)cc1</smiles>

[319, 321, 322]

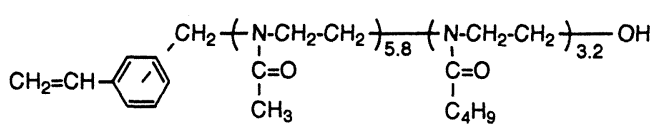

[474]

ALLYLICS

$$
\begin{aligned}
& \mathrm{CH}_{2}=\mathrm{CH}-\left(\mathrm{CH}_{2}\right)_{8}-\mathrm{COO}-\left(\mathrm{CH}_{2}-\mathrm{CH}_{2}-\mathrm{O}\right)_{n}-\mathrm{CH}_{3} \quad[121,122] \\
& \mathrm{CH}_{2}=\mathrm{CH}-\left(\mathrm{CH}_{2}\right)_{m}-\mathrm{O}:=4,6,8 \\
& m:=2 \quad n:=2,4,6,8,9,11 \\
& m:=9
\end{aligned}
$$

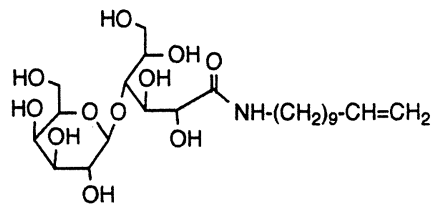

$[111,112]$

ACRYLATES

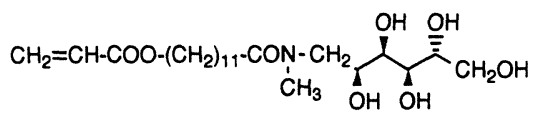

[300]

$$
\mathrm{CF}_{3}-\left(\mathrm{CF}_{2}\right)_{7}-\stackrel{\mathrm{O}}{\mathrm{O}}-\mathrm{N} 、\left(\mathrm{CH}_{2}-\mathrm{CH}_{2}-\mathrm{O}\right)_{11-14}-\mathrm{OOC}-\mathrm{CH}=\mathrm{CH}_{2}
$$

[489] 
Continued

METHACRYLATES

$$
\begin{aligned}
\mathrm{CH}_{2} & =\underset{\mathrm{C}}{\mathrm{C}}-\mathrm{COO}-\left(\mathrm{CH}_{2}\right)_{11}-\mathrm{O}-\left(\mathrm{CH}_{2}-\mathrm{CH}_{2}-\mathrm{O}\right)_{8}-\mathrm{CH}_{3} \\
\stackrel{\mathrm{C}}{\mathrm{C}} \mathrm{H}_{3} &
\end{aligned}
$$

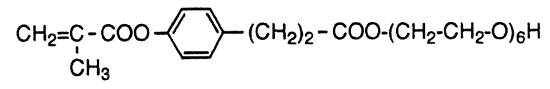

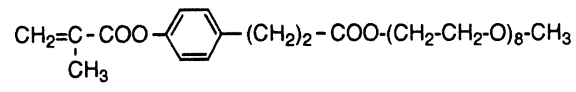

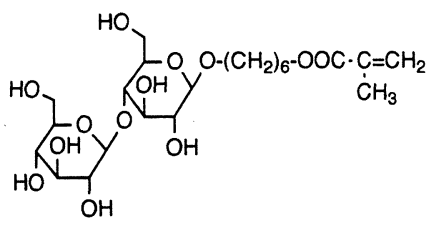

ACRYLAMIDES

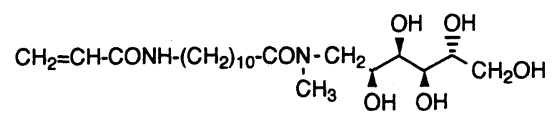

[240]
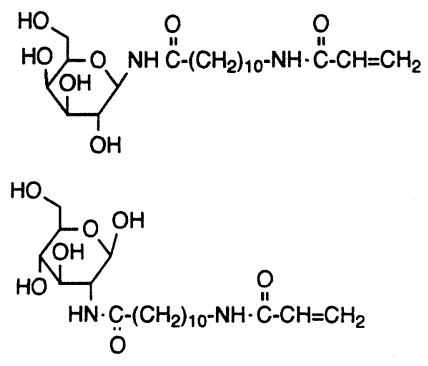

[95]

[95]

[240]

[240]
[392, 403, 507]

$[230,337]$

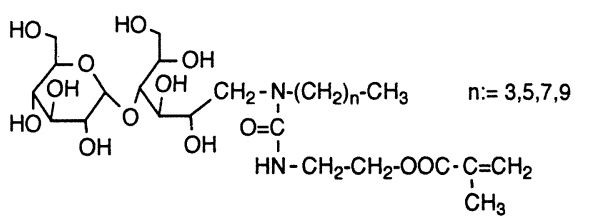

[301]

$(\underbrace{\mathrm{HO}}_{\mathrm{OH}}-\mathrm{OH} \mathrm{Y}^{\mathrm{O}-\mathrm{CH}_{2}})_{3} \mathrm{C}-\mathrm{NH}-\stackrel{\mathrm{O}}{\mathrm{C}}-\left(\mathrm{CH}_{2}\right)_{10}-\mathrm{NH} \cdot \stackrel{\mathrm{O}}{\mathrm{C}}-\mathrm{CH}=\mathrm{CH}_{2}$

[481]

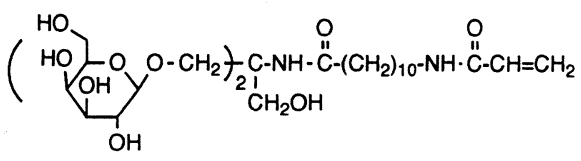

[481] 


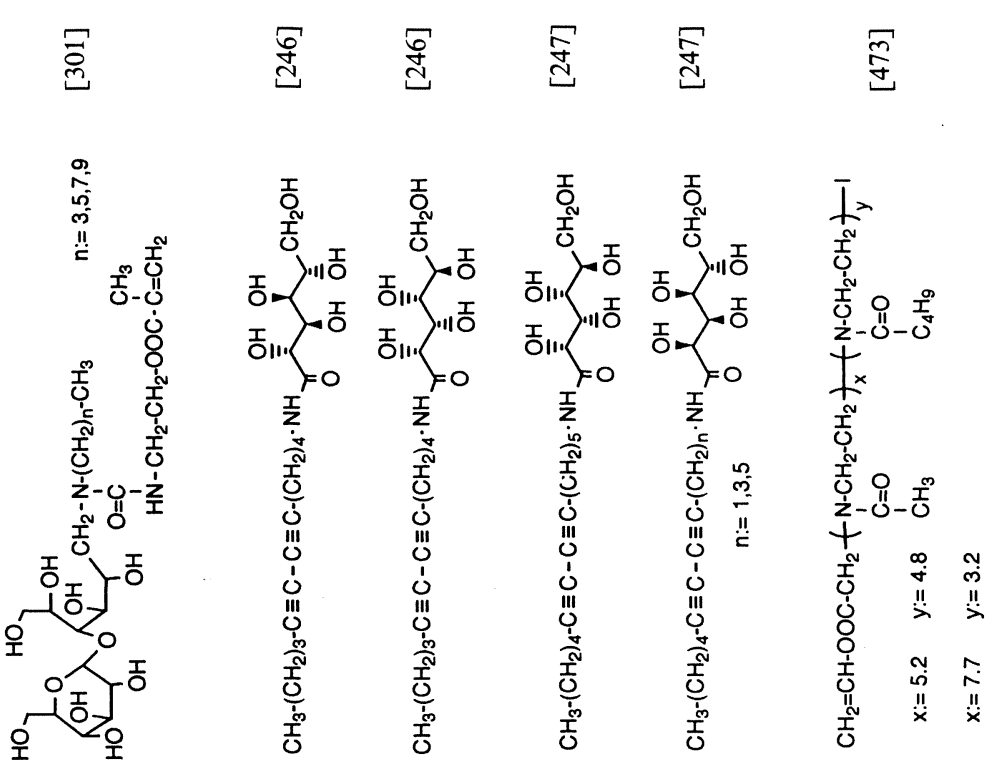

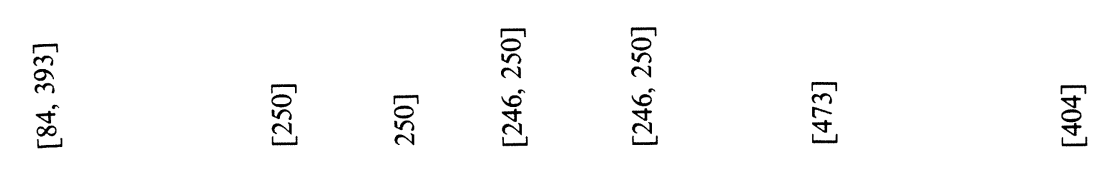

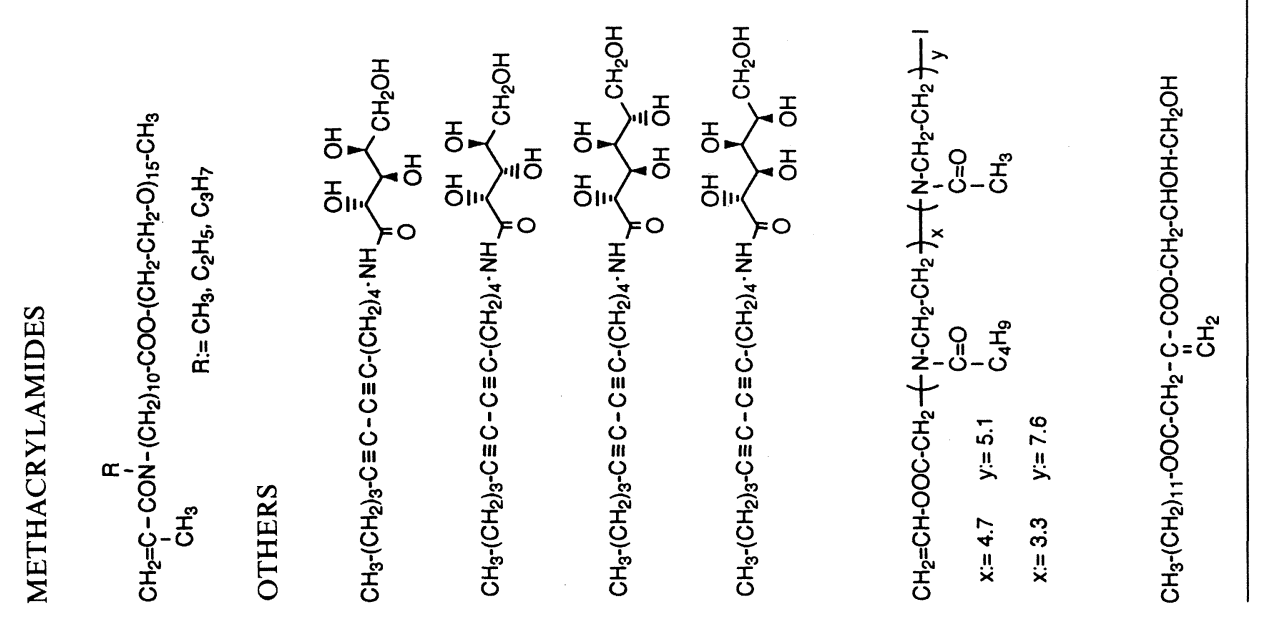


Table 4. Zwitterionic polymerizable surfactants

STYRENE DERIVATIVES

$\mathrm{CH}_{2}=\mathrm{CH} \longrightarrow\left(\mathrm{CH}_{2}\right)_{5}-\mathrm{O}-\stackrel{\mathrm{O}_{\mathrm{I}}^{-}}{\mathrm{P}}-\mathrm{O}-\mathrm{CH}_{2}-\mathrm{CH}_{2}-\mathrm{N}^{+}\left(\mathrm{CH}_{3}\right)_{3}$

[465]

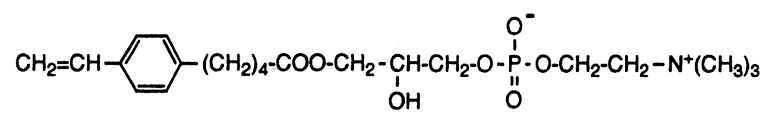

[468]

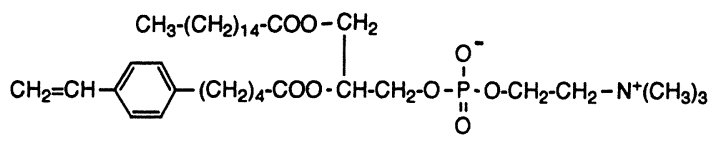

$[465,468]$

ALLYLICS

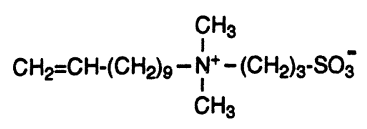

$[164,343]$<smiles>C=CCN(CCC)C(=O)CC[N+](C)(C)CCS(=O)(=O)[O-]</smiles>

[168]

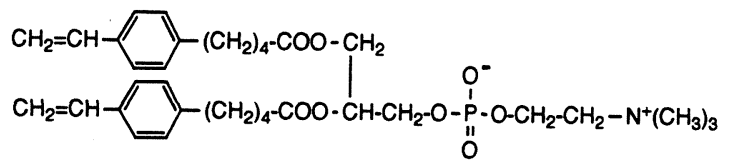

$[465,468]$

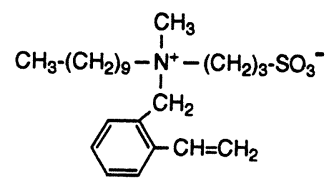

[331]

$[168,331]$

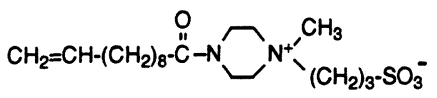

$[164,343]$ 
ACRYLATES

$\mathrm{CH}_{2}=\mathrm{CH}-\mathrm{COO}-\left(\mathrm{CH}_{2}\right)_{11}-\mathrm{C}_{\substack{\mathrm{N}^{+} \\ !}}^{\mathrm{CH}_{3}}-\left(\mathrm{CH}_{2}\right)_{n}-\mathrm{SO}_{3}^{-} \quad \mathrm{R}:=-\mathrm{CH}_{3}, \mathrm{C}_{4} \mathrm{H}_{9} \quad \mathrm{n}:=3,4$

$[227,245,331,343,406,407]$

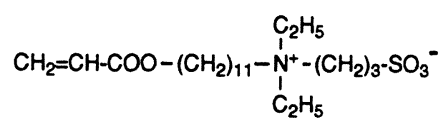<smiles>C=CC(=O)OOCC[N+](C)(CCC)CCO</smiles>

$[227,245,331,406]$

METHACRYLATES

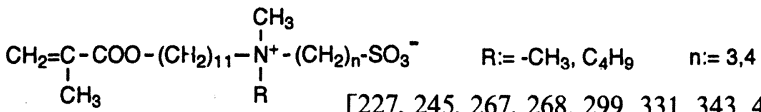

$[227,245,267,268,299,331,343,406,407]$

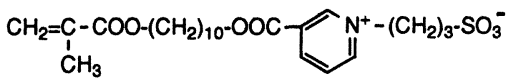

$[227,245,267,268,343]$
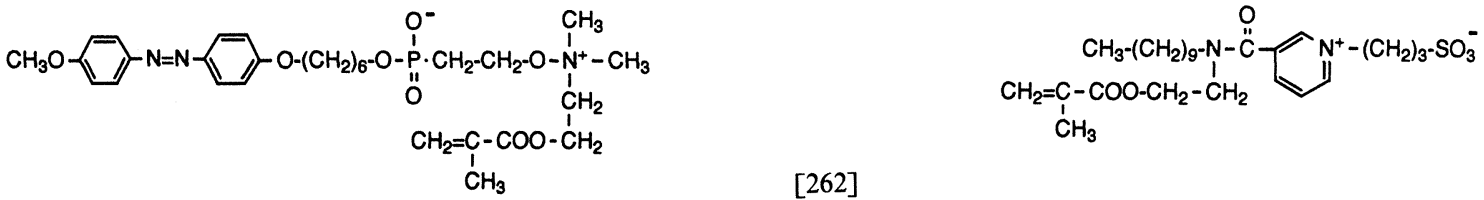

$[227,245,248,267]$

[262] 
ACRYLAMIDES AND METHACRYLAMIDES

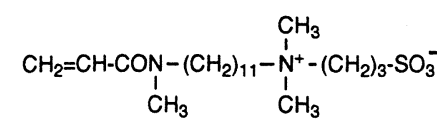

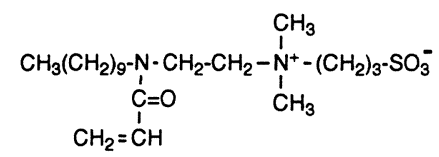

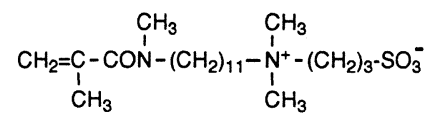

OTHERS

$\stackrel{\mathrm{C}}{!} \mathrm{H}_{3}$
$\mathrm{CH}_{3}-\left(\mathrm{CH}_{2}\right)_{9}-\stackrel{\mathrm{N}^{+}-\left(\mathrm{CH}_{2}\right)_{3}-\mathrm{SO}_{3}^{-}}{!} \underset{\mathrm{C}}{\mathrm{C}} \mathrm{H}_{2}-\mathrm{COO}-\mathrm{CH}=\mathrm{CH}_{2}$

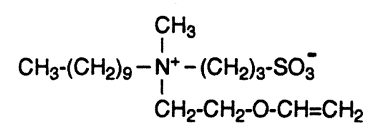

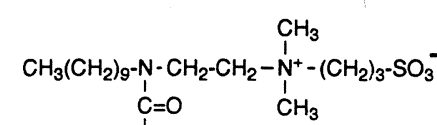
$\mathrm{CH}_{2}=\mathrm{CH}-\mathrm{CH}=\stackrel{\mathrm{I}}{\mathrm{C}} \mathrm{H}$

$\mathrm{CH}_{3}-\left(\mathrm{CH}_{2}\right)_{9}-\mathrm{N}-\mathrm{CO}-\mathrm{CH}=\mathrm{CH}-\mathrm{N}^{+}-\left(\mathrm{CH}_{2}\right)_{3}-\mathrm{SO}_{3}^{-}$
$[167,331,343]$

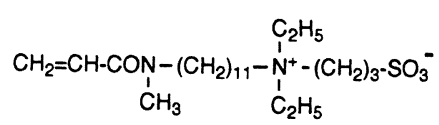

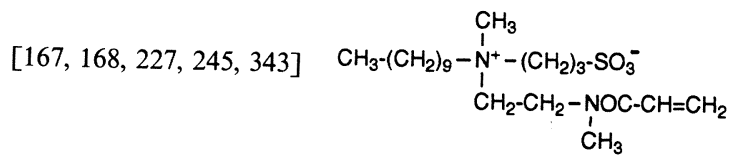

$[167,227,245,331]$

$$
\mathrm{CH}_{2}=\mathrm{CH}-\mathrm{CONH}-\left(\mathrm{CH}_{2}\right)_{10}-\mathrm{NH}-\mathrm{CO}
$$<smiles>CCCOC(=O)C=CC(=O)OCC[N+](C)(C)CCS(=O)(=O)[O-]</smiles>

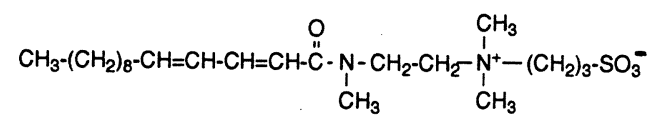<smiles>CCCCCCCCCCC=CC=CC(=O)N1CC[N+](C)(CCCC)CC1</smiles>

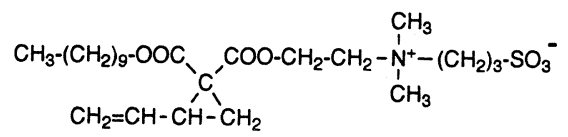

$[168,331]$ 
Table 5. Polymerizable surfactants with spacer groups

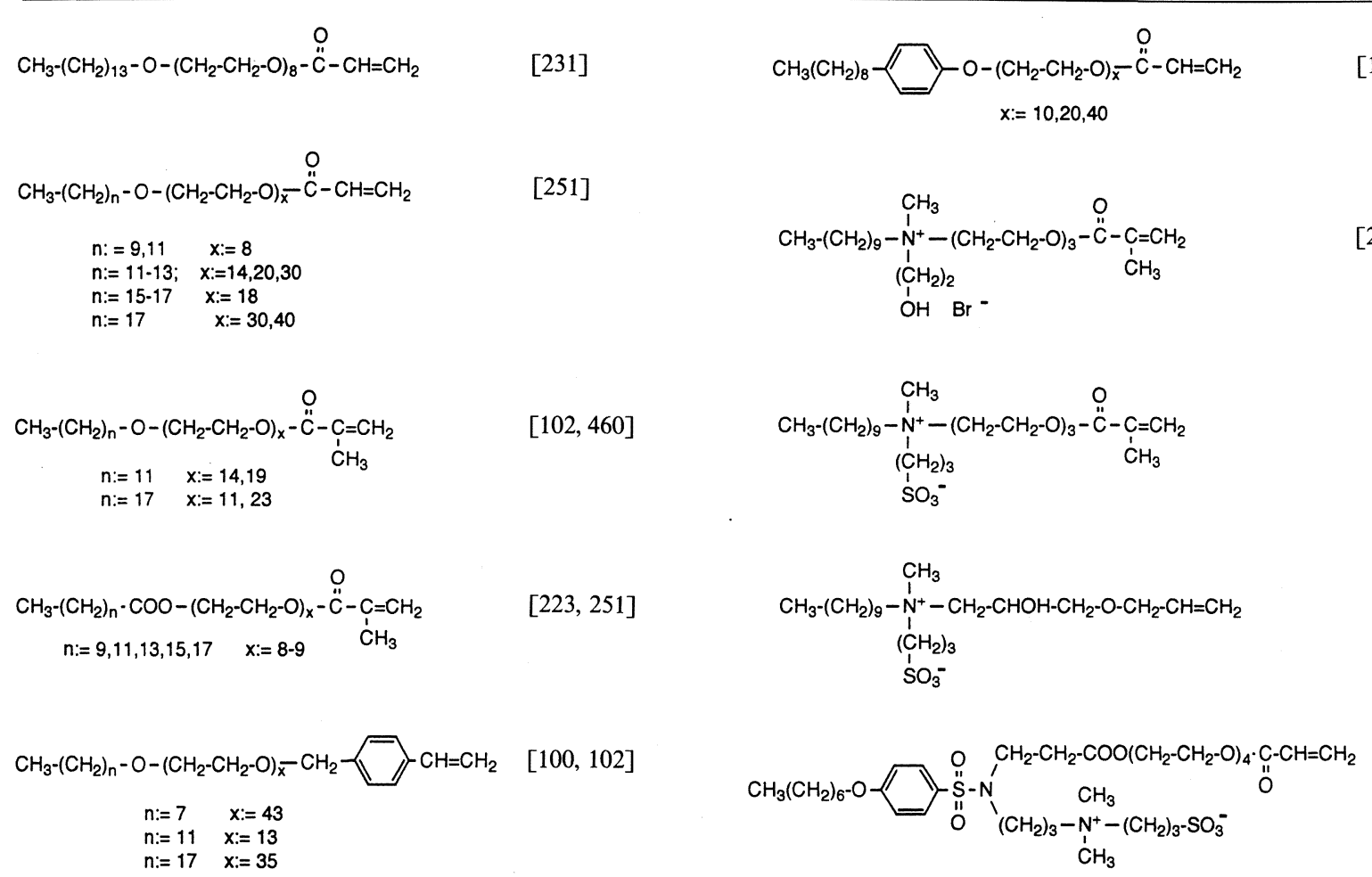


Within other applications, polysoaps have been studied as protective coatings [489, 490], photoswitchable systems [205], and proposed for chemical muscles [75].

\section{Survey on Polymerizable Surfactants}

As pointed out in Sect. 2.2, the polysoaps with the best defined molecular structure are produced by the polymerization of reactive surfactants. Because a known structure is a basic requirement, such reactive surfactants play a crucial role for model studies of polysoaps. The following tables $1-5$ list a number of polymerizable surfactants to give an idea of their present variety. The tables are by no means comprehensive as, for example, patents are omitted. It should be realized as well that many potentially useful compound are reported in the literature (namely unsaturated long chain carboxylic acids) without considering their use as reactive surfactants so far.

\section{Conclusions}

Like all water-soluble polymers, polysoaps are intriguing substances from the scientific and the practical point of view. Having improved our knowledge of polysoaps considerably, the work of the past two decades has revealed some general relationships between the molecular architecture and key properties in aqueous solutions such as viscosity, surface activity and solubilization which cover much of the present data. These relationships provide useful guidelines for the application of polysoaps and for the synthesis of new types of polysoaps. With the uprise of water-based polymer technology, polysoaps and related systems may offer a great practical potential in the future. Nevertheless, a number of problems must still be resolved. As systematic structural investigations have just started, many novel aspects of polysoap systems are expected from future work.

\section{References}

1. Tanford C (1973) The hydrophobic effect. Wiley, New York

2. Evans DF (1988) Langmuir 4: 3

3. Blockzijl W, Engberts JBFN (1993) Angew Chem Int Eng Ed 32: 1545

4. Glass JE (ed) (1989) Polymers in aqueous media. Adv chemistry series 223, Am Chem Soc, Washington DC 
5. El-Nokaly MA (ed) (1989) Polymer association structures, ACS Symposium Ser. 384, Am Chem Soc, Washington DC

6. Tomalia DA, Naylor AM, Goddard III WA (1990) Angew Chem Int Eng Ed 29: 138

7. Bader H, Dorn K, Hupfer H, Ringsdorf H (1985) Adv Polym Sci 64: 1

8. Ringsdorf H, Schlarb B, Venzmer J (1988) Angew Chem Int Eng Ed 27: 113

9. O'Brien DF, Liman U (1989) Angew Makromol Chem 166/167: 21

10. O'Brien DF, Ramaswami V (1989) in: Kroschwitz JI (ed) Encyclopedia of Polymer Science and Technology, Vol. 11, 2nd edn. Wiley-Interscience, New York, p 108

11. Paleos C (1990) J Macromol Sci Rev C30: 379

12. Tieke B (1985) Adv Polym Sci 71: 129

13. Embs F, Funhoff D, Laschewsky A, Licht U, Ohst H, Prass W, Ringsdorf H, Wegner G, Wehrmann R (1991) Adv Mater 3: 25

14. Arslanov VV (1992) Adv Coll Interface Sci 40: 307

15. Miyashita T (1993) Prog Polym Sci 18: 263

16. Shimomura M (1993) Prog Polym Sci 18: 295

17. Kawaguchi M (1993) Prog Polym Sci 18: 341

18. Lindmann B, Wennerström H (1980) Topics in Current Chem 87: 1

19. Hoffmann H (1984) Ber Bunsenges Phys Chem 88: 1078

20. Zana R (1986) J Chim Phys Chim Biol 83: 603

21. Falbe J (ed) (1987) Surfactants in Consumer Products. Springer, Berlin Heidelberg New York

22. Charvolin J, Sadoc JF (1988) J Phys Chem 92: 5787

23. Chevalier Y, Zemb T (1990) Rep Prog Phys 53: 279

24. Bekturov EA, Bakauova ZKh (1986) Synthetic Water-Soluble Polymers in Solution. Hütig \& Wepf, Basel

25. Schmolka IR (1977) J Am Oil Chem Soc 59: 110

26. Hancock RI (1984) in: Tadros TF (ed) Surfactants. Academic Press, New York, p 287

27. Wanka G, Hoffmann H, Ulbricht W (1990) Colloid Polym Sci 268: 101

28. Brown W, Schillén K, Almgren M, Hvidt S, Bahadur P (1991) J Phys Chem 95: 1850

29. Deng Y, Ding J, Stubbersfield RB, Heatley F, Attwood D, Price C, Booth C (1992) Polymer 33: 1963

30. Hurter PN, Scheutjens JMHM, Hatton TA (1993) Macromolecules 26: 5592

31. Astafieva I, Zhang XF, Eisenberg A (1993) Macromolecules 26: 7339

32. Sawamoto M (1993) Trends in Polym Sci 1: 111

33. Kanaoka S, Omura T, Sawamoto M, Higashimura T (1992) Macromolecules 25: 6407

34. Rein D, Lamps JP, Rempp P, Lutz P, Papanagopoulos D, Tsitsilianis C (1993) Acta Polym 44: 225

35. Geeraert JM, Toncheva V, Goethals EJ (1993) Frontiers in Polymerization Symposium, Liège (Belgium) 6-8. Oct.

36. Seagusa T, Yamada A, Kobayashi S (1978) Polymer J 11: 53

37. Chujo Y, Shishino T, Tsukahara Y, Yamashita Y (1985) Polymer J 17: 133

38. Wesslén B, Wesslén KB (1992) J Polym Sci Polym Chem Ed A30: 355

39. Shoda SI, Masuda E, Furukawa M, Kobayashi S (1992) J Polym Sci Polym Chem Ed A30: 1489

40. Bayer U, Stadler R, Schmidt M (1993) Polym Prepr Am Chem Soc Div Polym Chem 34(2): 572

41. Kim YH, Webster OW (1990) J Am Chem Soc 112: 4592

42. Turro NJ, Barton JK, Tomalia DA (1991) Acc Chem Res 24: 332

43. Newkome GR, Moorefield CN, Baker GR, Saunders MJ, Grossmann SH (1991) Angew Chem 103: 1207 (Int Eng Ed 30: 1178)

44. Hawker CJ, Wooley KL, Frechet JMJ (1993) J Chem Soc Perkin Trans 1, 1287

45. Newkome GR, Moorefield CN (1994) Macromol Symp 77: 63

46. Strauss UP, Jackson EG (1951) J Polym Sci 5: 649

47. Jackson EG, Strauss UP (1951) J Polym Sci 5: 473

48. Layton LH, Jackson EG, Strauss UP (1952) J Polym Sci 9: 295

49. Strauss UP, Gershfeld NL (1954) J Phys Chem 58: 747

50. Medalia AI, Freedman HH, Sinha S (1959) J Polym Sci 40: 15

51. Sinha SK, Medalia AI (1957) J Am Chem Soc 79: 281

52. Woermann D, Wall FT (1960) J Phys Chem 64: 581

53. Ito K, Ono H, Yamashita Y (1964) J Coll Sci 19: 28

54. Dubin PL, Strauss UP (1975) in: Rembaum A, Sélégny E (eds) Polyelectrolytes and Their Applications. Reidel D Publishers, Dordrecht (NL), p 3 
55. Strauss UP (1989) in: Glass JE (ed) Polymers in Aqueous Media. Adv Chemistry Series 223, Am Chem Soc, Washington DC, p 317

56. Kunitake T, Nakashima H, Takarabe K, Nagai M, Tsuge A, Yanagi H (1981) J Am Chem Soc 103: 5945

57. Soldi V, De Magalhaes Erismann N, Quina FH (1988) J Am Chem Soc 110: 5137

58. Nakaya T, Yasuzawa M, Imoto M (1989) Macromolecules 22: 3180

59. Kokkinia A, Paleos CM, Dais P (1989) Polym Prepr Am Chem Soc Div Polym Chem 30 (2): 448

60. Penzcek S, Pretula J (1993) Macromolecules 26: 2228

61. Larrabee jr CE, Sprague ED (1979) J Polym Sci Polym, Lett Ed 17: 749

62. Friberg SE, Thundatil R, Stoffer JO (1979) Science 205: 607

63. Thundatil R, Stoffer JO, Friberg SE (1980) J Polym Sci Polym Chem Ed A18: 2629

64. Sprague ED, Duecker DC, Larrabee jr CE (1981) J Am Chem Soc 103: 6797

65. Paleos CM, Stassinopoulou CI, Malliaris A (!983) J Phys Chem 87: 251

66. Arai K, Maseki Y, Ogiwara Y (1987) Makromol Chem Rapid Commun 8: 563

67. Arai K, Sugita J, Ogiwara Y (1987) Makromol Chem 188: 2511

68. Durairaj B, Blum FD (1990) Langmuir 5: 370

69. Gambogi RJ, Blum FD (1990) J Colloid Interface Sci 140: 525

70. Shibasaki Y, Fukuda K (1992) Colloids Surfaces 67: 195

71. Arai K, Okabe T (1992) Polymer J 24: 769

72. Boyer B, Lamaty G, Leydet A, Roque JP, Sama P (1992) New J Chem 16: 883

73. Arai K, Yamazaki K (1993) Polymer J 25: 1169

74. Denton JM, Duecker DC, Sprague ED (1993) J Phys Chem 97: 756

75. Strauss UP, Gershfeld NL, Crook EH (1956) J Phys Chem 60: 577

76. Hamid S, Sherrington DC (1987) Polymer 28: 332

77. a) Chang Y, McCormick CL (1993) Macromolecules 26: 6121 b) McCormick CL, Chang Y (1994) Macromolecules 27: 2151

78. Anton P, Köberle P, Laschewsky A (1993) Makromol Chem 194: 1

79. Zuckerberg A, Diver A, Peeri Z, Gutnick DL, Rosenberg E (1979) Appl Env Microbiol 37: 414

80. Cooper DG, McDonald CR, Duff SJB, Kosaric N (1981) Appl Env Microbiol 40: 408 (1981)

81. Roe ET, Swern D (1953) J Am Chem Soc 75: 5479

82. Bistline jr RG, Stirton AJ, Weil JK, Port WS (1956) J Am Oil Chem Soc 33: 44

83. Freedman HH, Mason JP, Medalia AI (1958) J Org Chem 23: 76

84. Kammer U, Elias HG (1972) Kolloid Z u Z. Polymere 250: 344

85. Salamone JC, Isreal SC, Snider B, Taylor P, Raia D (1972) Polym Prepr Am Chem Soc Div Polym Chem 13 (1): 271

86. Salamone JC, Israel SC, Taylor P, Snider B (1973) Polymer 14: 639

87. Finkelmann H, Rehage G (1984) Adv Polym Sci 60/61: 1

88. Hamid S, Sherrington DC (1986) J Chem Soc Chem Commun 936

89. Hamid S, Sherrington DC (1987) Polymer 28: 325

90. Paleos C, Malliaris A (1990) J Macromol Sci Rev C28: 403

91. Malyukova YeB, Naumova SV, Gritskova IA, Bondarev AN, Zubov VP (1991) Vysokomol Soyed A33: 1469 (English translation: Polym Sci USSR 33: 1361)

92. Yegorov VV, Zaitsev SYu, Zubov VP (1991) Vysokomol Soyed A33: 1587 (English translation: Polym Sci USSR 33: 1475)

93. Guyot A, Tauer K (1994) Adv Polym Sci 111: 43

94. Ringsdorf H, Thunig D (1977) Makromol Chem 178: 2205

95. Siol W (1979) Mizellbildende Monomere- Synthese und Untersuchung des Polymerisationsverhaltens. Thesis, Universität Mainz (Germany)

96. Batrakova EV, Orlov YuN, Egorov VV, Zubov VP, Kabanov VA (1985) Vysokomol Soyed B27: 87

97. Egorov V (1990) Makromol Chem Macromol Symp 31: 157

98. Yeoh KW, Chew CH, Gan LM, Koh LL, Teo HH (1989) J Macromol Sci Chem A26: 663

99. Yeoh KW, Chew CH, GAn LM, Koh LL (1990) J Macromol Sci Chem A27: 63

100. Ito K, Tanaka K, Tanaka H, Imai G, Kawaguchi S, Itsuno S (1991) Macromolecules 24: 2348

101. Chao D, Itsuno S, Ito K (1991) Polymer J 23: 1045

102. Ito K, Kobayashi H (1992) Polymer J 24: 199

103. Cochin D, Zana R, Candau F (1993) Polymer Int 30: 491

104. Cochin D, Zana R, Candau F (1993) Macromolecules 26: 5765

105. Dais P, Paleos CM, Nika G, Malliaris A (1993) Makromol Chem 194: 445

106. Paleos CM, Dais P, Malliaris A (1984) J Polym Sci Polym Chem Ed A22: 3383 
107. Shapiro YuE, Orlov YuN, Egorov VV, Zubov VP (1984) Vestn Mosk Univ Ser 2: Khim 25: 595

108. Peiffer DG (1990) J Polym Sci Polym Chem Ed A28: 619

109. Arai K, Miyahara S (1990) Makromol Chem 191: 2647

110. Arai K, Miyahara S, Okabe T (1991) Makromol Chem 192: 2183

111. André B, Boyer B, Lamaty G, Leydet A, Roque JP (1991) Tetr Lett 32: 1881

112. Boyer B, Durand S, Lamaty G, Moussamou-Missima JM, Pavia AA, Pucci B, Roque JP, Rouvière J (1991) J Chem Soc Perkin Trans 2: 1311

113. Boyer B, Lamaty G, Moussamou-Missima JM, Pavia AA, Pucci B, Roque JP (1991) Tetr Lett 32: 1191

114. Nagai K, Satoh H, Kuramoto N (1992) Polymer 33: 5303

115. Tribet C, Gaboriaud R, Lelievre J (1992) Polymer Int 29: 79

116. Esumi K, Nakao T, Ito S (1993) J Coll Interface Sci 156: 256

117. Arai K, Yamazaki K (1993) Polymer J 25: 1169

118. Nagai K, Ohishi Y (1994) J Polym Sci Polym Chem Ed A32: 445

119. Sonessa AJ, Cullen W, Ander P (1980) Macromolecules 13: 195

120. Knapick EG, Hirsch JA, Ander P (1985) Macromolecules 18: 1015

121. Finkelmann H, Lühmann B, Rehage G (1982) Colloid Polym Sci 260: 56

122. Finkelmann H, Lühmann B, Rehage G (1984) Angew Makromol Chem 123/124: 217

123. Finkelmann H, Lühmann B, Rehage G (1985) Makromol Chem 186: 1059

124. Lühmann B, Finkelmann H (1987) Colloid Polym Sci 265: 506

125. Luca C, Avram E, Petrariu I (1988) J Macromol Sci Chem A25: 345

126. Finkelmann H, Jahns E (1989) in El-Nokaly MA (ed) Polymer Association Structures, ACS Symposium Ser. 384, Am Chem Soc, Washington DC, $p 1$

127. Paleos CM, Tsiourvas D, Anastassopoulu J, Theophanides T (1992) Polymer 33: 4047

128. Tsiourvas D, Paleos CM, Malliaris A (1993) J Polym Sci Polym Chem Ed A31: 387

129. a) Geckeler KE, Zhou R (1994) Macromol Rapid Commun 15: 55

b) Palmer V, Zhou R, Geckeler KE (1994) Angew Makromol Chem 215: 175

130. Strauss UP, Assony SJ, Jackson EG, Layton LH (1952) J Polym Sci 9: 509

131. Jorgensen HE, Strauss UP (1961) J Phys Chem 65: 1873

132. Nakagawa T, Inoue H (1964) Kolloid Z u Z Polymere 195: 93

133. Inoue $H$ (1964) Kolloid $Z$ u Z Polymere 195: 102

134. Inoue $H$ (1965) Kolloid $Z$ u Z Polymere 196: 1

135. Klotz IM, Royer GP, Sloniewsky AR (1969) Biochem 8: 4752

136. Royer GP, Klotz IM (1969) J Am Chem Soc 91: 5885

137. Okube T, Ise N (1973) J Org Chem 38: 3120

138. Rodulfo T, Hamilton JA, Cordes EH (1974) J Org Chem 39: 2281

139. Kunitake T, Shinkai S, Hirotsu S (1975) J Polym Sci Polym Lett Ed C13: 377

140. Shinkai S, Kunitake T (1976) Biopolymers 15: 1129

141. Kunitake T, Shinkai S, Hirotsu S (1976) Biopolymers 15: 1143

142. Shinkai S, Ide T, Manabe O (1978) Bull Chem Soc Jpn 51: 3635

143. Tanchuk YuV, Pop GS (1978) Coll J USSR 40: 1209 (English translation 40: 1024)

144. Pop GS, Tanchuk YuV (1979) Ukr Khim Zh 45: 991

145. Sisido M, Akiyama K, Imanishi Y, Klotz IM (1984) Macromolecules 17: 198

146. Richlin J, Strauss UP (1986) Polymer Prepr Am Chem Soc Div Polym Chem 27(1): 425

147. Moriya M, Nishimura A, Hoaoda K, Takai M, Hidaka H (1986) J Am Oil Chem Soc 63: 263

148. Hidaka H, Onai T, Murata M, Fujiwara K, Takai M, Moriya M (1987) J Coll Interface Sci 119 : 565

149. Wang KT, Iliopoulos I, Audebert R (1988) Polym Bull 20: 577

150. Tsiourvas D, Paleos CM, Dais P (1989) J Appl Polym Sci 38: 257

151. Iliopoulos I, Wang KT, Audebert R (1991) Langmuir 7: 617

152. Seo T, Take S, Miwa K, Hamada K, Iijima T (1991) Macromolecules 24: 4255

153. Kuo PL, Ni SC, Lai CC (1992) J Appl Polym Sci 45: 611

154. McCormick CL, Hoyle CE, Clark MD (1992) Polymer 33: 243

155. a) Rios HE, Rojas JS, Gamboa IC, Barraza RG (1993) J Coll Interface Sci 156: 388 b) Rios HE, Aravena MH, Barraza RG (1994) J Colloid Interface Sci 165: 259

156. Salamone JC, Taylor P, Snider B, Israel SC (1975) J Polym Sci Polym Chem Ed A13: 161

157. Schulz DN, Kaladas JJ, Maurer JJ, Bock J, Pace SJ, Schulz WW (1987) Polymer 28: 2110

158. Tagagishi T, Nakata Y, Kuroki N (1974) J Polym Sci Polym Chem Ed A12: 807

159. a) Salamone JC, Thompson AM, Raheja MK, Su CH, Watterson AC (1988) Polym Prepr Am Chem Soc Div Polym Chem 29 (1): 281 
b) Salamone JC, Thompson AM,Su CH, Watterson AC (1989) Polym Prepr Am Chem Soc Div Polym Chem 30 (1): 333

160. Salamone JC, Thompson AM, Rice WC, Lai KT, Boden MW, Luo YM, Raheja MK, Su CH, Watterson AC (1989) in: Saegusa T, Higashimura T, Abe A (eds) Frontiers in Macromolecular Science, Blackwell Scientific, Oxford, p 227

161. Do CH, Butler GB (1989) Polym Prepr Am Chem Soc Div Polym Chem 30(2): 352

162. Peiffer DG (1990) Polymer 31: 2353

163. Yeoh KW, Chew CH, Gan LM, Koh LL, Ng SC (1990) J Macromol Sci Chem A27: 71.1

164. Anton P, Laschewsky A (1991) Makromol Chem Rapid Commun 12: 189

165. Peiffer DG (1991) Polymer 32: 134

166. Watterson AC, Hunter CR, Salamone JC (1992) Polym Prepr Am Chem Soc Div Polym Chem 33(1): 1160

167. Köberle P, Laschewsky A, van den Boogaard D (1992) Polymer 33: 4029

168. Anton P, Laschewsky A (1993) Makromol Chem 194: 601

169. Pefferkorn E, Schmitt A, Varoqui R (1968) C R Acad Sc C267: 349

170. Varoqui R, Strauss UP (1968) J Phys Chem 72: 2507

171. Dubin PL, Strauss UP (1970) J Phys Chem 74: 2842

172. Schmitt A, Varoqui R, Skoulios A (1969) CR Acad Sci C268: 1469

173. Mathis A, Skoulious A, Varoqui R, Schmitt A (1974) Eur Polym J 10: 1011

174. Timofeevskii SL, Baikov VE, Panarin EF, Pautov VD (1994) Vysokomol Soyed A36: 15 (Eng. translation: Polym Sci USSR 36: 10

175. Strauss UP, Vesnaver G (1975) J Phys Chem 79: 1558 and 2426

176. Strauss UP, Schlesinger MS (1978) J Phys Chem 82: 571

177. Strauss UP, Schlesinger MS (1978) J Phys Chem 82: 1527

178. Mathis A, Schmitt A, Skoulios A, Varoqui R (1979) Eur Polym J 15: 255

179. Martin PJ, Morss LR, Strauss UP (1980) J Phys Chem 84: 577

180. Strauss UP, Barbieri BW (1982) Macromolecules 15: 1347

181. Barbieri BW, Strauss UP (1985) Macromolecules 18: 411

182. Varoqui R, Pefferkorn E (1985) in: Dubin P (ed) Microdomains in Polymer Solutions. Plenum Press, New York, p 225

183. Guillet JE, Rendall WA (1986) Macromolecules 19: 224

184. Hsu JL, Strauss UP (1987) J Phys Chem 91: 6238

185. Chu DY, Thomas JK (1987) Macromolecules 20: 213

186. Binana-Limbelé W, Zana R (1987) Macromolecules 20: 1331

187. McGlade MJ, Randall FJ, Tcheurekdjian N (1987) Macromolecules 20: 1782

188. Meier C (1989) Lyotrop flüssigkristalline Copolymere aus nicht-amphiphilen Monomeren Thesis, Universität Freiburg (Germany)

189. McGlade MJ, Olufs JL (1988) Macromolecules 21: 2346

190. Shih LB, Mauer DH, Verbrugge CJ, Wu CF, Chang SL, Chen SH (1988) Polym Prepr Am Chem Soc Div Polym Chem 29(2): 451

191. Shih LB, Shen EY, Chen SH (1988) Macromolecules 21: 1387

192. Shih LB, Mauer DH, Verbrugge CJ, Wu CF, Chang SL, Chen SH (1988) Macromolecules 21: 3235

193. Morishima Y, Kobayashi T, Nozakura S (1989) Polymer J 21: 267

194. Weinert RJ, Piirma I (1989) J Appl Polym Sci 38: 1295

195. Hamad E, Qutubuddin S (1990) Macromolecules 23: 4185

196. Binana-Limbelé W, Zana R (1990) Macromolecules 23: 2731

197. Chu DY, Thomas JK (1991) Macromolecules 24: 2212

198. Miyashita T, Arito Y, Matsuda M (1991) Macromolecules 24: 872

199. Yang YJ, Engberts JFBN (1991) Rec Trav Chim Pays-Bas 110: 384

200. Yang YJ, Engberts JFBN (1991) J Org Chem 56: 4300

201. Ito K, Hashimura K, Itsuno S, Yamada E (1991) Macromolecules 24: 3977

202. Morishima Y, Tominaga Y, Kamachi M, Okada T, Hirata Y, Mataga N (1991) J Phys Chem 95: 6027

203. Morishima Y, Tsuji M, Kamachi M, Hatada K (1992) Macromolecules 25: 4406

204. Seki M, Morishima Y, Kamachi M (1992) Macromolecules 25: 6540

205. Koňák C, Kopečková P, Kopeček J (1992) Macromolecules 25: 5451

206. Benrraou M, Zana R, Varoqui R, Pefferkorn E (1992) J Phys Chem 96: 1468

207. Hamad E, Qutubuddin S (1992) J Chem Phys 96: 6222

208. Maltesh C, Xu Q, Somasundaran P, Benton WJ, Nguyen H (1992) Langmuir 8: 1511 
209. Ueda T, Oshida H, Kurita K, Ishihara K, Nakabayashi N (1992) Polymer J 24: 1259

210. Sakurai I, Kawamura Y, Suetsugu T, Nakaya T (1992) Macromolecules 25: 7256

211. Nowakowska M, Foyle VP, Guillet JE (1993) J Am Chem Soc 115: 5975

212. Varadaraj R, Bock J, Brons N, Pace S (1993) J Phys Chem 97: 12991

213. Kuo PL, Hung MN (1993) J Appl Polym Sci 48: 1571

214. Betton F, Theretz A, Elaissari A, Pichot C (1993) Colloids Surfaces B1: 97

215. Zdanowicz VS, Strauss UP (1993) Macromolecules 26: 4770

216. Watterson AC, Haralabakopoulos A, Salamone JC (1993) Polym Prepr Am Chem Soc Div Polym Chem 34(1): 610

217. Morishima Y (1994) Trends in Polym Sci 2: 31

218. Xie X, Hogen-Esch TE (1994) Polym Prepr Am Chem Soc Polym Chem Div 35(1) 498

219. Nagai K, Fujii I, Kuramoto N (1992) Polymer 33: 3060

220. Hill A, Candau F, Selb J (1993) Macromolecules 26: 4521

221. Xin Y, Hu Y, Zeldin M, Fife WK (1993) Macromolecules 26: 4670

222. Yassini M, Hogen-Esch TE (1994) Polym Prepr Am Chem Soc Polym Chem Div 35(1) 478

223. Hamid S, Sherrington DC (1984) Brit Polym J 16: 39

224. Paleos CM, Malliaris A, Dais P (1987) Polym Prepr Am Chem Soc Polym Chem Div 28(2): 434

225. Paleos CM, Margomenou-Leonidopoulou G, Malliaris A (1988) Mol Cryst Liq Cryst 161: 385

226. Michas J, Paleos CM, Dais P (1989) Liq Cryst 5: 1737

227. Laschewsky A, Zerbe I (1991) Polymer 32: 2070

228. Ishihara K, Tsuji T, Sakai Y, Nakabayashi N (1993) J Polym Sci Polym Chem Ed A32: 859

229. Wagner D (1985) Über den Einfluß der Polymerfixierung von Tensiden auf das Aggregationsverhalten in Wäßriger Lösung. Thesis, TU Clausthal (Germany)

230. Charreyre MT, Boullanger P, Pichot C, Delair T, Mandrand B, Llauro MF (1993) Makromol Chem 194: 117

231. Jahns E, Finkelmann H (1987) Colloid Polym Sci 265: 304

232. Laschewsky A (1991) Colloid Polym Sci 269: 785

233. Elbert R, Laschewsky A, Ringsdorf H (1985) J Am Chem Soc 107: 4134

234. Laschewsky A, Ringsdorf H, Schmidt G, Schneider J (1987) J Am Chem Soc 109: 788

235. Ringsdorf H, Schmidt G, Schneider J (1987) Thin Solid Films 152: 207

236. Percec V, Pugh C (1989) in McArdle CB (ed) Side Chain Liquid Crystals. Blackie \& Son Ltd, Glasgow, p 30

237. Zentel R (1989) in: Allen G, Bevington JC (eds) Comprehensive Polymer Science Vol 5. Pergamon Press, Oxford (UK), p 723

238. Kobayashi K, Sumitomo H (1980) Macromolecules 13: 234

239. Abid SK, Hamid SM, Sherrington DC (1987) J Coll Interface Sci 120: 245

240. Gallot B, Marchin B (1989) Liq Crystals 5: 1729

241. Barakat Y, Gendy TS, Mohammed AI, Youssef AFM (1989) Brit Polym J 21: 383

242. Barakat Y, Gendy TS, Basily IK, Mohammed AI (1989) Brit Polym J 21: 451

243. Barakat Y, Basily IK, Mohammed AI, Youssef AFM (1989) Brit Polym J 21: 459

244. Gallot B (1991) Mol Cryst Liq Cryst 203: 137

245. Laschewsky A, Zerbe I (1991) Polymer 32: 2081

246. Frankel DA, O’Brien DF (1991) J Am Chem Soc 113: 7436

247. Fuhrhop JH, Blumtritt R, Lehmann C, Luger P (1991) J Am Chem Soc 113: 7436

248. Ahlheim M, Hallensleben ML (1992) Makromol Chem 193: 779

249. Abid SK, Sherrington DC (1993) Eur Polym J 29: 153

250. Frankel DA, O'Brien DF (1994) Macromol Symp 77: 141

251. Ferguson P, Sherrington DC, Gough A (1993) Polymer 34: 3281

252. Shimizu T, Kwak JC, Minakata A (1985) J Polym Sci Polym Phys Ed B23: 1139

253. Kopolow S, Hogen-Esch TE, Smid J (1973) Macromolecules 3: 133

254. Roland B, Smid J (1983) J Am Chem Soc 105: 5269

255. Roland B, Kimura K, Smid J (1984) J Coll Interface Sci 97: 392

256. Menger FM, Tsuno T (1990) J Am Chem Soc 112: 6723

257. Kaneka M, Yamada A (1984) Adv Polym Sci 55: 2

258. Morishima Y (1992) Adv Polym Sci 104: 51

259. Morishima Y, Tominaga Y, Nomura S, Kamachi M, Okada T (1992) J Phys Chem 96: 1990

260. Morishima Y, Tsuji M, Seki M, Kamachi M (1993) Macromolecules 26: 3299

261. Husson F, Herz J, Luzzati V, Wyart J (1961) CR Acad Sci C252: 3290

262. Sugiyama K, Shiraishi K (1989) Makromol Chem 190: 2381

263. Matsuo T, Sakamoto T, Takuma K, Sakura K, Ohsako T (1981) J Phys Chem 85: 1277 
264. Tundo P, Kippenberger DJ, Politi MJ, Klahn P, Fendler JH (1982) J Am Chem Soc 104: 5352

265. Nakahira T, Grätzel M (1985) Makromol Chem Rapid Comm 6: 341

266. Okahata Y, Ariga K, Seki T (1986) J Chem Soc Chem Commun 73

267. Anton P, Köberle P, Laschewsky A (1992) Prog Colloid Polym Sci 89: 56

268. Anton P, Heinze J, Laschewsky A (1993) Langmuir 9: 77

269. Anton P (1993) Redoxaktive Polyseifen: Wege zu schaltbaren Polymeren. Thesis, Universität Mainz (Germany)

270. Collard DM, Fox MA (1991) J Am Chem Soc 113: 9414

271. Coche-Guerente L, Deronzier A, Galland B, Labbe P, Moutet JC, Reverdy G (1991) J Chem Soc Chem Commun 386

272. Chen SA, Hua MY (1993) Macromolecules 26: 7108

273. Shi S, Wudl F (1990) Macromolecules 23: 2119

274. Rau IU, Rehahn M (1994) Acta Polymer 45: 3

275. Salamone JC, Israel SC, Taylor P, Snider B (1974) J Polym Sci Symp 45: 65

276. Ghesquiere D, Chachaty C, Ban B, Loucheux C (1976) Makromol Chem 177: 1601

277. Ikeda T, Tazuke S (1983) Makromol Chem Rapid Comm 4: 459

278. Ikeda T, Tazuke S, Suzuki Y (1984) Makromol Chem 185: 869

279. Nagai K, Ohishi Y, Inaba H, Kudo S (1985) J Polym Sci Polym Chem Ed A23: 1221

280. Nagai K, Ohishi Y (1987) J Polym Sci Polym Ed A25: 1

281. Schambil F, Schwuger MJ (1987) in: Falbe J (ed) Surfactants in Consumer Products, Springer, Berlin Heidelberg New York, p 133

282. Wang KT, Iliopoulos I, Audebert R (1989) Polym Prepr Am Chem Soc Div Polym Chem 30 (2): 377

283. Yeoh KW, Chew CH, Gan LM, Koh LL (1989) Polym Bull 22: 123

284. Gan LM, Yeoh KW, Chew CH, Koh LL, Tan TL (1991) J Appl Polym Sci 42: 225

285. Magny B, Iliopoulos I, Audebert R (1991) Polymer Comm 32: 456

286. Yegorov VV, Ksenofontova OB (1991) Vysokomol Soyed A33: 1780 (english translation: Polym Sci USSR 33: 1665)

287. Seo T, Take S, Akimoto T, Hamada K, Iijima T (1991) Macromolecules 24: 4801

288. Cochin D, Candau F, Zana R, Talmon Y (1992) Macromolecules 25: 4220

289. Yasuda Y, Rindo K, Tsushima R, Aoki S (1993) Makromol Chem 194: 485

290. Yasuda Y, Rindo K, Tsushima R, Aoki S (1993) Makromol Chem 194: 1893

291. Yasuda Y, Rindo K, Aoki S (1993) Polym J 25: 1203

292. Cochin D, Candau F, Zana R (1993) Macromolecules 26: 5755

293. Nakaya T, Nishio K, Memita M, Imoto M (1993) Makromol Chem Rapid Comm 14: 77

294. Yassini M, Hogen-Esch TE (1992) Polym Prepr Am Chem Soc Polym Chem Div 33(1): 933

295. Seery TAP, Yassini M, Hogen-Esch TE, Amis EJ (1992) Macromolecules 25: 4784

296. Zhang YX, Da AH, Butler GB, Hogen-Esch TE (1992) J Polym Sci Polym Chem Ed A30: 1383

297. Hwang FS, Hogen-Esch TE (1993) Macromolecules 26: 3156

298. Ringsdorf H, Simon J, Winnik FM (1992) Macromolecules 25: 5353

299. Köberle P, Laschewsky A, Lomax TD (1991) Makromol Chem Rapid Commun 12: 427

300. Finkelmann H, Schafheutle M (1986) Colloid Polym Sci. (1986) 264: 786

301. Klein J, Kunz M, Kowalczyk J (1990) Makromol Chem 191: 517

302. Fuhrhop JH, Spiroski D, Schnieder P (1991) React Polym 15: 215

303. Morishima Y, Itoh Y, Nozakura S (1981) Makromol Chem 182: 3135

304. Katchalsky A, Miller I (1951) J Phys Chem 55: 1182

305. Ohno N, Nitta K, Makino S, Sugai S (1973) J Polym Sci Polym Phys Ed B11: 413

306. Okuda T, Ohno N, Nitta K, Sugai S (1973) J Polym Sci Polym Phys Ed B11: 749

307. Vallin D, Huguet J, Vert M (1980) Polymer J 12: 113

308. Couvercelle JP, Huguet J, Vert M (1993) Macromolecules 26: 5015

309. De Winter W, Alaerts L (1981) in: Abstracts of the 27th IUPAC Symposium on Macromolecules Vol 1, Strasbourg, p 316

310. Plaisance M, Ter-Minassian-Saraga L (1976) J Coll Interface Sci 56: 33

311. Plaisance M, Ter-Minassian-Saraga L (1977) J Coll Interface Sci 59: 113

312. Bansleben DA, Vogl O (1985) J Polym Sci Polym Chem Ed A23: 703

313. Tyminski PN, Ponticello IS, O'Brien DF (1987) J Am Chem Soc 109: 654

314. Tauer K, Goebel KH, Kosmella S, Stähler K, Neelsen J (1990) Makromol Chem Macromol Symp 31: 107

315. Cornforth JW, D'Arcy Hart P, Rees RJW, Stock JA (1951) Nature 168: 150

316. Anton P, Laschewsky A, Eur Polym J, in press 
317. Kunitake T, Shinkai S, Hirotsu S (1977) J Org Chem 42: 306

318. Laughlin RG (1978) in: Brown HG (ed) Advances in Liquid Crystals Vol 3. Academic Press, New York, p 41 and ibid p 99

319. Chung DC, Kostelnik RJ, Elias HG (1977) Makromol Chem 178: 691

320. Wessling RA, Pickelman DM (1981) J Disp Techn 2: 281

321. Elias HG, Chung DC, Donkai N, Hellmann GP (1987) Makromol Chem 188: 537

322. Nagai K, Elias HG (1987) Makromol Chem 188: 1095

323. Berg JM, Claesson PM (1994) J Coll Interface Sci 163: 289

324. Cederstav AK, Novak BM (1992) Polym Prepr Am Chem Soc Div Polym Chem 33(1): 1090

325. Seery TAP, Wallow TI, Novak BM (1993) Polym Prepr Am Chem Soc Div Polym Chem 34(2): 727

326. Chaturvedi V, Tanaka S, Keriyama K (1993) Macromolecules 26: 2607

327. Gieselman MB, Reynolds JR (1993) Macromolecules 26: 5633

328. Watterson AC, Twu YK, Salamone JC (1993) Polym Prepr Am Chem Soc Div Polym Chem 34(2): 402

329. Cleij (1989) Enantioselective Ester Cleavage by Histidine Containing Oligopeptides at Micellar Interfaces. An Enzyme Model. Thesis, Rijksuniversiteit Utrecht (NL)

330. Mao G, Tsao Y, Tirrell M, Davis T, Hessel V, Ringsdorf H (1993) Langmuir 9: 3461

331. a) Köberle P, Laschewsky A (1994) Macromolecules 27: 2165

b) Köberle P, Laschewsky A Macromol Symp (in press)

332. Okubo T, Ise N (1977) Adv Polym Sci 25: 135

333. Ford WT, Badley RD, Chandran RS, Babu SH, Hassanein M, Srinivasan S, Turk H, Yu H, Zhu W (1992) in: Daniels ES, Sudol ED, El-Aasser MS (eds) Polymer Latexes, ACS Symposium Ser 492. Am Chem Soc, Washington DC, p 422

334. Batz HG (1977) Adv Polym Sci 23: 25

335. Ferruti P, Danusso F, Franchi G, Polentarutti N, Garattini S (1973) J Med Chem 16: 496

336. Pratten MK, Lloyd JB, Hörpel G, Ringsdorf H (1985) Makromol Chem 186: 725

337. Charreyre MT, Boullanger P, Declair T, Mandrand B, Pichot C (1993) Colloid Polym Sci 271: 668

338. Tanchuk YuV, Kotenko SI, Ladtschenko SYu, Yablonko BM (1988) UKr Chim Zh 54: 990

339. Fuoss RM, Strauss UP (1948) J Polym Sci 3: 246

340. Skolnick J, Fixman M (1977) Macromolecules 10: 944

341. Odijk T (1977) J Polym Sci Polym Phys Ed B15: 477

342. Mandel M (1988) in: Kroschwitz JI (ed) Encyclopedia of Polymer Science and Technology 2nd ed Vol 11. Wiley-Interscience, New York, p 739

343. Anton P, Laschewsky A (in press) Colloid Polym Sci

344. Förster S, Schmidt M, Antonietti M (1990) Polymer 31: 781

345. Schmidt M (1991) Macromolecules 24: 5361

346. Förster S, Schmidt M, Antonietti M (1992) J Phys Chem 96: 4008

347. Salamone JC, Israel SC, Taylor P, Snider B (1973) Polym Prepr Am Chem Soc Div Polym Chem 14(2): 778

348. Lunkenheimer K, Miller R (1987) J Coll Interface Sci 120: 176

349. Nitsch W, Kremnitz W, Schweyer G (1987) Ber Bunsenges Phys Chem 91: 218

350. Okubo T (1988) J Coll Interface Sci 125: 386

351. Kamide K, Saito M, Akedo T (1992) Polym Int 27: 35

352. Glatzhofer DT, Cho G, Lai CL, O’Rear EA, Fung BM (1993) Langmuir 9: 2949

353. Kuo PL, Hung MN, Lin YH (1993) J Appl Polym Sci 47: 1295

354. Gu T, Sjöblom J (1992) Colloids Surfaces 64: 39

355. Morishima Y, Nozakura S (1986) J Polym Sci Polym Symp 74: 1

356. Salamone JC, Rice WC (1988) in: Kroschwitz JI (ed) Encyclopeida of Polymer Science and Technology, Vol 11, 2nd edn. Wiley-Interscience, New York, p 514

357. Laschewsky A, unpublished

358. McBain MEL, Hutchinson E (1955) in: Solubilization and Related Phenomena. Academic Press, New York

359. Elworthy PH, A.T. Florence AT, MacFarlane CB (1968) in: Solubilization by Surface-Active Agents. Chapman and Hall, London

360. Hoffmann H (1994) Adv Mater 6: 116

361. Boyer B, Lamaty G, Leydet A, Roque JP, Sama P (1992) New J Chem 16: 887

362. Grieser F, Drummond CJ (1988) J Phys Chem 92: 5580

363. Dong DC, Winnik MA (1984) Can J Chem 62: 2560 
364. Mukerjee P, Ko JS (1992) J Phys Chem 96: 6090

365. Winnik FM (1993) Chem Rev 93: 587

366. Ephardt H, Fromherz P (1993) J Phys Chem 97: 4540

367. Gao Z, Kwak JCT, Labonté R, Marangoni DG, Wasylishen RE (1990) Colloids Surfaces 45: 269

368. Hoshino T, Imamura Y (1990) Bull Chem Soc Jpn (1990) 63: 502

369. Fujiwara H, Kanzoki K, Kimura A, Tanka K, Da YZ (1992) J Chem Soc Chem Commun 736

370. Zana R, Lang J (1990) Colloids Surfaces 48: 153

371. Kalyanasundaram K, Thomas JK (1977) J Am Chem Soc 99: 2039

372. Street jr KW, Acree jr WE (1986) Analyst 111: 1197

373. Gao Z, Wasylishen RE, Kwak JCT (1989) Macromolecules 22: 2544

374. Kiefer M (1990) Synthese und Untersuchungen zum Hämolyse und Solubilisierungsverhalten nichtionogener amphiphiler Seitenkettenpolymere. Thesis, Universität Freiburg (Germany)

375. Cochin D (1991) Polymérisation de tensioactifs sous forme micellaire. Thesis, Université Louis Pasteur, Strasbourg (France)

376. Yang YJ, Engberts JBFN (1992) Eur Polym J 28: 881

377. Esumi K, Watanabe N, Meguro K (1989) Langmuir 5: 1420

378. Esumi K, Watanabe N, Meguro K (1991) Langmuir 7: 1775

379. Owenson B, Pratt LR (1984) J Phys Chem 88: 2905

380. Cabane B, Duplessix R, Zemb T (1985) J Physique 46: 2161

381. Gruen DWR (1985) Progr Colloid Polym Sci 70: 6

382. Chevalier Y, Cachaty C (1985) J Phys Chem 89: 875

383. Jansson M, Li P, Stilbs P (1987) J Phys chem 91: 5279

384. Jansson M, Li P, Stilbs P (1991) J Coll Interface Sci 142: 593

385. Bacaloglu R, Blasko A, Bunton CA, Cerichelli G, Shirazi A (1991) Langmuir 7: 1107

386. Ebelhäuser R, Spieß HW (1987) Makromol Chem 188: 2935

387. Fahmy T, Wesser J, Spieß HW (1989) Angew Makromol Chem 166/167: 39

388. Disch S, Schnepp W, Schmidt C (1992) Makromolekulares Kolloquium Freiburg (Germany)

389. Schnepp W (1994) Deuterium-NMR-Untersuchungen an deuterierten lyotropen Flüssigkristallen. Thesis, Universität Freiburg (Germany)

390. Aniansson EAG, Wall SN, Almgren M, Hoffmann H, Kielmann I, Ulbricht W, Zana R, Lang J, Tondre C (1976) J Phys Chem 80: 905

391. Magny B, Iliopoulos I, Audebert R (1991) Polym Prepr Am Chem Soc Div Polym Chem 32(1): 577

392. Richtering W, Löffler R, Burchard W (1992) Macromolecules 25: 3642

393. Elias HG (1973) J Macromol Sci Chem A7: 601

394. Laschewsky A, Schmidt M, unpublished

395. Bachmann L, Dasch W, Kutter P (1981) Ber Bunsenges Phys Chem 85: 883

396. Bellare JR, Kaneko T, Evans DF (1988) Langmuir 4: 1066

397. Vinson PK, Bellare JR, Davis HT, Miller WG, Scriven LE (1991) J Coll Interface Sci 142: 74

398. Herz J, Husson F, Luzzati V (1961) C R Acad Sc C252: 3462

399. Herz J, Reiss-Husson F, Rempp P, Luzzati V (1964) J Polym Sci C4: 1275

400. Gallot B, Douy A (1987) Mol Cryst Liq Cryst 153: 367

401. Gallot B, Douy A (1989) Markromol Chem Macromol Symp 24: 321

402. Gallot B, Marchin B (1989) Liq Crystals 5: 1719

403. Löffler R, Finkelmann H (1990) Makromol Chem Rapid Commun 11: 321

404. Naitoh K, Ishii Y, Tsujii K (1991) J Phys Chem 95: 7915

405. Friberg S, Yu B, Ahmed AU, Campbell GA (1993) Colloids Surfaces 69: 239

406. Köberle P, Laschewsky A, Tsukruk V (1992) Makromol Chem193: 1815

407. Tsukruk V, Mischenko N, Köberle P, Laschewsky A (1992) Makromol Chem 193: 1829

408. Hessel V, Ringsdorf H, Festtag R, Wendorff JH (1993) Makromol Chem Rapid Commun 14: 707

409. Geetha B, Mandel AB, Ramasami T (1993) Macromolecules 26: 4083

410. Fuoss RM, Edelson D (1951) J Am Chem Soc 73: 269

411. Menger FM, Wrenn S (1974) J Phys Chem 78: 1387

412. Fuhrhop JH, Fritsch D (1986) Acc Chem Res 19: 130

413. Menger FM, Littau CA (1991) J Am Chem Soc 113: 1451

414. Rosen MJ (1993) Chemtech 30

415. Menger FM, Littau CA (1993) J Am Chem Soc 115: 10083

416. Robinson DI, Sherrington DC, Suckling CJ (1984) Tetr Lett 40: 785 
417. Hamid SM, Sherrington DC, Suckling DJ (1986) Colloid Polym. Sci 264: 883

418. Murakami Y, Nakano A, Akiyoshi K, Fukuya K (1981) J Chem Soc Perkin Trans 1: 2800

419. Menger FM, Takeshita M, Chow JF (1981) J Am Chem Soc 103: 5938

420. Menger FM, Angel DeGreiff AJ, Jaeger DA (1984) J Chem Soc Chem Commun 545

421. Menger FM (1986) Top Curr Chem 136: 2

422. Keller-Griffith R, Ringsdorf H, Vierengel A (1986) Colloid Polym Sci 264: 924

423. Murakami Y, Nakano A, Miyata R, Matsuda Y (1979) J Chem Soc Perkin Trans 1: 1669

424. Hessel V, Ringsdorf H, Laversanne R, Nallet F (1993) Rec Trav Chim Pays-Bas 112: 339

425. Hessel V a) (1990) Multipolare Polymerisierbare Amphiphile: Photoreaktionen zur Stabilisierung von Zylindermizellen. Diplomarbeit, Universität Mainz (Germany) b) (1993) Multipolare Amphiphile. Thesis, Universität Mainz (Germany)

426. Cipiciani A, Fracassini MC, Germani R, Savelli G, Bunton CA (1987) J Chem Soc Perkin Trans 2: 547

427. Masuyama A, Yokota M, Zhu YP, Kida T, Nakatsuji Y (1994) J Chem Soc Perkin Trans 2: 547

428. Zana R, Yiv S, Kale KM (1980) J Coll Interface Sci 77: 456

429. McKenzie DC, Bunton CA, Nicoli DF, Savelli G (1987) J Phys Chem 91: 5709

430. Ikeda K, Yasuda M, Ishikawa M, Esumi K, Meguro K, Binana-Limbele W, Zana R (1989) Colloid Polym Sci 267: 825

431. Ikeda K, Ishikawa M, Yasuda M, Esumi K, Meguro K, Binana-Limbele W, Zana R (1989) Bull Chem Soc Jpn 62: 1032

432. Yasuda M, Ikeda K, Esumi K, Meguro K (1989) Bull Chem Soc Jpn 62: 3648

433. a) Zhu YP, Masuyama A, Okahara M (1990) J Am Oil Chem Soc 67: 459

b) Zhu YP, Masuyama A, Okahara M (1990) J Am Oil Chem Soc 68: 268

434. Zhu YP, Masuyama A, Kobata Y, Nakatsuji Y, Okahara M, Rosen MJ (1993) J Coll Interface Sci 158: 40

435. Alami E, Beinert G, Marie P, Zana R (1993) Langmuir 9: 1465

436. Forrest BJ, Hecker De Carvalho L, Reeves LW (1981) J Am Chem Soc 103: 245

437. Wong RC, Ikeda K, Meguro K, Söderman O, Olsson U, Lindman B (1989) J Phys Chem 93 : 4861

438. Ikeda K, Khan A, Meguro K, Lindmann B (1989) J Coll Interface Sci 133: 192

439. Ishikawa M, Matsumura KI, Esumi K, Meguro K, Binana-Limbele W, Zana R (1992) J Coll Interface Sci 151: 70

440. Meguro K, Ikeda K, Otsugi A, Taya M, Yasuda M, Esumi K (1987) J Coll Interface Sci 118 372

441. Deinega YuF, Ul'berg ZR, Marotchko LG, Rudi VP, Denisenko VP (1974) Kolloidn Zh 36 649

442. Deviniski F, Masarova L, Lacko I (1985) J Coll Interface Sci 105: 235

443. Devinski F, Lacko I, Bittererova F, Tomeckova L (1986) J Coll Interface Sci 114: 314

444. Rozycka-Roszak B, Witek S, Przestalski S (1989) J Coll Interface Sci 131: 181

445. Zana R, Benrraou M, Rueff R (1991) Langmuir 7: 1072

446. Parreira HC, Lukenbach ER, Lindemann MKO (1979) J Am Oil Chem Soc 56: 1015

447. Ul'berg ZR, Podol'skaya VI (1978) Kolloidn Zh 40: 292

448. Devinski F, Lacko I, Imam T (1991) J Coll Interface Sci 143: 336

449. Zhou GB, Smid J (1993) Langmuir 9: 2907

450. Zhou GB, Smid J (1993) Polymer 34: 5128

451. Lühmann B (1985) Über den Einfluß einer Polymerfixierung auf das lyotrope Mesophasenverhalten nichtionischer Amphiphile. Thesis, TU Clausthal 1985

452. Kuo PL, Chen CJ (1993) J Polym Sci Polym Chem Ed A31: 99 (1993)

453. Hyde AJ, Robb DJM (1963) J Phys Chem 67: 2089

454. Greene BW, Saunders FL (1970) J Coll Interface Sci 33: 393

455. De Winter W, Mariën A (1984) Makromol Chem Rapid Commun 5: 593

456. Gan LM, Chew CH (1984) J Disp Sci Tech 5: 179

457. Chew CH, Gan LM (1985) J Polym Sci Polym Chem Ed A23: 2225

458. Chen S, Chang HS (1985) J Polym Sci Polym Chem Ed A23: 2615

459. Malyukova EB, Nesmelova SV, Gritskova IA, Pravednikov AN, Egorov VV, Zubov VP, Kabanov VA (1985) Dokl Akad Nauk SSSR 284: 1420

460. Ito K, Yokoyama S, Arakawa F (1986) Polym Bull 16: 345

461. Tsaur SL, Fitch RM (1987) J Coll Interface Sci 115: 450

462. Tsaur SL, Fitch RM (1987) J Coll Interface Sci 115: 463

463. Hassanein M, Ford WT (1988) Macromolecules 21: 525 
464. Choubal M, Ford WT (1989) J Polym Sci Polym Chem Ed A27: 1873

465. Yamaguchi K, Watanabe S, Nakahama S (1989) Makromol Chem 190: 1195

466. Guillaume JL, Pichot C, Guillot J (1990) J Polym Sci Polym Chem Ed A28: 137

467. Raj WRP, Sasthav M, Cheung HM (1992) Langmuir 8: 1931

468. Watanabe S, Ozaki H, Mitsuhashi K, Nakahama S, Yamaguchi K (1989) Makromol Chem 193: 2781

469. Babu SH, Ford WT (1992) J Polym Sci Polym Chem Ed A30: 1917

470. Urquiola MB, Dimonie VL, Sudol ED, El-Aasser MS (1992) J Polym Sci Polym Chem Ed A30: 2619

471. Urquiola MB, Dimonie VL, Sudol ED, El-Aasser MS (1992) J Polym Sci Polym Chem Ed A30: 2631

472. Urquiola MB, Sudol ED, Dimonie VL, El-Aasser MS (1993) J Polym Sci Polym Chem Ed A31: 1403

473. Uyama H, Honda Y, Kobayashi S (1993) J Polym Sci Polym Chem Ed A31: 123

474. Kobayashi S, Uyama H, Lee SW, Matsumoto Y (1993) J Polym Sci Polym Chem Ed A31: 3133

475. Arai K (1993) Makromol Chem 194: 1975

476. Nagai K, Satoh H, Kuramoto N (1993) Polymer 34: 4969

477. Raj WRP, Sasthav M, Cheung HM (1993) J Appl Polym Sci 49: 1453

478. Aoyagi T, Terashima O, Nagase Y, Matsui K (1991) Polymer 32: 2106

479. Holt P, Thadani C (1973) Makromol Chem 169: 55

480. Aoyagi T, Terashima O, Suzuki N, Matsui K, Nagase Y (1990) J Controlled Release 13: 63

481. Pucci B, Polidori A, Rakotomanomana N, Chorro M, Pavia AA (1993) Tetr Lett 34: 4185

482. Shinkai S (1982) Prog Polym Sci 8: 1

483. Bunton CA, Nome F, Quina FH, Romsted LS (1991) Acc Chem Res 24: 357

484. Shimidzu T (1977) Adv Polym Sci 23: 55

485. Engberts JFBN (1992) Pure Appl Chem 64: 1653

486. Flach HN, Grassert I, Oehme G (1994) Macromol Chem Phys 195: 3289

487. Suh J, Scarpa IS, Klotz IM (1976) J Am Chem Soc 98: 7060

488. Boutevin B, Robin JJ, Boyer B, Roque JP, Senhaji O (1994) Macromol Chem Phys 195: 129

489. Torstensson M, Hult A (1992) Polym Bull 29: 549

490. Schmidt DL, Coburn CE, Dekoven BM, Potter GE, Meyers GF, Fischer DA (1994) Nature 368: 39

491. a) Senhaji $O$ (1993) Synthèse de tensioactifs méthacryliques et étude physico-chimique de leurs télomères et polymères. Thesis, Université de Montpellier (France)

b) Boutevin B, Robin JJ, Roque JP, Senhaji O (1994) Macromol Chem Phys 195: 2177

492. Yasuda Y, Rindo K, Aoki S (1992) Makromol Chem 193: 2875

493. Gan LM, Chew CH, Yeoh KW, Koh LL (1990) J Coll Interface Sci 137: 597

494. Imae T, Chew CH, Gan LM (1991) Colloids Surfaces 61: 75

495. Greene BW, Sheetz DP, Filer TD (1970) J Coll Interface Sci 32: 96

496. Greene BW, Sheetz DP (1970) J Coll Interface Sci 32: 96

497. Fang TR, Zhu XB (1991) Polym Bull 25: 467

498. Rehse H, Ritter H (1988) Makromol Chem 189: 529

499. Keller-Griffith R (1986) Strukturvariation von Amphiphilen: Multipolare und polymerisierbare Tenside. Thesis, Universität Mainz (Germany)

500. León A, Abuin E, Lissi E, Gargallo A, Radic D (1987) J Coll Interface Sci 115: 529

501. León A, Gargallo A, Radic D, Horta A (1991) Polymer 32: 761

502. Von Berlepsch H, Strey R (1993) Ber Bunsenges Phys Chem 97: 1403

503. Fife WK, Ranganathan P, Zeldin M (1989) Polym Prep Am Chem Soc Polym Chem Div 30 (2): 123

504. Fife WK, Ranganathan P, Zeldin M (1990) J Org Chem 55: 5610

505. Paleos CM, Voliotis S, Margomenou-Leonidopoulou G, Dais P (1980) J Polym Sci Polym Chem Ed A18: 3463

505. Yegorov VV, Batrakova YeV, Zubov VP (1990) Vysokomol Soyed A32: 927 (english translation: Polym Sci USSR 32: 861)

506. Wibbing M (1986) Monomere und polymere multipolare Amphiphile - Synthese und Phasenverhalten in wäßrigen Lösungen. Diplomarbeit, Universität Mainz (Germany)

507. Richtering W, Löffler R, Burchard W (1992) J Phys Chem 96: 3883

Editor: Prof. Ringsdorf

Received: August 1994 